Daniela Miwa Uemura Kawaguti

Investigações numéricas do escoamento ao redor de quatro cilindros circulares não alinhados

São Paulo 
Daniela Miwa Uemura Kawaguti

\title{
Investigações numéricas do escoamento ao redor de quatro cilindros circulares não alinhados
}

\author{
Versão Corrigida \\ (Versão original encontra-se na unidade que aloja \\ o Programa de Pós-graduação) \\ Dissertação apresentada à Escola \\ Politécnica da Universidade de São Paulo \\ para obtenção do título de Mestre em \\ Ciências. \\ Área de concentração: Engenharia de \\ estruturas \\ Orientador: Prof. Dr. Guilherme Rosa \\ Franzini
}

São Paulo 
Autorizo a reprodução e divulgação total ou parcial deste trabalho, por qualquer meio convencional ou eletrônico, para fins de estudo e pesquisa, desde que citada a fonte.

Este exemplar foi revisado e corrigido em relação à versão original, sob responsabilidade única do autor e com a anuência de seu orientador.

São Paulo, $\frac{24}{\text { Assinatura do autor: }}$ de $\frac{\text { Janeiro }}{\text { Oanila fawaguti }}$ de 2020

\section{Catalogação-na-publicação}

Kawaguti, Daniela Miwa Uemura Investigações numéricas do escoamento ao redor de quatro cilindros circulares não alinhados / D. M. U. Kawaguti -- versão corr. -- São Paulo, 2020. $79 \mathrm{p}$.

Dissertação (Mestrado) - Escola Politécnica da Universidade de São Paulo. Departamento de Engenharia de Estruturas e Geotécnica.

1.Fenômeno de interferência 2.Fluidodinâmica computacional 3.Escoamento ao redor de múltiplos cilindros I.Universidade de São Paulo. Escola Politécnica. Departamento de Engenharia de Estruturas e Geotécnica II.t. 


\section{Agradecimentos}

Agradeço aos meus pais, Hilario e Lilian; aos meus irmão, Tatiana, Mariana, Fabio e Isabela e à minha sobrinha Clarisse por estarem presentes em todos os momentos da minha vida e me apoiarem em todas as minhas decisões.

Ao Fabricio Rezende por todo amor, paciência e companheirismo.

Ao meu orientador Guilherme Franzini por acreditar no meu potencial e me dar todo o suporte necessário para que eu pudesse me desenvolver como aluna e pesquisadora desde a graduação até a conclusão do mestrado.

À Universidade de São Paulo pela minha formação como engenheira civil e pela contribuição no meu desenvolvimento acadêmico e profissional. Aos professores, colegas e funcionários do Laboratório de Mecânica Offshore pela convivência e aprendizados durante todo o caminho trilhado dessa pesquisa.

A Office of Naval Research (ONR) pelo suporte financeiro para a condução de um projeto de pesquisa com foco em estudos relacionados a turbinas eólicas offshore e que custeou essa dissertação. 
"No problem can be solved from the same consciousness that created it. We must to learn to see the world anew." - Albert Einstein 


\section{Resumo}

O escoamento ao redor de múltiplos cilindros é um problema encontrado em diversas aplicações tecnológicas como em colunas de plataformas offshore, chaminés industriais e edifícios. Ainda que seja bastante recorrente, é um problema bastante complexo devido ao surgimento do fenômeno de interferência. Tal fenômeno, provocado pela presença de dois ou mais corpos em proximidade, é regido pela variação de diversos parâmetros como a configuração geométrica, a quantidade de cilindros presentes no arranjo, o número de Reynolds e o ângulo de incidência do escoamento. Diversas pesquisas sobre o tema têm sido realizadas com o objetivo de melhor entender o problema. É nesse contexto que se insere o presente trabalho, com a perspectiva de contribuir para o desenvolvimento do assunto, focando no estudo do campo de escoamento ao redor de um agrupamento de quatro cilindros não alinhados, para dois diferentes ângulo de incidência, $\beta=0^{\circ}$ e $180^{\circ}$. A influência da proximidade entre os cilindros é investigada por meio de uma análise numérica baseada na fluidodinâmica computacional (CFD), em particular o método dos volumes finitos. As simulações têm caráter bidimensional, sendo o escoamento caracterizado pelo número de Reynolds $(R e)$ igual a 200. As análises dos padrões de escoamento, bem como das forças fluidodinâmicas e do número de Strouhal mostram a relação entre a proximidade entre cilindros e o fenômeno de interferência sobre o escoamento.

Palavras-chave: Fenômeno de interferência, Fluidodinâmica computacional, Escoamento ao redor de múltiplos cilindros. 


\section{Abstract}

The flow around multiple cylinders is a problem found in a number of technological applications such as in columns of offshore platforms, industrial chimneys and buildings. Although recurrent, it is a very complex problem due to the appearance of the interference phenomenon. Such phenomenon, caused by the presence of two or more bodies in proximity, is governed by variation in several parameters such as the geometric configuration, number of cylinders present in the arrangement, Reynolds number and angle of incidence of the flow. Several pieces of research on the subject were carried at aiming at the improvement of the understanding of the problem. It is in this context that the present work is presented, with the perspective of contributing to the development of the subject, focusing on the study of the flow around a group of four non-aligned cylinders, for two different angles of incidence, $\beta=0^{\circ}$ and $180^{\circ}$. The influence of the proximity between the cylinders is investigated by means of numerical analysis based on computational fluid dynamics (CFD), particularly the finite volume method. The simulations are two-dimensional and the Reynolds number $(R e)$ is equal to 200. The analyzes of the flow patterns, as well as the fluid dynamics forces and the Strouhal number show the relationship between the proximity between cylinders and the phenomenon of interference on the flow.

Keywords: Interference phenomenon, Computational fluid dynamics, Flow around multiple cylinders. 


\section{Lista de ilustrações}

Figura 1 - Exemplos de estruturas que sofrem o fenômeno de interferência. . . . . 15

Figura 2 - Partes do escoamento perturbado. . . . . . . . . . . . 18

Figura 3 - Modelo de geração e desprendimento de vórtices. . . . . . . . . . . . 18

Figura 4 - Influência dos efeitos viscosos e inerciais no escoamento para diferentes valores de número de Reynolds. . . . . . . . . . . . . . . . . . . 20

Figura 5 - Forças atuantes em um corpo bidimensional imerso em um fluido: (a) distribuição de pressão. (b) distribuição de cisalhamento e (c) forças resultantes de sustentação $(L)$ e arrasto $(D) \ldots \ldots$. . . . . . . . . 22

Figura 6 - Curva da relação entre coeficientes de força e o número de Reynolds para um cilindro isolado. . . . . . . . . . . . . . . . . 23

Figura 7 - Curva da relação entre número de Strouhal e $R e^{-\frac{1}{2}}$ para um cilindro isolado. . . . . . . . . . . . . . . . . 2 23

Figura 8 - Fluxograma do método dos volumes finitos para o método centralizado. 29

Figura 9 - Modelo de malha bidimensional. . . . . . . . . . . . . . . 30

Figura 10 - Discretização do modelo matemático para malha centralizada. . . . . . 31

Figura 11 - Fluxograma de resolução das equações . . . . . . . . . . . . . . . . . . 32

Figura 12 - Geometria do modelo investigado. . . . . . . . . . . . . . . . . 35

Figura 13 - Condições de contorno. . . . . . . . . . . . . . . . . . . . . 36

Figura 14 - Dimensões do domínio. . . . . . . . . . . . . . . . . . . 36

Figura 15 - Malha típica do modelo do domínio. . . . . . . . . . . . . . . 37

Figura 16 - Dimensões do modelo inicial M1. . . . . . . . . . . . . . . . . . 37

Figura 17 - Série temporal do coeficiente de sustentação para o caso de cilindro isolado. . . . . . . . . . . . . . . . . . . 42

Figura 18 - Contorno de vorticidade no plano xy para um particular instante para o caso de cilindro isolado. . . . . . . . . . . . . . . . . . . . . . . 42

Figura 19 - Contorno de vorticidade no plano xy para um particular instante para $\beta=0^{\circ}$ e $s=3 D \ldots \ldots \ldots \ldots \ldots \ldots$

Figura 20 - Linhas de corrente do campo de velocidades para um particular instante para $\beta=0^{\circ}$ e $s=3 D \ldots \ldots \ldots \ldots 4 \ldots \ldots$. . . . . . . . . . . . . . . 44

Figura 21 - Linhas de corrente do campo de velocidades para um particular instante para $\beta=180^{\circ}$ e $($ a) $s=3 D$ e $($ b) $s=3,5 D \ldots \ldots \ldots$

Figura 22 - Contorno de vorticidade no plano xy para um particular instante para $\beta=180^{\circ}$ e (a) $s=3 D$ e (b) $s=3,5 D \ldots \ldots . \ldots . \ldots 45$

Figura 23 - Contorno de vorticidade no plano xy para um particular instante para $\beta=0^{\circ}$ e (a) $s=3,5 D$; (b) $s=4 D$; (c) $s=4,5 D$ e (d) $s=5 D \ldots .$. 
Figura 24 - Contorno de vorticidade no plano xy para um particular instante para $\beta=180^{\circ}$ e (a) $s=4 D$; (b) $s=4,5 D$ e (c) $s=5 D$.

Figura 25 - Variação do coeficiente de arrasto médio com o espaçamento $s$ para (a) $\beta=0^{\circ}$ e (b) $\beta=180^{\circ} \ldots \ldots \ldots \ldots$. . . . . . . . . . . . . 48

Figura 26 - Contorno de pressão ao redor dos cilindros para $\beta=0^{\circ}$ e $s=3 D$. . . 48

Figura 27 - Contorno de pressão ao redor dos cilindros para $\beta=0^{\circ}$ e (a) $s=3,5 D$; (b) $s=4 D ;$ (c) $s=4,5 D$ e (d) $s=5 D \ldots \ldots \ldots \ldots$

Figura 28 - Variação do coeficiente de arrasto médio do sistema com o espaçamento $s$ para (a) $\beta=0^{\circ}$ e (b) $\beta=180^{\circ} \ldots \ldots \ldots . \ldots . \ldots 50$

Figura 29 - Variação do coeficiente de sustentação médio com o espaçamento $s$ para (a) $\beta=0^{\circ}$ e (b) $\beta=180^{\circ}$.

Figura 30 - Variação do r.m.s. do coeficiente de sustentação com o espaçamento $s$ $\operatorname{para}(\mathrm{a}) \beta=0^{\circ}$ e (b) $\beta=180^{\circ}$.

Figura 31 - Variação dos valores pico-a-pico do coeficiente de sustentação com o espaçamento $s$ para (a) $\beta=0^{\circ}$ e (b) $\beta=180^{\circ} \ldots \ldots \ldots$. . . . . .

Figura 32 - Séries temporais do coeficiente de sustentação para $\beta=0^{\circ}$ e (a) $s=3 D$; (b) $s=3,5 D$; (c) $s=4 D$; (d) $s=4,5 D$ e (e) $s=5 D \ldots \ldots$. . .

Figura 33 - Séries temporais do coeficiente de sustentação para $\beta=0^{\circ}$ e $s=3 D$ para (a) $t=0$ a $300 \mathrm{~s}$ e (b) $t=300$ a 1200 s.

Figura 34 - Séries temporais do coeficiente de sustentação para $\beta=0^{\circ}$ e $s=3,5 D$ para (a) $t=0$ a $100 \mathrm{~s}$ e (b) $t=100$ a $600 \mathrm{~s} \ldots \ldots \ldots . \ldots 55$

Figura 35 - Série temporal do coeficiente de arrasto para $s=3 D$ e $\beta=0^{\circ}$. . . . 56

Figura 36 - Série temporal do coeficiente de sustentação para $\beta=180^{\circ}$ e (a) $s=3 D$; (b) $s=3,5 D$; (c) $s=4 D$; (d) $s=4,5 D$ e (e) $s=5 D$. . . . . . . .

Figura 37 - Variação do número de Strouhal com o espaçamento $s$ para (a) $\beta=0^{\circ}$ e (b) $\beta=180^{\circ}$.

Figura 38 - Espectro de amplitude do coeficiente de sustentação em cada cilindro para $\beta=180^{\circ}$ e (a) $s=3 D$; (b) $s=3,5 D$; (c) $s=4 D$; (d) $s=4,5 D$ e (e) $s=5 D$.

Figura 39 - Espectro de amplitude do de sustentação em cada cilindro para $\beta=0^{\circ}$ e (a) $s=3 D$; (b) $s=3,5 D$; (c) $s=4 D$; (d) $s=4,5 D$ e (e) $s=5 D$. .

Figura 40 - Série temporal do coeficiente de arrasto para $\beta=0^{\circ}$ e (a) $s=3,5 D$; (b) $s=4 D ;($ c) $s=4,5 D$ e $(\mathrm{d}) s=5 D \ldots \ldots \ldots \ldots$

Figura 41 - Série temporal do coeficiente de arrasto para $\beta=180^{\circ}$ e (a) $s=3 D$; (b) $s=3,5 D$; (c) $s=4 D$; (d) $s=4,5 D$ e (e) $s=5 D \ldots \ldots$. . . .

Figura 42 - Linhas de corrente para um particular instante do campo de velocidades para $\beta=0^{\circ}$ e (a) $s=3,5 D$; (b) $s=4 D$; (c) $s=4,5 D$ e (d) $s=5 D .$.

Figura 43 - Linhas de corrente para um particular instante do campo de velocidades para $\beta=180^{\circ}$ e (a) $s=4 D$; (b) $s=4,5 D$ e (c) $s=5 D \ldots \ldots$ 


\section{Lista de tabelas}

Tabela 1 - Parâmetros adotados nas simulações. . . . . . . . . . . . . . . 35

Tabela 2 - Tipo de domínio utilizado em cada caso s. . . . . . . . . . . 38

Tabela 3 - Número de elementos do caso $s=3 D$ e domínio M1. . . . . . . . . 38

Tabela 4 - Coeficientes de arrasto médio de cada cilindro para o caso $s=3 D$ e domínio M1. . . . . . . . . . . . . . . . . . 39

Tabela 5 - Diferença dos coeficientes de arrasto médio de cada cilindro para o caso $s=3 D$ e domínio M1. . . . . . . . . . . . . . . . . . 39

Tabela 6 - Coeficientes de sustentação médio de cada cilindro para o caso $s=3 D$ e domínio M1. . . . . . . . . . . . . . . . . . . . . 40

Tabela 7 - Número de Strouhal de cada cilindro para o caso $s=3 D$ e domínio M1. 40

Tabela 8 - Coeficientes de arrasto médio das malhas E, utilizando os modelos M1 e M2 para o caso $s=3 D \ldots \ldots$. . . . . . . . . . . . 40

Tabela 9 - Número de elementos das malhas E para todos os casos $s$ utilizando o domínio M2. . . . . . . . . . . . . . . . . . . . 41

Tabela 10 - Comparação dos resultados obtidos para o caso de cilindro isolado a número de Reynolds $R e=200$. . . . . . . . . . . . . . . . . . . . 41

Tabela 11 - Resumo dos resultados para todos os casos $s$ e $\beta=0^{\circ}$. . . . . . . . 65

Tabela 12 - Resumo dos resultados para todos os casos $s$ e $\beta=180^{\circ}$. . . . . . . 66 


\section{Lista de abreviaturas e siglas}

CFD Computational Fluid Dynamics ou Fluido Dinâmica Computacional

fft $\quad$ Fast Fourier Transform

FIV Flow-Induced Vibration ou Vibração Induzida pelo Escoamento

FVM Finite Volume Method ou Método dos Volumes Finitos

PISO Pressure-Implicit with Splitting of Operators 


\section{Lista de símbolos}

\begin{tabular}{|c|c|}
\hline$\alpha$ & Ângulo entre CT e CM em relação à linha de centro \\
\hline$\beta$ & Ângulo de incidência \\
\hline$A$ & Área projetada de um cilindro exposta à corrente \\
\hline $\mathbf{u}$ & Campo de velocidade \\
\hline $\mathrm{CM}$ & Cilindro central \\
\hline $\mathrm{CF}$ & Cilindro frontal ou a montante \\
\hline $\mathrm{CT}$ & Primeiro cilindro a jusante \\
\hline $\mathrm{CB}$ & Segundo cilindro a jusante \\
\hline $\mathrm{CI}$ & Cilindro isolado \\
\hline$C_{D}$ & Coeficiente de arrasto \\
\hline$C_{D f}$ & Coeficiente de arrasto associado à fricção \\
\hline$C_{D p}$ & Coeficiente de arrasto associado à pressão \\
\hline$\overline{C_{D}}$ & Coeficiente de arrasto médio \\
\hline$\sigma_{C_{D}}$ & Desvio padrão de $C_{D}$ \\
\hline$\overline{C_{D \text { sist. }}}$ & Coeficiente de arrasto médio do sistema \\
\hline$C_{D^{*}}$ & Flutuação do coeficiente de arrasto \\
\hline$C_{L}$ & Coeficiente de sustentação \\
\hline$\overline{C_{L}}$ & Coeficiente de sustentação médio \\
\hline$\sigma_{C_{L}}$ & Desvio padrão de do coeficiente de sustentação \\
\hline$C_{L^{*}}$ & Flutuação do coeficiente de sustentação \\
\hline$\widehat{C_{L}}$ & Valor pico-a-pico do coeficiente de sustentação \\
\hline$L$ & Comprimento do cilindro \\
\hline$\rho$ & Massa específica do fluido \\
\hline
\end{tabular}


Diâmetro do cilindro

$H \quad$ Distância horizontal entre CF e os cilindros à jusante

$B \quad$ Distância vertical entre CT e CB

F $\quad$ Forças dinâmicas (arrasto ou sustentação)

$S_{M} \quad$ Força gravitacional e de volume

$f \quad$ Frequência de emissão de vórtices

$A, B, C, D, E$ Malhas (do caso menos refinado para o mais refinado)

M1 Modelo do domínio inicial

M2 Modelo do domínio final

Re Número de Reynolds

$S_{t} \quad$ Número de Strouhal

$\Delta t \quad$ Passo de tempo

$(x, y, z) \quad$ Posição da partícula

p Pressão

$t \quad$ Tempo

$\tau \quad$ Tensão viscosa ou tensão de cisalhamento

$U_{\infty} \quad$ Velocidade do escoamento incidente

$\mu \quad$ Viscosidade dinâmica do fluido 


\section{Sumário}

OBJETIVOS E GANHOS ESPERADOS . . . . . . . . . . 14

INTRODUÇÃO E ORGANIZAÇÃO DO TEXTO . . . . . . . . 15

ESCOAMENTO AO REDOR DE CILINDROS . . . . . . . . . 17

3.1

Partes do escoamento perturbado

Processo de geração e desprendimento de vórtices 18

FLUIDODINÂMICA COMPUTACIONAL . . . . . . . . . . . 27

SIMULAÇÕES NUMÉRICAS . . . . . . . . . . . . . . . . 34

6.1 Características dos padrões de escoamento . . . . . . . . . . 43

6.1.1 Razão de espaçamento média . . . . . . . . . . . . . . 43

6.1 .2 Razão de espaçamento larga . . . . . . . . . . . . . . . . 45

$6.2 \quad$ Coeficiente de arrasto médio . . . . . . . . . . . . . 47

$6.2 .1 \quad$ Coeficiente de arrasto médio por cilindro . . . . . . . . . . . . 47

$6.2 .2 \quad$ Coeficiente de arrasto médio do sistema . . . . . . . . . . . . 50 
$6.3 \quad$ Coeficiente de sustentação . . . . . . . . . . . . . . . . 51

$6.4 \quad$ Número de Strouhal . . . . . . . . . . . . . . . . . . . . 57

$6.5 \quad$ Resumo dos resultados . . . . . . . . . . . . 65

7 CONSIDERAÇÕES FINAIS . . . . . . . . . . . 67

REFERÊNCIAS .................... 70

APÊNDICES

APÊNDICE A - SÉRIES TEMPORAIS DOS COEFICIENTES DE ARRASTO ................... 74

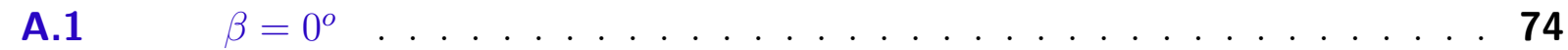

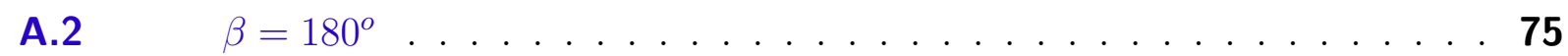

APÊNDICE B - LINHAS DE CORRENTE . . . . . . . . . . 76

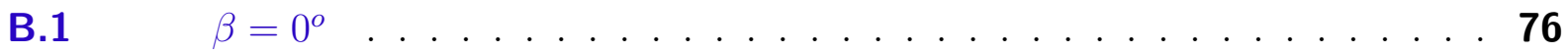

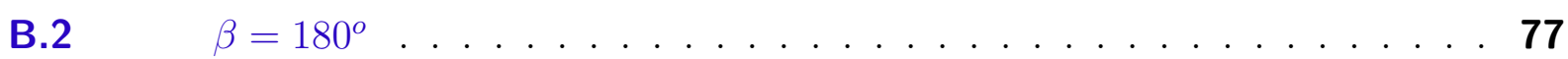




\section{Objetivos e ganhos esperados}

O principal objetivo desta dissertação é estudar, via abordagem da fluidodinâmica computacional (CFD), o escoamento ao redor de um conjunto de quatro cilindros não alinhados. As simulações em CFD são bidimensionais e é utilizada a ferramenta comercial ANSYS FLUENT ${ }^{\circledR}$ para realizá-las. Ferramentas numéricas como, por exemplo o MATLAB ${ }^{\circledR}$ são utilizadas como apoio ao pós-processamento dos resultados.

Em particular, é de interesse o estudo dos efeitos de interferência decorrentes da presença de corpos em arranjos não alinhados. Tal estudo envolve o entendimento da influência do espaçamento entre cilindros sobre o campo de escoamento para a configuração de cilindros proposta. Isso é realizado por meio da análise quantitativa e qualitativa das forças hidrodinâmicas sobre os cilindros (representadas pelos coeficientes de arrasto $\left(C_{D}\right)$ e de sustentação $\left(C_{L}\right)$ ) e do número de Strouhal $\left(S_{t}\right)$. É ainda realizada uma análise qualitativa do campo de escoamento, envolvendo a caracterização da vorticidade na região de esteira, os campos de pressão e as linhas de corrente do escoamento ao redor dos cilindros.

Dentre as diversas aplicações tecnológicas que lidam com os efeitos do fenômeno de interferência citam-se a de colunas de turbinas eólicas offshore flutuantes, chaminés e edifícios. Espera-se que este trabalho, de caráter fundamental, contribua para o entendimento do problema de escoamento ao redor de múltiplos corpos agrupados, ainda que existam diferenças relevantes em relação ao número de Reynolds (Re) adotado neste estudo e àqueles observados nos projetos de engenharia. Além disso, espera-se que este trabalho possa contribuir à literatura do tema de diferentes formas, sendo as principais: pela configuração geométrica diferenciada, pela quantidade de cilindros presentes no arranjo e pela diferenciação dos ângulos de incidência analisados. 


\section{Introdução e organização do texto}

O escoamento uniforme ao redor de agrupamentos de cilindros (ou outros corpos) é um problema clássico da mecânica dos fluidos. Seu interesse permeia tanto entre a comunidade acadêmica quanto a industrial devido as suas diversas aplicações. Dentre os exemplos de aplicação tecnológica deste problema, elencam-se o escoamento ao redor das colunas de plataformas offshore, chaminés industriais e edifícios. A Figura 1 traz exemplos de sistemas de engenharia nos quais os efeitos de interferência entre corpos são de importância na caracterização do campo de escoamento.

Fatores como a disposição dos cilindros, a proximidade entre eles e o ângulo de incidência do escoamento afetam o campo de velocidades ao redor dessas estruturas e, por consequência, os esforços hidrodinâmicos. Tal comportamento causado pela presença de um ou mais corpos em proximidade é chamado de fenômeno de interferência. Isto mostra a complexidade do assunto que há tempos já vem sendo abordado experimentalmente.

Figura 1 - Exemplos de estruturas que sofrem o fenômeno de interferência.

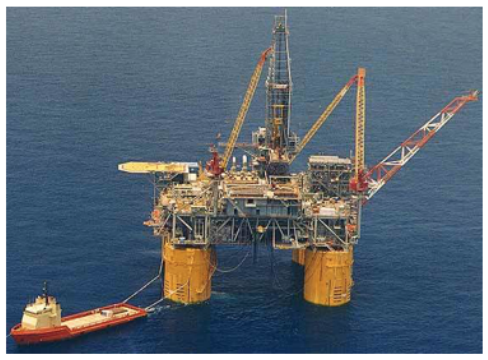

(a) Plataformas offshore

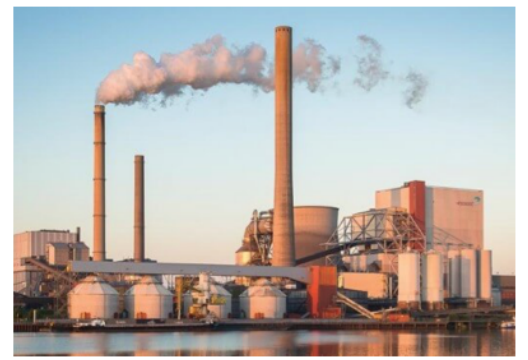

(b) Chaminés industriais

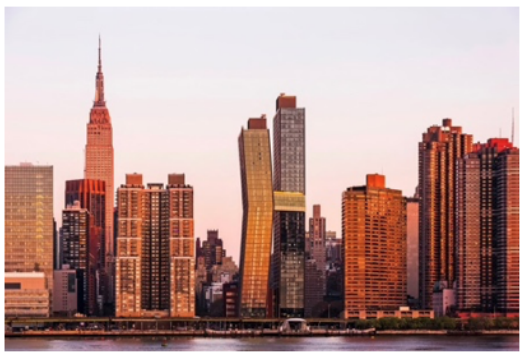

(c) Edifícios

Fonte: Reproduzido de (a) https://www.offshore-technology.com/projects/mars/, https://www.hadek.com/industrial-chimney/e (c) https://www.domusweb.it/en/architecture/2018/09/01/theglass-skybridge-linking-american-copper-buildings.html

A disposição e quantidade de corpos agrupados possui grande impacto na organização do escoamento. Para estruturas compostas de múltiplas colunas, uma primeira abordagem possível é o estudo do escoamento ao redor de agrupamentos de cilindros rígidos. Contudo, este é um problema de alta complexidade devido à variedade de fatores envolvidos, configurando em um problema com lacunas de conhecimento a serem preenchidas. Além disso, limitações físicas impedem a reprodução de algumas condições do escoamento em laboratório como, por exemplo, alcançar determinadas faixas de números de Reynolds, restringindo assim as análises experimentais.

Com a facilitação de estudos de caráter numérico, a partir do desenvolvimento da capacidade computacional, foi então possível expandir as investigações sobre o tema, o 
que levou a um melhor entendimento do problema e proporcionou o desenvolvimento de novas tecnologias. Desde então, métodos numéricos como o FVM (Método dos Volumes Finitos) têm sido aplicados aos mais variados problemas de engenharia, desencadeando um grande desenvolvimento em um dos ramos da mecânica computacional conhecido como fluidodinâmica computacional $(\mathrm{CFD})^{1}$.

A fluidodinâmica computacional tem recebido grande atenção nas últimas décadas. Parte dessa atenção é devida à relativa facilidade de mudanças nos arranjos geométricos e nas propriedades dos fluidos. Note, no entanto, que essa técnica ainda pode ser custosa computacionalmente e ainda não é capaz de substituir os experimentos conduzidos em laboratório. Essa é a abordagem escolhida para os estudos descritos nesta dissertação, a qual visa o fenômeno do comportamento do escoamento uniforme ao redor de um arranjo de quatro cilindros fixos e não colineares para um único número de Reynolds, a saber, $R e=200$. O leitor nota que o número de Reynolds escolhido é significativamente distinto daquele encontrado em qualquer das aplicações tecnológicas ( $R e \gg 200)$ ilustradas na Figura 1 . Essa escolha foi feita visando um estudo de cunho fundamental sobre o problema e que, como será visto nos capítulos subsequentes, já traz alguns comportamentos distintos daqueles observados quando do caso de um cilindro isolado.

Do ponto de vista de organização, este texto está divido em outros cinco capítulos. O capítulo 3 traz uma revisão bibliográfica sobre o tema do escoamento ao redor de cilindros, além de abordar algumas das lacunas de conhecimento encontradas na literatura. Em seguida, dedica-se um capítulo à discussão de conceitos da fluidodinâmica computacional, no qual serão abordados os principais aspectos relacionados ao assunto.

O modelo matemático, com todas as informações pertinentes ao desenvolvimento das simulações e com a metodologia utilizada para realizá-las é objeto do capítulo 5 . Seguindo para o capítulo 6, apresentam-se os resultados obtidos pelas simulações que darão embasamento para o capítulo 7, no qual são apresentadas as considerações finais desta pesquisa. 


\section{Escoamento ao redor de cilindros}

Este capítulo destina-se à apresentação do problema do escoamento ao redor de cilindros. Para uma melhor abordagem do tema, inicialmente, serão apresentadas as características gerais relacionadas ao problema, importantes para o entendimento e desenvolvimento desta pesquisa. A parte inicial é baseada em Meneghini (2002), Munson, Young e Okiishi (2004) e em Carmo (2005). Em seguida, a última parte deste capítulo focará na apresentação de algumas pesquisas relacionadas ao tema do escoamento ao redor de múltiplos cilindros.

\subsection{Partes do escoamento perturbado}

O escoamento ao redor de um cilindro depende de vários parâmetros como velocidade (intensidade e direção), dimensões do corpo e sua rugosidade. Todos estes fatores interferem nas regiões de escoamento perturbado as quais correspondem às parcelas do domínio do fluido afetadas pela presença de corpos. Existem 4 partes distintas, ilustradas na Figura 2, que são caracterizadas por um tipo de comportamento específico. Essas regiões do escoamento perturbado são denominadas por:

1. Região estreita de escoamento retardado

2. Camada limite

3. Região lateral de fluido deslocado e acelerado

4. Região de esteira

As regiões 1 e 3, embora apresentem comportamentos bastante interessantes, foram até então pouco exploradas na literatura. A primeira região situa-se à montante do corpo e apresenta grande flutuação de velocidade. Já na terceira região, que é localizada na porção mais afastada do corpo, o fluido penetra vigorosamente na região de esteira devido ao gradiente de pressão entre as duas regiões. Além disso, essa região é passível de efeito de blocagem que ocorre quando há proximidade das paredes do domínio do corpo.

A camada limite (região 2) é uma fina camada do escoamento encontrada próxima da superfície do cilindro e é onde os efeitos viscosos são importantes. No caso de corpos rombudos ${ }^{1}$ como os cilindros, existe um importante aspecto denominado de separação da camada limite. Este fenômeno decorre da existência de um gradiente adverso de pressão e

1 Em inglês, bluff-body. Corpo que quando imerso em uma corrente de fluido, gera a separação do escoamento em uma região apreciável de sua superfície. 
Figura 2 - Partes do escoamento perturbado.

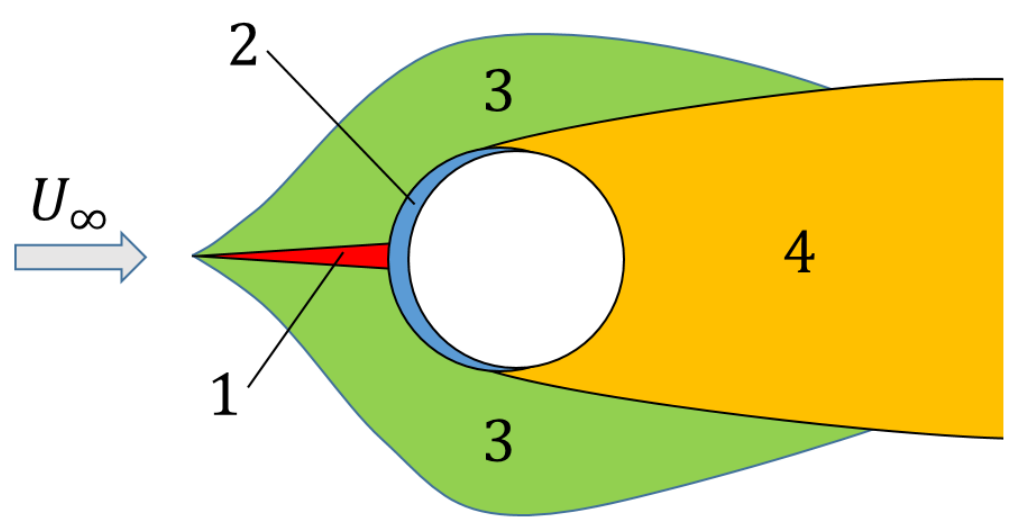

Fonte: Autora.

da viscosidade não nula do fluido. A partir desta separação forma-se a região 4, a qual depende fortemente do estado do escoamento (laminar, de transição ou turbulento) do fluido.

\subsection{Processo de geração e desprendimento de vórtices}

A interação entre as camadas cisalhantes de circulação opostas, resultantes da separação da camada limite, leva à formação de vórtices na região de esteira. Tal mecanismo físico foi sugerido por Gerrard (1996). Segundo ele, a formação de um vórtice e seu sentido de circulação seriam originários de uma das camadas cisalhantes. A velocidade do crescimento do vórtice atrairia a camada cisalhante oposta, levando à ruptura da conexão entre a camada cisalhante e o vórtice. A Figura 3 ilustra este modelo de formação e desprendimento de vórtices de Gerrard.

Figura 3 - Modelo de geração e desprendimento de vórtices.

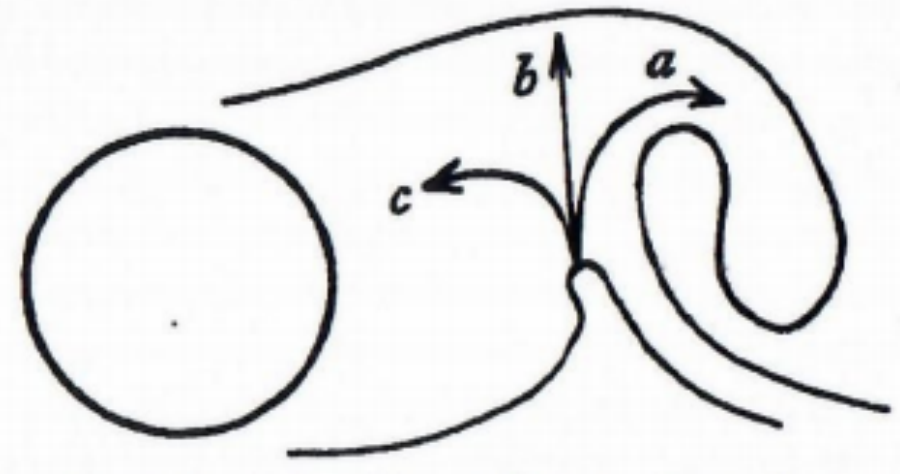

Fonte: Reproduzido de Gerrard (1996).

Observa-se que as partículas de fluido da camada cisalhante, atraídas pelo crescimento 
do vórtice formado, seguem uma entre três trajetórias, cada qual com uma função distinta no processo. Além disso, a quantidade de partículas deslocadas para cada um destes caminhos governa a pressão da parte posterior do corpo (chamada de pressão de base) e a frequência de formação e desprendimento de vórtices, bem como suas intensidades.

A parcela de fluido que segue o caminho "a" incorpora-se ao vórtice formado pela camada cisalhante oposta. Esta mistura de fluidos leva ao decréscimo da circulação do vórtice formado. Isso se deve ao fato de que as vorticidades das parcelas de fluido da camada cisalhante atraída e do vórtice formado têm sinais contrários

A fração do escoamento que segue o caminho "b" move-se em direção à camada cisalhante oposta. O crescimento do vórtice e a intensificação do fluxo de partículas que o alimenta resulta na atração de maiores quantidades de partículas da camada cisalhante oposta. O choque entre esses dois fluxos de partículas com vorticidades de sinais opostos leva à ruptura do canal de alimentação do vórtice. Este então desprende-se da camada cisalhante e é convectado à jusante da esteira.

Por fim, a porção do escoamento que se desloca em direção ao caminho "c" retorna à região de esteira próxima ao corpo. Essas partículas de fluido contribuem para a geração de um novo vórtice, porém agora na camada cisalhante oposta a do vórtice anteriormente formado. Isto, conclui então ciclo do processo de formação e desprendimento de vórtices.

\subsection{Regimes de escoamento ao redor de um cilindro}

O número de Reynolds é o parâmetro adimensional que define a razão entre as forças de inércia e as forças viscosas atuando no fluido. Matematicamente, ele é definido por:

$$
R e=\frac{\rho U_{\infty} D}{\mu}
$$

na qual $\rho$ é a massa específica do fluido, $U_{\infty}$ é a velocidade do escoamento incidente, $D$ é a dimensão característica do corpo (no caso de um cilindro, seu diâmetro) e $\mu$ é a viscosidade dinâmica do fluido.

Sua variação provoca grandes mudanças no campo de escoamento do fluido, alterando a influência e intensidade dos efeitos viscosos e inerciais. Em geral, para número de Reynolds próximos de zero, os efeitos inerciais tendem a ser bem pequenos, predominando os efeitos viscosos. Já para números de Reynolds tendendo ao infinito, estes papéis tendem a se inverter, como pode ser observado na Figura 4.

O regime de escoamento é dividido em três tipos: laminar, de transição e turbulento. Cada regime é definido por uma faixa de número de Reynolds e suas fronteiras (ou números de Reynolds críticos) são determinadas experimentalmente. Contudo, vale ressaltar que é 
Figura 4 - Influência dos efeitos viscosos e inerciais no escoamento para diferentes valores de número de Reynolds.

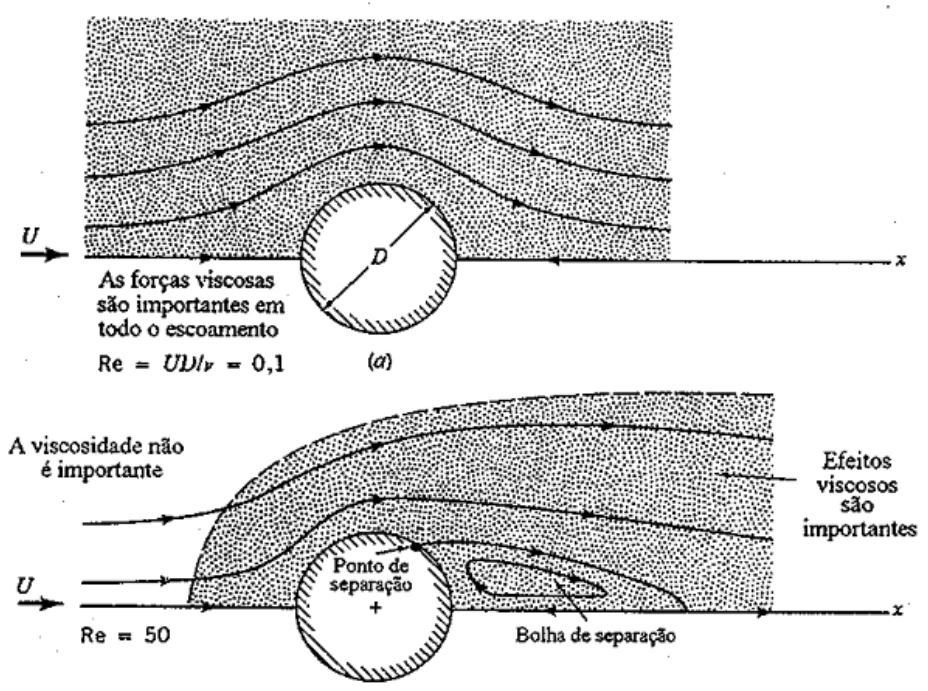

(b)

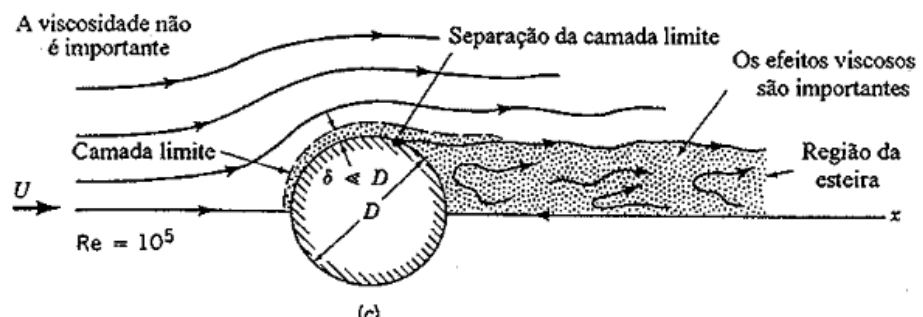

Fonte: Reproduzido de Munson, Young e Okiishi (2004).

possível encontrar, na literatura, variações nos números de Reynolds críticos. Isso ocorre pois, apesar do controle realizado em cada experimento, as perturbações não podem ser totalmente isoladas de sorte que cada experimento é diferente entre si, resultando em números de Reynolds críticos diferentes.

O escoamento laminar ao redor de cilindro fixo é definido para um intervalo de número de Reynolds entre 0 e aproximadamente 180. Apesar de abranger uma pequena faixa de valores em comparação com os outros regimes de escoamento, três comportamentos distintos podem ser observados à medida que o número de Reynolds varia. A primeira fase, $0<R e<5$, caracteriza-se pela grande influência de efeitos viscosos e pela simetria das linhas de corrente em relação ao eixo do cilindro. Para valores de $R e>5$, observa-se um ponto de separação das linhas de corrente e a formação de bolhas de separação ou de recirculação estacionárias. À medida que o número de Reynolds aumenta, o ponto de separação das camadas cisalhantes move-se à montante do escoamento, chegando a uma configuração quase tangencial à superfície do cilindro. Por volta de $R e=47,5$, as camadas cisalhantes começam a enrolar-se em torno delas mesmas, levando à formação de vórtices. Por fim, entre $50 \sim 70<R e<150 \sim 200$, observa-se o surgimento de uma esteira de von 
Kármán, resultante do processo de geração e desprendimento de vórtices. Este mecanismo de desprendimento de vórtices é conhecido na literatura inglesa como vortex shedding.

O regime de transição ocorre após o estado laminar, com início em torno de $R e=200$. A partir desse ponto, as estruturas que se formam na esteira deixam de ter caráter bidimensional devido ao surgimento de instabilidades nas camadas cisalhantes. Essas instabilidades surgem entre o ponto de separação da camada limite e a região de formação dos vórtices, resultando em um ponto de transição para a turbulência. Com o aumento do número de Reynolds, esse ponto de transição desloca-se para a região à montante do escoamento até finalmente alcançar o ponto de separação e a camada cisalhante, que até então era laminar. Tal mecanismo, que varia em função do número de Reynolds, resulta em alterações nos regimes de formação e desprendimento de vórtices, bem como nas forças hidrodinâmicas e no número de Strouhal (mais adiante apresentado). Por fim, o ponto de transição para a turbulência avança até que toda a camada limite seja afetada, chegando-se perto do ponto de estagnação.

O estado no qual todas as regiões do escoamento perturbado são governados pelos efeitos de turbulência é chamado de regime turbulento. Neste regime, o número de Reynolds crítico que delinearia o limiar entre o final do regime de transição e seu início não é conhecido. Contudo, a fronteira teórica final deste regime é definida para número de Reynolds tendendo ao infinito.

\subsection{Números adimensionais que caracterizam o escoamento}

Esta seção destina-se à apresentação de dois grupos de números adimensionais importantes na mecânicas dos fluidos: os coeficientes de forças fluidodinâmicas e o número de Strouhal. Esses números adimensionais são amplamente utilizados para a caracterização de escoamentos e também serão usados neste trabalho.

A interação existente entre um corpo e o fluido que o envolve pode ser descrita em termos das forças que agem na interface que os separada. Essas forças são causadas por duas componentes que atuam na superfície do corpo: tensão de cisalhamento, devido aos efeitos viscosos e tensão normal, devida à pressão. Os efeitos globais dessas tensões dão origem à uma resultante na direção do escoamento incidente (força de arrasto) e à uma outra na direção normal a ele (força de sustentação). Essas forças podem ser adimensionalizadas pela pressão dinâmica $\left(\frac{1}{2} \rho U_{\infty}^{2}\right)$ e pela área projetada do corpo exposta à corrente livre $(A)$ obtendo-se:

$$
C_{F}=\frac{F}{\frac{1}{2} \rho U_{\infty}^{2} A}
$$

na qual $F$ representa quaisquer uma das componentes da força resultante. A Figura 5 
ilustra as forças atuantes em um corpo submerso para o caso bidimensional.

Figura 5 - Forças atuantes em um corpo bidimensional imerso em um fluido: (a) distribuição de pressão. (b) distribuição de cisalhamento e (c) forças resultantes de sustentação $(L)$ e arrasto $(D)$.

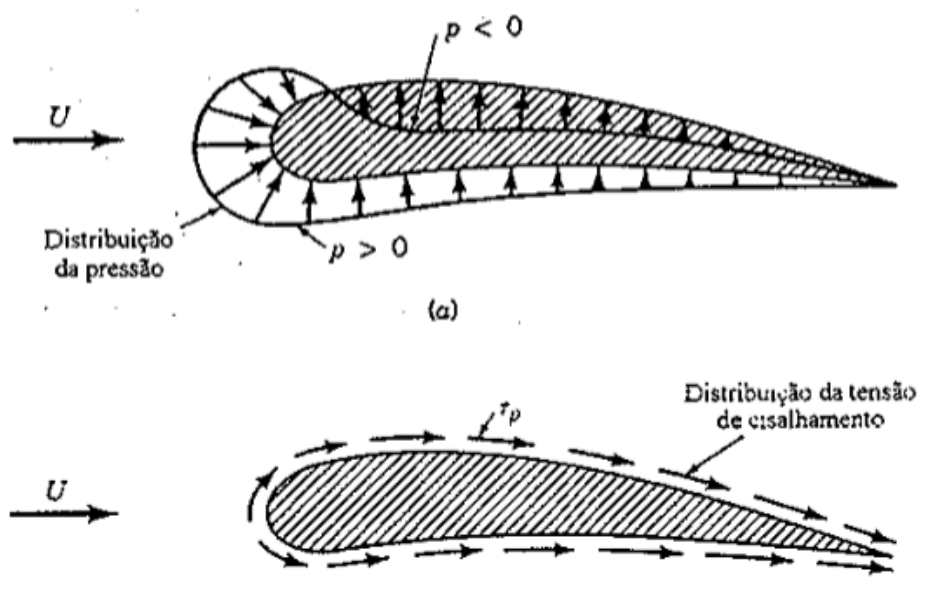

(b)

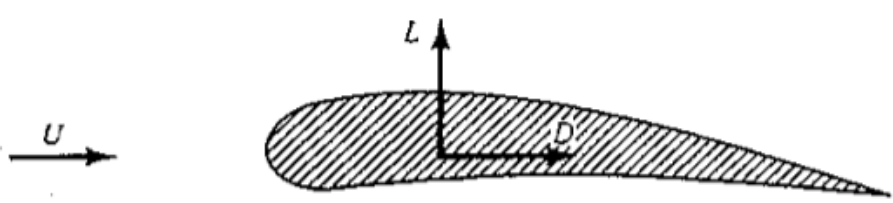

(c)

Fonte: Reproduzido de Munson, Young e Okiishi (2004).

As forças de arrasto e sustentação (e, por consequência, os correspondentes coeficientes) são dependentes do regime de escoamento em análise e, portanto, variam em função do número de Reynolds. Além disso, os coeficientes de força podem ser decompostos em um termo médio $\left(\overline{C_{D}}, \overline{C_{L}}\right)$ e outro de flutuação $\left(C_{D}{ }^{\prime}, C_{L}{ }^{\prime}\right)$. Uma outra análise pode ser feita quanto à parcela representativa dos efeitos viscosos $\left(C_{D f}\right)$ e da pressão $\left(C_{D p}\right)$ do coeficiente de arrasto. A Figura 6 mostra a variação das médias dos coeficientes de força em relação ao número de Reynolds para o caso de um cilindro isolado. Observa-se ainda a presença do termo $C_{L}^{\prime}$ para $R e=200$, responsável pelos efeitos de geração de vórtices.

Já o número de Strouhal $\left(S_{t}\right)$ é o adimensional que representa a frequência de emissão de vórtices e é calculado por:

$$
S_{t}=\frac{f D}{U_{\infty}}
$$

na qual $f$ é a frequência de emissão de vórtices em Hz e $D$ o diâmetro do cilindro. A relação entre o número de Strouhal e o número de Reynolds está representada na Figura 
Figura 6 - Curva da relação entre coeficientes de força e o número de Reynolds para um cilindro isolado.

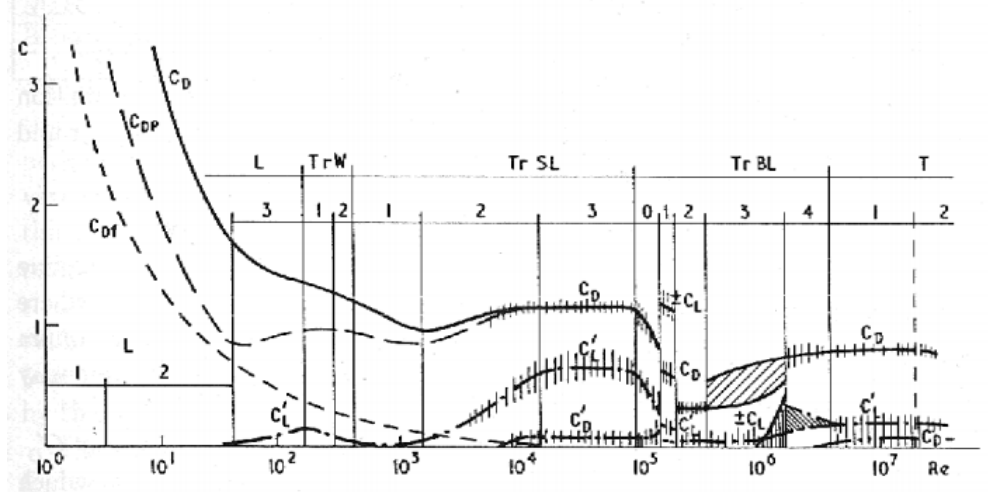

Fonte: Reproduzido de Zdravkovich (1997, apud Carmo (2005)).

7, na qual é possível identificar descontinuidades na curva $S_{t}(R e)$ ou em sua derivada nas proximidades de $R e=200$.

Figura 7 - Curva da relação entre número de Strouhal e $R e^{-\frac{1}{2}}$ para um cilindro isolado.

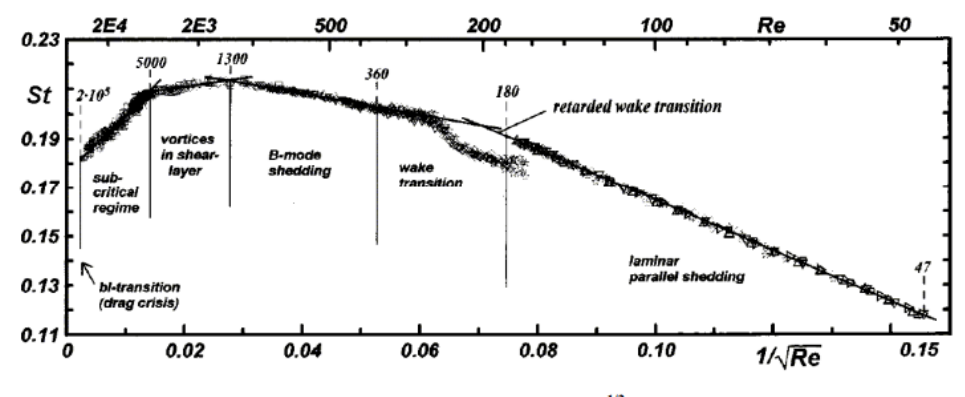

Fonte: Reproduzido de Fey, König e Eckelmanm (1998, apud Carmo (2005)).

\subsection{Escoamento ao redor de múltiplos cilindros}

O escoamento ao redor de múltiplos cilindros tem sido um tema bastante investigado nas últimas décadas. Como visto no capítulo 2, plataformas offshore, trocadores de calor, prédios, linhas de transmissão de energia e risers são alguns dos exemplos de aplicações práticas desse assunto na engenharia.

A presença de cilindros próximos e o efeito do fenômeno de interferência são assuntos presentes nos contextos de corpos fixos (foco deste trabalho) e também em problemas de vibrações induzidas pelo escoamento. A proximidade entre os cilindros resulta em consequências diretas aos coeficientes de forças fluido-dinâmicas, às emissões de vórtices e aos padrões de escoamento. Diversos trabalhos já exploraram esses efeitos sobre o escoamento por meio de diferentes aspectos como número de Reynolds, rugosidade superficial, turbulência, seção geométrica, espaçamento entre cilindros e ângulo de ataque. 
Grande atenção tem sido dada principalmente para casos de escoamento ao redor de um ou dois cilindros, sendo poucas as pesquisas que abordam o tema para mais de dois cilindros. Revisões de literatura para o caso de dois cilindros já foram realizadas por Zdravkovich (1977), Sumner (2010) e Zhou e Alam (2016). Diversas características específicas dessas particulares configurações já foram investigadas, aumentado o entendimento no assunto. Informações podem ser encontradas em Dehkordi, Moghaddam e Jafari (2011), Sarvghad-Moghaddam, Nooredin e Ghadiri-Dehkordi (2011), Sumner, Price e Paidoussis (2000) para configurações em tandem ${ }^{2}$, side-by-side ${ }^{3}$ ou staggered ${ }^{4}$; Wang, Yan e Wang (2013), para cilindros de diâmetros diferentes e Zhao et al. (2016), para cilindros de seção transversal quadrada.

O escoamento ao redor de três ou mais cilindros possui geometria e características do escoamento mais complexas, levando a uma maior gama de possibilidades de estudos. Em relação a esse problema, algumas pesquisas já vêm abordando aspectos específicos. Gu e Sun (2001) propuseram uma classificação dos padrões de escoamento para a configuração de triângulo equilátero ${ }^{5}$ para $R e=1,4 \times 10^{4}$ e $R e=5,5 \times 10^{4}$. Essa classificação foi dividida em quatro faixas de razões de espaçamento: pequena $(1,7 \leq s / D \leq 2,0)$, média $(2,5 \leq s / D \leq 3,0)$, de transição $(s / D=2,2)$ e grande $(s / D \geq 4)$. Além disso, foi apontada a ocorrência de três efeitos de interferência: efeito de proximidade, recolamento das camadas cisalhantes e efeito de esteira. Classificação semelhante foi utilizada por Zheng, Zhang e Lv (2016) em seu estudo para mesma configuração de cilindros, porém para $R e=100$ e 200. Nessa pesquisa, observou-se que as faixa de espaçamento da classificação dos padrões de escoamento variam em relação ao número de Reynolds.

Discutem-se, agora, alguns trabalhos existentes com foco no agrupamento de quatro cilindros. Lam, Gong e So (2008), em seu estudo do escoamento ao redor de quatro cilindros em configuração quadrada, apontaram para importância dos efeitos tridimensionais em cilindros de baixa razão de aspecto (igual a 16), distanciados por uma razão de espaçamento crítica $(s / D=3,5-4,0)$. Para estas condições, eles observaram que as simulações $2 D$ não representavam de forma aceitável o problema, sendo, portanto, necessário o uso simulações $3 D$.

Alam, Zheng e Hourigan (2017), estudaram as características do escoamento ao redor de quatro cilindros em configuração side-by-side para $R e=100$ e quatro espaçamentos entre cilindros. O escomento foi classificado em quatro tipos de regime, dependendo do espaçamento entre cilindros aplicado ao modelo. Os autores observaram que independente do tipo de regime do escoamento, os coeficientes de forças hidrodinâmicas $C_{D}$ e $C_{L}$ eram

2 Cilindros paralelos, separados horizontalmente por uma distância $s$.

3 Cilindros paralelos, separados verticalmente por uma distância $s$.

4 Cilindros paralelos, separados por uma distância $s$ e um ângulo $\alpha$ em relação à direção do escoamento incidente.

5 Nesta configuração, os centros dos cilindros ocupam os vértices do triângulo. 
as mesmas entre os pares de cilindros internos e externos. Contudo, o coeficiente de arrasto dos cilindros internos era maior que o encontrado para os cilindros externos e o coeficiente de sustentação dos cilindros externos era maior que o dos cilindros internos. Já em relação ao $S_{t}$, foi encontrado o mesmo valor para todos os cilindros para o primeiro e último regimes e diferentes valores entre os cilindros internos e externos para o segundo e terceiro regimes.

Bao, Wu e Zhou (2012), investigaram o escoamento ao redor de seis cilindros de seção quadrada em configuração tandem para $R e=100$, variando-se o espaçamento entre cilindros. Foram identificados seis diferentes tipos de escoamentos. Os autores observaram que, mesmo com o aumento do espaçamento entre cilindro, o efeito de blindagem do primeiro cilindro e a redução do efeito Bernoulli nas superfícies laterais dos cilindros a jusante interferem na distribuição da pressão do escoamento.

\subsubsection{Características dos padrões de escoamento}

O espaçamento entre cilindros tem grande impacto sobre o comportamento do escoamento e suas propriedades. A fim de se caracterizar essa relação, Zdravkovich (1987) classificou o fenômeno de interferência entre dois cilindros em:

1. interferência de proximidade, ocorre quando a distância entre cilindros é suficientemente pequena, a ponto do escoamento ao redor de um cilindro ser afetado pela presença do outro cilindro

2. interferência de esteira, ocorre quando um cilindro está imerso ou próximo da região de esteira do outro cilindro;

3. interferência combinada, que é uma combinação entre a interferência de proximidade e a interferência de esteira.

Classificações similares foram adotadas para descrever os padrões de escoamento ao redor de três cilindros, como pode ser visto em Gu e Sun (2001), Bao, Zhou e Huang (2010), Zheng, Zhang e Lv (2016). Essas classificações foram divididas em função da razão de espaçamento em três categorias: pequena, média e larga. Contudo, as faixas de espaçamento são definidas de acordo com os padrões de escoamento observados e que possuem relação direta com o tipo de interferência governante. Desse modo, essas faixas de razão de espaçamento variam em função dos diversos parâmetros que governam o escoamento. O presente texto adotará uma classificação similar à utilizada por Gu e Sun (2001), Bao, Zhou e Huang (2010), Zheng, Zhang e Lv (2016). 


\subsection{Lacunas de conhecimento}

As pequisas calcadas na literatura existente levaram à observação de algumas lacunas de conhecimento, a saber, estudos com quatro ou mais cilindros; variações de geometrias diferentes das tradicionais e análises do escoamento para diferentes ângulos de incidência com relação a um dado eixo. Grande parte dos trabalhos se concentra no estudo do escoamento ao redor de um, dois ou três cilindros, com variação da geometria do cilindro, sendo as formas mais recorrentes as circulares e quadradas, e ainda com variação na configuração geométrica do arranjo. A maioria dos arranjos geométricos estudados são os tradicionais arranjos tandem, side-by-side e staggered. Contudo, com o aumento do número de cilindros presentes nos modelos, diferentes configurações podem ser aplicadas, bem como podem ser analisados também diferentes ângulos de incidência do escoamento. A variação de tais parâmetros leva então a um número muito grande análises que podem ser realizadas. Devido a isso, o estudo, tanto numérico quanto experimental, do escoamento ao redor de múltiplos cilindros é bastante complexo.

Com bases nas lacunas de conhecimento acima apresentadas, este trabalho pretende explorar o campo do escoamento ao redor de quatro cilindros agrupados e não alinhados. Para tanto, será investigada uma configuração geométrica diferente das já abordadas na literatura. O principal aspecto a ser avaliado é o efeito de interferência do escoamento para diferentes razões de espaçamento entre cilindros $(3,0 \leq s / D \leq 5,0)$, bem como o impacto desse fenômento sobre as forças hidrodinâmicas e sobre os padrões de escoamento, incluindo a frequência de emissão de vórtices (representada pelo número de Strouhal). A condição de escoamento utilizada neste problema será para número de Reynolds $R e=200$ e o estudo terá caráter numérico e bidimensional, utilizando o Método dos Volumes Finitos. 


\section{Fluidodinâmica computacional}

Este capítulo trata sobre uma das áreas de conhecimento da mecânica dos fluidos chamada de fluidodinâmica computacional. Aqui, são abordados os principais conceitos acerca do assunto e que serão fundamentais para um melhor entendimento desta pesquisa. O conteúdo deste capítulo é baseado no livro de Versteeg e Malalasekera (2007) e nos tutoriais de ANSYS FLUENT ${ }^{\circledR}$ de Weidner e Wallingford (2017).

\subsection{Introdução à fluidodinâmica computacional}

Fluidodinâmica computacional (CFD) é uma área do conhecimento da mecânica dos fluidos que lida com a análise de sistemas que envolvem escoamento fluidos, transferência de calor e outros fenômenos, tais como reações químicas, por meio de simulações computacionais. Os códigos de CFD são, em geral, estruturados em três partes: pré-processamento, solver e pós-processamento.

No pré-processamento, é definido o modelo matemático do problema físico a ser analisado. Ele é caracterizado por aspectos como condições de contorno, geometria, malha e propriedades do fluido, além de princípios físicos e hipóteses que auxiliarão na descrição do problema. Esses elementos são fundamentais para a acurácia dos resultados obtidos pelas simulações, pois permitem que o modelo matemático se torne uma boa representação da realidade.

No solver estão contidas as equações que descrevem o fluido e o método numérico utilizado para resolvê-las. Essas equações governantes dos fluidos são obtidas através das leis fundamentais da dinâmica dos fluidos: conservação da massa, conservação de momento e conservação de energia. Para a resolução do problema, o domínio deixa de ser considerado um meio contínuo e passa a ser discretizado por meio de uma técnica numérica. Dentre as principais técnicas utilizadas estão o método dos elementos finitos, o método das diferenças finitas, os métodos espectrais e o método dos volumes finitos (FVM), sendo este último o mais amplamente utilizado entre os códigos de CFD e aquele que será utilizado nesta dissertação. Por fim, na fase de pós-processamento, são observados os resultados obtidos pela simulação numérica através de gráficos, figuras e até animações que auxiliam no entendimento e análise do problema.

O uso de softwares de CFD para a resolução de problemas de engenharia tem sido bastante recorrente. Isto se deve à relativa facilidade de criação de modelos numéricos e de obtenção de seus resultados. Contudo, tais ferramentas não substituem a necessidade de análises experimentais, já que essas constituem no único método existente de validação de 
um código numérico, ainda que para casos específicos seja possível a validação por modelos analíticos. Os códigos CFD, portanto, não são capazes de substituir os experimentos, porém são uma poderosa ferramenta adicional na resolução de problemas.

\subsection{Equações que governam o escoamento de fluidos}

As equações que governam o escoamento de fluidos originam-se das leis de conservação da física:

1. Conservação da massa e

2. Conservação da quantidade de movimento (2 $2^{\mathrm{a}}$ Lei de Newton)

Há ainda a lei da conservação da energia. Contudo, para estudos de sistemas que não envolvem transferência de calor e que lidam com escoamentos incompressíveis, é possível desprezar seus efeitos. Esta dissertação tem como foco simulações numéricas que tomam partido das hipóteses acima explicitadas.

As equações assumem tanto a forma diferencial, quanto integral, dependendo do domínio na qual são aplicadas, podendo ser em partículas infinitesimais ou volumes de controle (VC), respectivamente. As duas formas são equivalentes, conduzindo à mesma solução final.

Além disso, o formato das equações também decorre do sistema de referência adotado para descrever o fluido. Dentre eles, destacam-se os sistemas: lagrangeano e euleriano. No sistema lagrangeano, cada propriedade da partícula é representada em função de sua posição inicial $(x, y, z)$ no espaço e de um instante de tempo $t$. Contudo, tal método torna-se bastante limitado quando se trabalha com um número grande de partículas. Por esta razão, o sistema euleriano é usualmente mais utilizado, descrevendo o fluido a partir de pontos ou regiões fixas no espaço.

As leis de conservação da massa e da conservação da quantidade de movimento para um escoamento incompressível são representadas, respectivamente, pelas Equações tridimensional 4.1 e 4.2 .

- Equação da continuidade ou da conservação da massa:

$$
\frac{\partial}{\partial x}\left(\rho u_{i}\right)=0
$$

na qual $\rho$ é a massa específica, $t$ o tempo, $u$ a velocidade do fluido e $x$ a direção da coordenada. 
- Equação da conservação da quantidade de movimento linear:

$$
\frac{\partial}{\partial t}\left(\rho u_{i}\right)+\frac{\partial}{\partial x_{j}}\left(\rho u_{i} u_{j}\right)=\frac{\partial \tau_{i j}}{\partial x_{j}}
$$

na qual $\mu$ é a viscosidade dinâmica, $\delta_{i j}$ é o delta de Kronecker, $p$ é a pressão e $\tau_{i j} \mathrm{o}$ tensor tensao para fluidos newtonianos, com viscosidade dinamica constante (Equação 4.3)

$$
\tau_{i j}=-p \cdot \delta_{i j}+\mu \cdot\left(\frac{\partial u_{i}}{\partial x_{j}}+\frac{\partial u_{j}}{\partial x_{i}}\right)
$$

\subsection{Métodos dos volumes finitos}

O método dos volumes finitos é uma técnica numérica utilizada para a resolução das equações que governam os fluidos. Essa técnica consiste na divisão do domínio em pequenos volumes de controle nos quais as equações de conservação na forma integral são aplicadas. Tal procedimento resulta em um conjunto de equações algébricas (uma para cada equação de conservação, em cada volume de controle). A Figura 8 apresenta um fluxograma das principais etapas contidas no método.

Figura 8 - Fluxograma do método dos volumes finitos para o método centralizado.

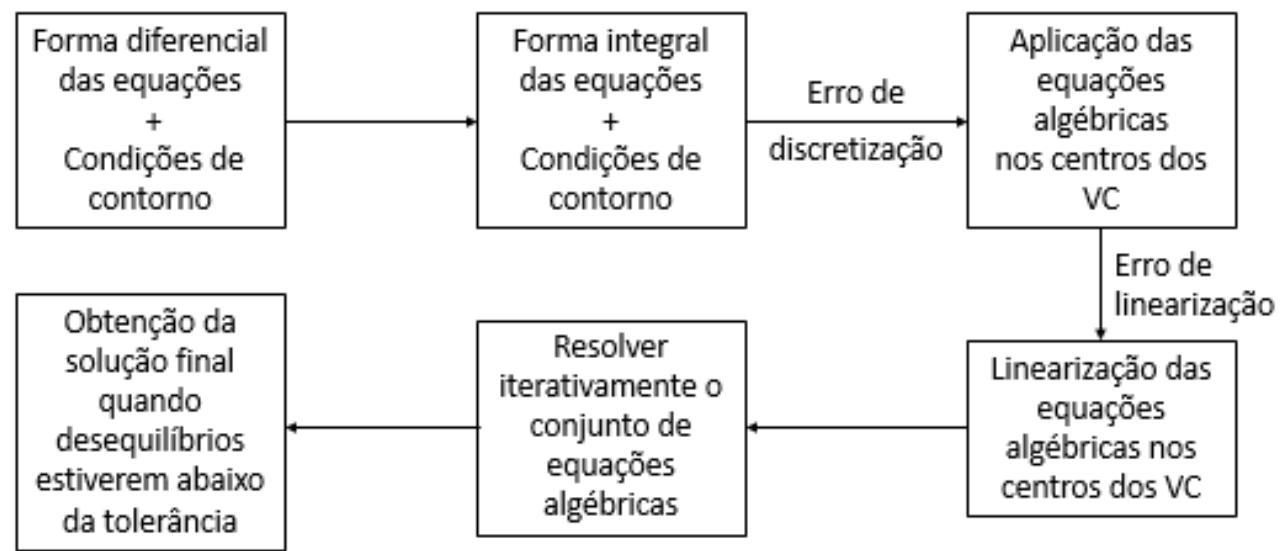

Fonte: Autora.

Nas próximas subseções serão apresentados os conceitos de malha, discretização, solução de equações e erros numéricos, importantes para o entendimento do método.

\subsubsection{Malha}

A malha é constituída por um conjunto finito de volumes de controle, que podem adquirir geometrias variadas. Em relação ao modelo matemático, a malha se traduz na 
representação do domínio do escoamento, particionado em elementos discretos. A Figura 9 ilustra a configuração de uma malha bidimensional formada por elementos quadriláteros.

A quantidade de elementos de uma malha é um dos fatores condicionantes para a minimização de erros de discretização. Como será visto na subseção 4.3.4, o aumento do número de elementos pode levar a diminuição de tal erro. Contudo, o refinamento da malha aumenta o custo computacional de processamento da simulação, podendo se tornar fator limitante para a obtenção da solução.

Figura 9 - Modelo de malha bidimensional.

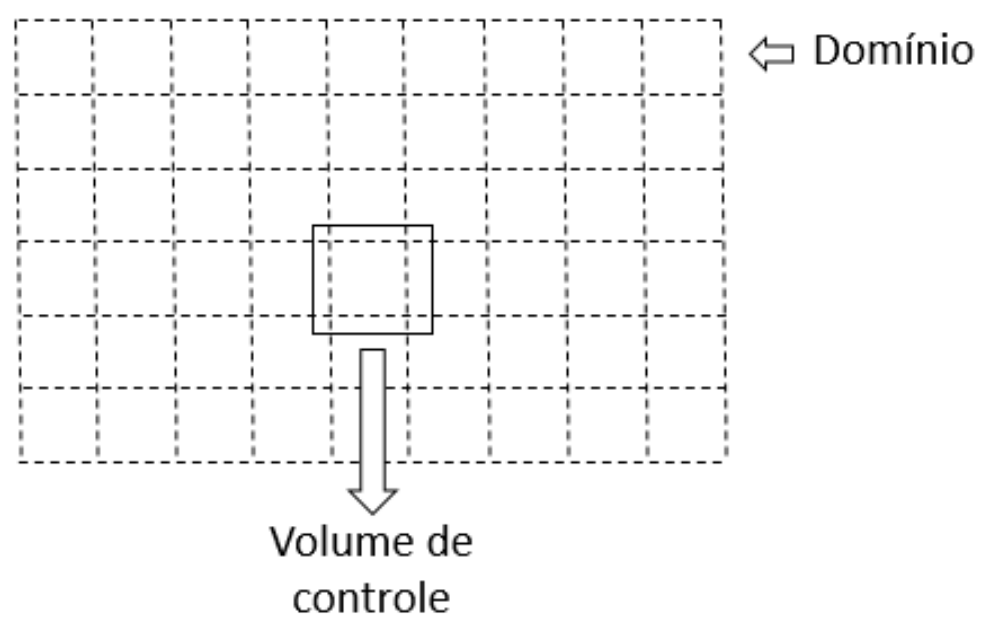

Fonte: Autora.

\subsubsection{Discretização}

A discretização é a etapa na qual o problema (ou modelo matemático) é reduzido à determinação de um conjunto de valores de propriedades (como, por exemplo, campos de velocidade e de pressão) em determinados pontos $C_{n, n}$, conforme mostra a Figura 10. Esse processo envolve a integração das equações de conservação na forma diferencial sobre cada volume de controle do domínio.

A forma integral dessas equações permite que elas sejam aplicadas sobre o domínio discretizado, resultando em um conjunto de equações algébricas. Aproximações lineares das propriedades dos centros $C_{n, n}$ de volumes de controle adjacentes são utilizadas nos cálculos de gradientes nas faces destes elementos (representadas por $\times$, na Figura 10). Tal técnica recebe o nome de diferenciação central. Vale ainda ressaltar que essas aproximações adicionam um erro de discretização à solução.

Outra etapa importante no processo de discretização é a linearização. Devido ao fato das equações algébricas possuírem termos não-lineares, a linearização desses termos é fator condicionante para a resolução destas equações. Essa etapa introduz um novo tipo de erro chamado erro de linearização. 
Figura 10 - Discretização do modelo matemático para malha centralizada.

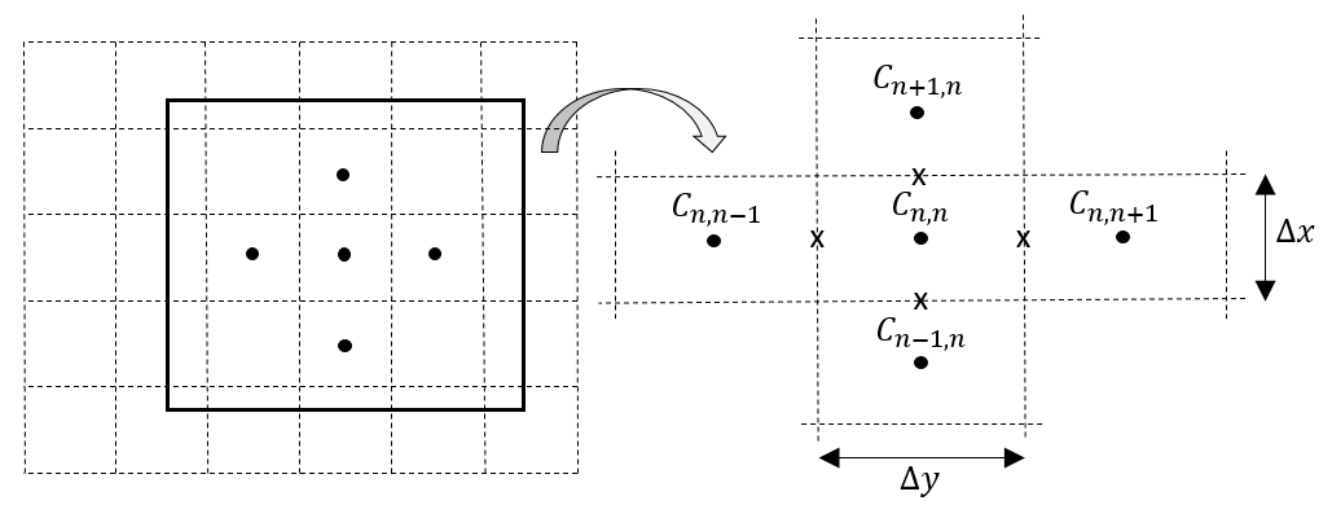

Fonte: Autora.

\subsubsection{Solução das equações}

As condições de contorno do escoamento - velocidades prescritas, condições de saída e de simetria - são aplicadas aos volumes de controle adjacentes à fronteira do domínio e alteram as equações algébricas. O sistema de equações algébricas resultante das etapas anteriores pode então ser resolvido por meio de métodos matriciais de solução, resultando em um conjunto de valores distribuídos nos pontos $C_{n, n}$ do domínio.

O processo de solução envolve a suposição de valores iniciais das propriedades e uma contínua correção desses valores a fim de que as leis de conservação sejam válidas em cada volume de controle. Esse processo iterativo é realizado até que o desequilíbrio de fluxos de entrada e saída (massa e momento) de cada volume de controle fique abaixo de uma determinada tolerância aceitável, como pode ser observado pela Figura 11.

Vale ressaltar que além do método acima descrito existem também outros critérios de erro.

\subsubsection{Erros Numéricos}

Acurácia e nível de confiança dos resultados são fatores essenciais que justificam as aplicações da modelagem em CFD como uma ferramenta complementar nas aplicações em engenharia. Um meio de quantificar a credibilidade das soluções numéricas é através de um conjunto de boas práticas chamado de verificação e validação. Essas atividades são essencialmente diferentes e foram definidas por Eça, Vaz e Hoekstra (2010) como:

verificação: exercício matemático que aborda erros de codificação e numéricos. Consiste em duas etapas:

1. Verificação do código: através da avaliação de erros, tem por objetivo avaliar o código que contém o algoritmo necessário para resolver o modelo matemático. 
Figura 11 - Fluxograma de resolução das equações

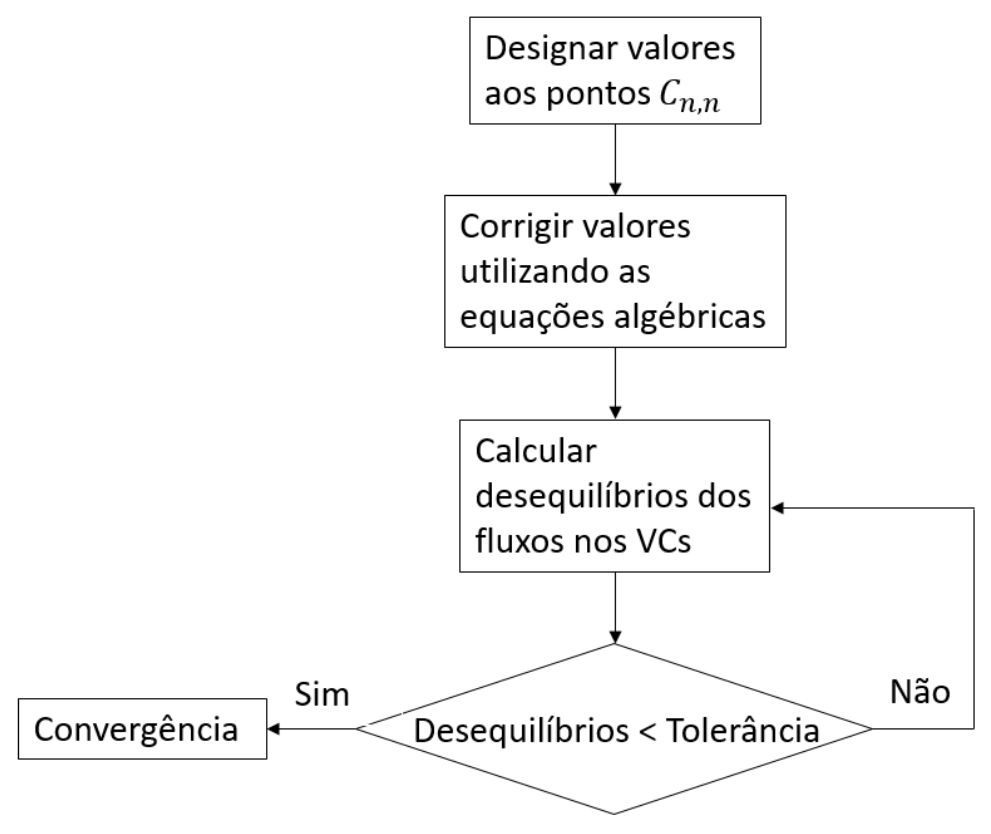

Fonte: Autora.

2. Verificação da solução: visa estimar a incerteza/erro do resultado numérico na qual a solução exata não é conhecida.

validação: etapa na qual lida-se com erros de modelagem, objetivando-se provar que o modelo matemático é uma boa representação do problema físico (real).

Nas etapas de construção do FVM são incorporados diversos erros ao processo. Eles consistem em deficiências existentes no modelo de CFD que não são causadas por falta de conhecimento. Suas causas são devido à:

- Erros numéricos: erros de arredondamento, erros de iteração ou convergência e erros de discretização

- Erros de codificação: erros ou problemas nos códigos de CFD

- Erros do usuário: erros devido ao mau uso do programa de CFD

Ao se tratar de erros numéricos, dois aspectos fundamentais para a obtenção de bons resultados são: convergência e independência de malha. A obtenção de tais características depende de uma série de fatores relacionados aos erros de arredondamento, iteração e discretização.

O erro de arredondamento está relacionado à precisão da máquina, ou seja, à representação computacional do número real através de dígitos finitos. Práticas como o uso de pressão relativa (gauge pressure) a um ponto de referência específico são utilizadas como métodos de controle desse tipo de erro pois evita a perda de dígitos significativos. 
O erro de iteração resulta do processo iterativo das equações algébricas necessário para se obter a solução final. A convergência ocorre se a diferença entre a solução final e a solução atual diminui à medida que o número de iterações aumenta. Tal processo estabelece um critério de truncamento no qual as iterações cessam quando a solução for suficientemente próxima da solução final. Existem diversos métodos utilizados para a criação de critérios de truncamento, como por exemplo o método dos resíduos. Nos códigos de CFD, a convergência é atingida por meio da especificação de uma tolerância para os resíduos globais das equações de massa, quantidade de movimento e energia. O truncamento então ocorre quando todos os resíduos forem menores do que essa tolerância pré-estabelecida.

Por fim, o erro de discretização corresponde ao erro introduzido na discretização do domínio. No método clássico, isso envolve a aproximação de derivadas de espaço e tempo por meio do truncamento de expansões de séries de Taylor que negligencia termos de maiores ordens. A distribuição e magnitude do erro de discretização são altamente influenciados pela malha - modelo, tipo e número de elementos dentre outros. O controle desse tipo de erro pode ser feito através da progressiva redução do passo de tempo e do aumento de número de elementos da malha.

Contudo, vale ressaltar que existem ainda deficiências que são causadas por falta de conhecimento. Estas são chamas de incertezas, sendo suas principais causas:

- Incertezas nas variáveis de entrada: falta de acurácia do modelo matemático (por exemplo, condições de contorno, propriedades dos materiais e geometria) devido à limitação de informações ou aproximações estabelecidas.

- Incerteza do modelo físico: divergência entre o modelo matemático e a realidade devido à inapropriada representação do problema físico (como o tipo de regime: laminar, de transição e turbulento) ou às simplificações ou hipóteses assumidas no processo de modelagem (como o estado do escoamento e a incompressibilidade do escoamento). 


\section{Simulações numéricas}

Este capítulo destina-se à apresentação do modelo matemático investigado. Inicialmente, serão definidos a geometria, os parâmetros numéricos, as condições de contorno e domínio do fluido. Em seguida, será realizado um estudo de malha para o caso $s=3 D$, o qual tem por finalidade ajustar e otimizar o modelo matemático proposto. Por fim, serão apresentados dados relativos ao escoamento ao redor de um cilindro isolado e que serão utilizados como base de comparação para os resultados obtidos (apresentados no capítulo $6)$.

\subsection{Modelo matemático}

Esta seção apresenta os parâmetros que caracterizarão o modelo matemático e está dividida em quatro subseções: geometria e parâmetros do modelo matemático (subseção 5.1.1), condições de contorno (subseção 5.1.2) e domínio do fluido (subseção 5.1.3).

\subsubsection{Geometria e parâmetros do modelo matemático}

O modelo matemático investigado neste trabalho é um caso bidimensional, composto de quatro cilindros circulares não alinhados, fixos e de diâmetro $D=1 \mathrm{~m}$. A fim de se facilitar o entendimento das discussões, esses cilindros são denominados por: cilindro frontal ou a montante $(\mathrm{CF})$, cilindro central (CM), primeiro cilindro a jusante (CT) e segundo cilindro à jusante (CB), conforme ilustra a Figura 12. Cada cilindro é espaçado em relação ao centro do cilindro CM por distância, definida como $s$. Foram explorados cinco casos de espaçamento $s$, sendo eles: $3 D ; 3,5 D ; 4 D ; 4,5 D$ e $5 D$.

Os cilindros a jusante (CT e CB) são afastados da linha de simetria do modelo segundo um ângulo $\alpha=30^{\circ}$. A distância horizontal entre $\mathrm{CF}$ e os cilindros a jusante é dada por $H$ e a distância vertical entre CT e CB vale B.

Com relação às características do escoamento, adotou-se: velocidade de escoamento uniforme $U_{\infty}=1 \mathrm{~m} / \mathrm{s}$, com direção inclinada à linha de simetria por um ângulo $\beta$; viscosidade dinâmica $\mu=0,005 \mathrm{~kg} / \mathrm{ms}$ e massa específica $\rho=1 \mathrm{~kg} / \mathrm{m}^{3}$, resultando em número de Reynolds igual a 200. Quanto às simulações, utilizaram-se o método dos volumes finito, cálculos com dupla-precisão e passo de tempo $\Delta t=0,01 s$. A Tabela 1 traz um resumo dos parâmetros que definem o modelo matemático. 
Figura 12 - Geometria do modelo investigado.

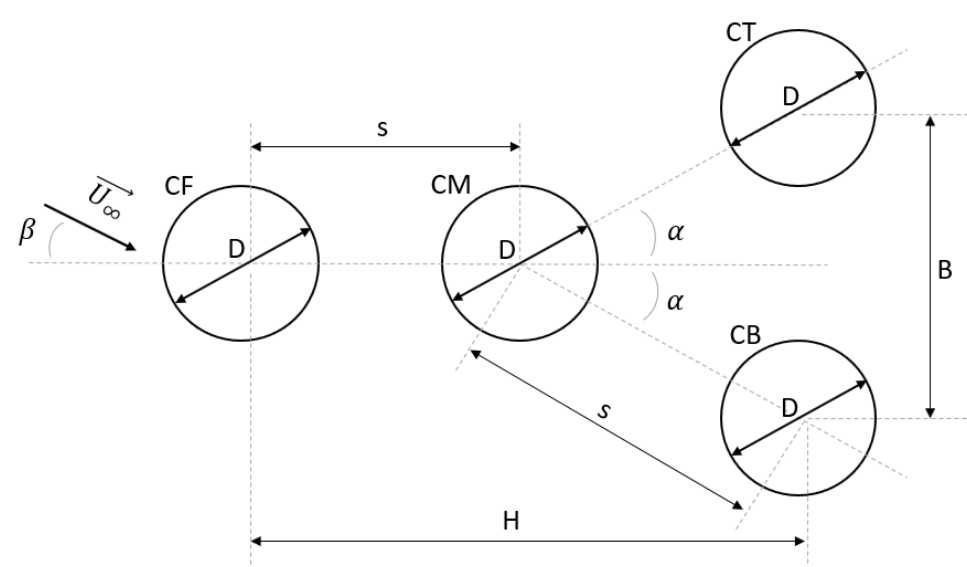

Fonte: Autora.

Tabela 1 - Parâmetros adotados nas simulações.

\begin{tabular}{c|c}
\hline \hline Parâmetros & Valores \\
\hline \hline$D$ & $1 \mathrm{~m}$ \\
\hline$\alpha$ & $30^{\circ}$ \\
\hline$\beta$ & $0^{\circ} \mathrm{e} 180^{\circ}$ \\
\hline$\left|\overrightarrow{U_{\infty}}\right|$ & $1 \mathrm{~m} / \mathrm{s}$ \\
\hline$\mu$ & $0,005 \mathrm{~kg} / \mathrm{ms}$ \\
\hline$\rho$ & $1 \mathrm{~kg} / \mathrm{m}^{3}$ \\
\hline$R e$ & 200 \\
\hline$s$ & $3 D ; 3,5 D ; 4 D ; 4,5 D$ e $5 D$ \\
\hline$\Delta t$ & $0,01 \mathrm{~s}$ \\
\hline \hline
\end{tabular}

Fonte: Autora.

\subsubsection{Condições de contorno e Modelo computacional}

Foram aplicados três casos de condições de contorno ao modelo matemático. Esses casos estão ilustrados na Figura 13 e são definidas por:

- Limite de entrada e laterais (linhas vermelhas): perfil de velocidade uniforme e de valor $1 \mathrm{~m} / \mathrm{s}$, no sentido $+\hat{\imath}$;

- Limite de saída (linha verde): pressão manométrica de saída igual a zero e gradiente das demais variáveis nulo;

- Paredes dos cilindros (circunferências azuis): condição de não-escorregamento, na qual representa o estado de velocidade nula do fluido em relação à parede. 
Figura 13 - Condições de contorno.

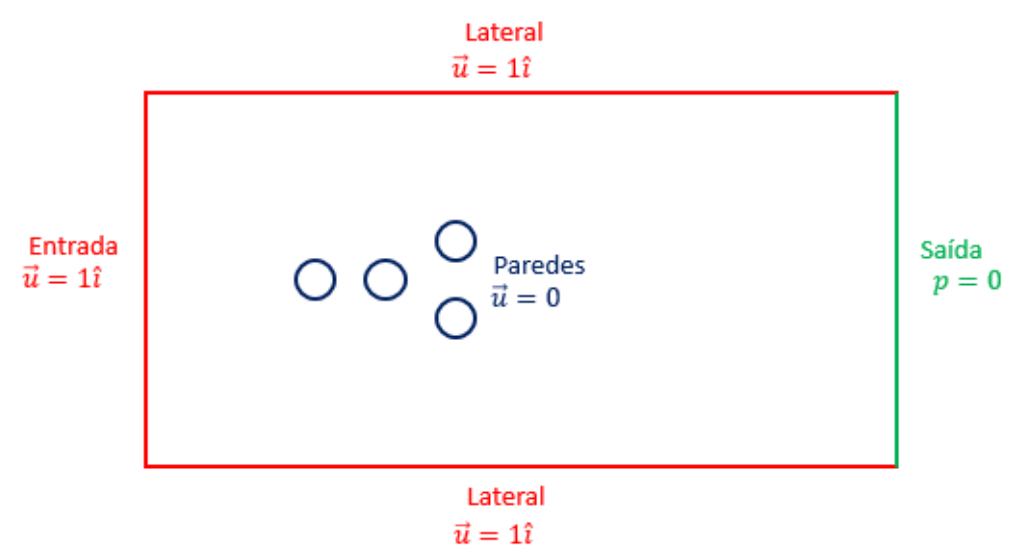

Fonte: Autora.

Para o cálculo de viscosidade, foi adotado um modelo de escoamento laminar. Como método de solução utilizou-se o algorítimo PISO (Pressure-Implicit with Splitting of Operators) com discretização espacial de segunda ordem para pressão e momento.

\subsubsection{Domínio do fluido}

As dimensões do domínio do fluido seguiram as mesmas diretrizes adotadas em Rosetti, Vaz e Fujarra (2012), no qual realizou-se uma série de simulações para o caso de cilindro isolado. Contudo, devido à geometria do modelo investigado, foram feitas alterações na escala do domínio.

O fator de escala $D$, diâmetro do cilindro, foi substituído por dois outros parâmetros. Para a escala vertical, optou-se por utilizar a dimensão $B$ e para a horizontal, a dimensão $H$. A Figura 14 ilustra as dimensões do domínio descrito acima.

Figura 14 - Dimensões do domínio.

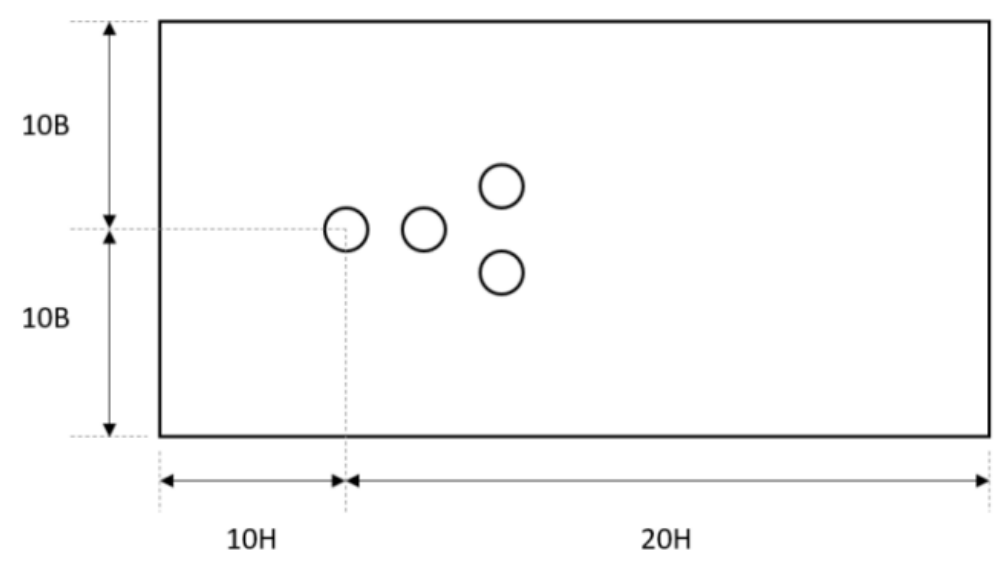

Fonte: Autora.

Além disso, foram aplicadas diferentes taxas de refinamento dependendo da região 
do domínio, conforme pode ser observado na Figura 15. Nota-se um maior refinamento das zonas ao redor dos cilindros e de suas esteiras. Isso se deve à tentativa de minimizar os erros de discretização referentes aos significativos gradientes de velocidades esperados nestas regiões.

Figura 15 - Malha típica do modelo do domínio.

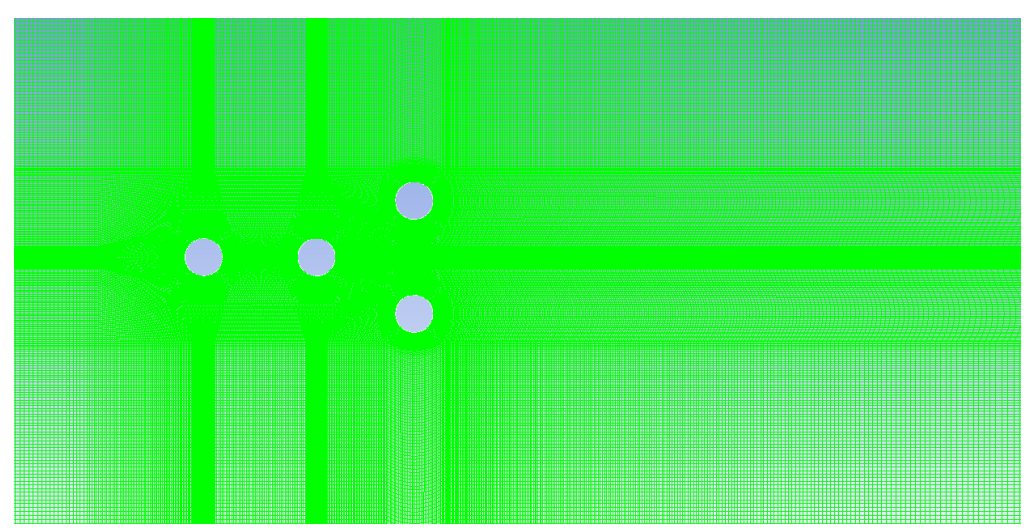

Fonte: Autora.

\subsection{Estudo de malha e processo de convergência}

Com vistas à minimização de efeitos de blocagem que poderiam eventualmente ocorrer, o primeiro modelo de domínio adotado nas simulações diferia daquele apresentado na subseção 5.1.3. A este primeiro modelo, ilustrado na Figura 16, dá-se o nome de M1 e ao modelo final (Figura 14), de M2.

Figura 16 - Dimensões do modelo inicial M1.

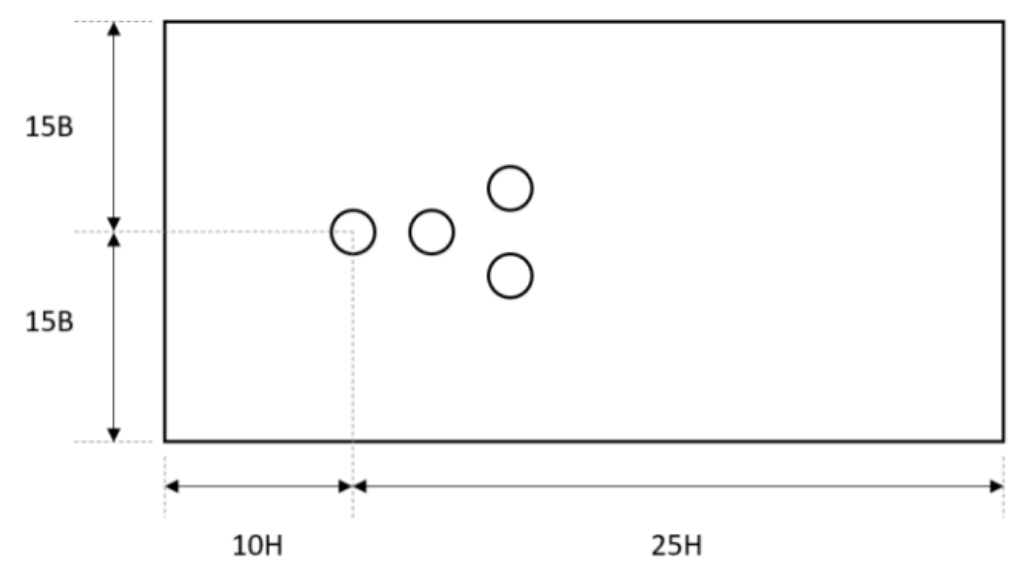

Fonte: Autora.

Apesar de possuírem geometrias bastante semelhantes, os dois modelos diferem em relação aos seus comprimentos. Tal alteração se deve à necessidade de reduzir o número de elementos utilizados nas simulações. O estudo de malha do caso $s=3 D$ mostrou 
que, conforme os resultados das simulações convergiam, o número de elementos cresciam consideravelmente, a ponto de tornar o custo computacional uma limitação de projeto, principalmente para os outros casos espaçamentos. Com base nessa informação, optou-se por criar o modelo M2 já ilustrado na Figura 14. A Tabela 2 mostra o tipo de modelo utilizado para cada valor de espaçamento entre cilindros.

Tabela 2 - Tipo de domínio utilizado em cada caso $s$.

\begin{tabular}{c|c}
\hline \hline$s$ & Modelo do Domínio \\
\hline \hline $3 D$ & M1 e M2 \\
\hline $3,5 D$ & $\mathrm{M} 2$ \\
\hline $4 D$ & $\mathrm{M} 2$ \\
\hline $4,5 D$ & $\mathrm{M} 2$ \\
\hline $5 D$ & $\mathrm{M} 2$ \\
\hline \hline
\end{tabular}

Fonte: Autora.

Com relação ao processo de convergência, esse consistiu em um estudo de refinamento de malha, no qual o domínio era refinado até que se atingisse a convergência dos resultados das simulações. Para tanto, foram necessários realizar cinco casos de refinamento que variavam em taxas de 1,2, 1,3, 1,4 e 1,5 da malha mais refinada. Ou seja, um bloco da malha mais fina, refinado a uma taxa de 1,5 , possuiria 2,25 vezes mais elementos do que o mesmo bloco na malha menos refinada. Cada caso de refinamento foi nomeado por: A, B, C, D e E em ordem crescente de refino. A Tabela 3 mostra o número de elementos de cada malha para o caso $s=3 D$, utilizando-se o domínio M1.

Tabela 3 - Número de elementos do caso $s=3 D$ e domínio M1.

\begin{tabular}{c|c|c|c|c|c}
\hline \hline$s$ & $\mathrm{~A}$ & $\mathrm{~B}$ & $\mathrm{C}$ & $\mathrm{D}$ & $\mathrm{E}$ \\
\hline \hline $3 D$ & 163.088 & 187.324 & 217.584 & 256.645 & 364.806 \\
\hline \hline
\end{tabular}

Fonte: Autora.

Utilizou-se como medida de verificação de convergência os resultados das séries temporais de coeficiente de arrasto $\left(C_{D}\right)$ em cada cilindro. Para cada uma dessas séries temporais, foram calculadas suas médias $\left(\overline{C_{D}}\right)$. Os resultados de cada caso de refinamento foram então comparados com os coeficientes de arrasto da malha mais refinada, calculandose a diferença entre seus valores, conforme a equação 5.1 .

$$
{ }_{j}^{E} \Delta C_{D}=\frac{\left|{ }_{j}^{E} \overline{C_{D}}-{ }_{j}^{i} \overline{C_{D}}\right|}{{ }_{j}^{E} \overline{C_{D}}} \times 100
$$


na qual ${ }_{j}^{E} \overline{C_{D}}$ é a média do coeficiente de arrasto do cilindro $j(j=\mathrm{F}, \mathrm{M}$, T e B) da malha mais refinada (no caso $s=3 D$, esta é representada pela malha $\mathrm{E}$ ) e ${ }_{j}^{i} \overline{C_{D}}$ é o coeficiente de arrasto médio do cilindro $j$ para a malha $i(i=\mathrm{A}, \mathrm{B}, \mathrm{C}$ e $\mathrm{D})$.

As Tabelas 4 e 5 exemplificam o processo de convergência para o caso $s=3 D$. A Tabela 4 apresenta os valores de $\overline{C_{D}}$ para cada cilindro em cada caso de refinamento. É possível observar que os valores de $\overline{C_{D}}$ para CT e CB são bastante similares. De fato, essa similaridade já era esperada, pois a geometria do modelo matemático é simétrica e a direção do escoamento do fluido é paralela à linha de centro.

A variação das médias dos coeficientes de arrasto $\left(\Delta C_{D_{j-E}}\right)$ para cada caso de refinamento é mostrada na Tabela 5. Nota-se que seus valores tendem a diminuir com o aumento da taxa refinamento, indicando o alcance da convergência dos resultados. Foi determinado que a validação do processo de convergência ocorreria para o caso em que se atingisse $\Delta C_{D_{j-E}}<1 \%$ para todos os cilindros.

Tabela 4 - Coeficientes de arrasto médio de cada cilindro para o caso $s=3 D$ e domínio M1.

\begin{tabular}{c|c|c|c|c}
\hline \hline Malha & CF & CM & CT & CB \\
\hline \hline A & 0,897 & $-0,224$ & 1,215 & 1,215 \\
B & 0,895 & $-0,222$ & 1,211 & 1,211 \\
C & 0,894 & $-0,221$ & 1,209 & 1,210 \\
D & 0,892 & $-0,220$ & 1,207 & 1,207 \\
E & 0,890 & $-0,218$ & 1,203 & 1,203 \\
\hline \hline
\end{tabular}

Fonte: Autora.

Tabela 5 - Diferença dos coeficientes de arrasto médio de cada cilindro para o caso $s=3 D$ e domínio M1.

\begin{tabular}{c|c|c|c|c}
\hline \hline Casos & CF & CM & CT & CB \\
\hline \hline E-A & $0,81 \%$ & $2,51 \%$ & $1,05 \%$ & $1,05 \%$ \\
E-B & $0,56 \%$ & $1,71 \%$ & $0,72 \%$ & $0,72 \%$ \\
E-C & $0,46 \%$ & $1,37 \%$ & $0,57 \%$ & $0,58 \%$ \\
E-D & $0,28 \%$ & $0,88 \%$ & $0,36 \%$ & $0,37 \%$ \\
\hline \hline
\end{tabular}

Fonte: Autora.

Os resultados das médias dos coeficientes de sustentação e do número de Strouhal de cada cilindro para as malhas refinadas (A a E) estão apresentados nas Tabelas 6 e 7 , respectivamente. O método de cálculo do número de Strouhal é descrito na Seção 6.4.

Tendo-se em vista que o processo de convergência do caso $s=3 D$ foi realizado utilizando-se a domínio M1, simulou-se um novo caso de refinamento E com a mesma 
Tabela 6 - Coeficientes de sustentação médio de cada cilindro para o caso $s=3 D$ e domínio M1.

\begin{tabular}{c|c|c|c|c}
\hline \hline Malha & CF & CM & CT & CB \\
\hline \hline A & $6,8 \mathrm{E}-5$ & $-5,43 \mathrm{E}-5$ & $-0,099$ & 0,099 \\
B & $4,2 \mathrm{E}-5$ & $-2,93 \mathrm{E}-5$ & $-0,099$ & 0,099 \\
C & $3,6 \mathrm{E}-5$ & $-8,99 \mathrm{E}-5$ & $-0,099$ & 0,099 \\
D & $3,4 \mathrm{E}-5$ & $-3,78 \mathrm{E}-5$ & $-0,099$ & 0,099 \\
E & $1,3 \mathrm{E}-5$ & $6,29 \mathrm{E}-5$ & $-0,099$ & 0,099 \\
\hline \hline
\end{tabular}

Fonte: Autora.

Tabela 7 - Número de Strouhal de cada cilindro para o caso $s=3 D$ e domínio M1.

\begin{tabular}{c|c|c|c|c}
\hline \hline Malha & CF & CM & CT & CB \\
\hline \hline A & 0 & 0,099 & 0,175 & 0,175 \\
B & 0 & 0,099 & 0,175 & 0,175 \\
C & 0,099 & 0,099 & 0,175 & 0,175 \\
D & 0 & 0,099 & 0,175 & 0,175 \\
E & 0,099 & 0,099 & 0,175 & 0,175 \\
\hline \hline
\end{tabular}

Fonte: Autora.

densidade de elementos da malha anterior, porém utilizando-se o domínio M2. Tal medida foi adotada para que se pudesse aproveitar os resultados de processo de convergência já realizado e comparar os resultados obtidos em cada caso de espaçamento $s$.

A Tabela 8 apresenta os resultados dos coeficientes de arrasto das malhas E para os domínios M1 e M2 em $s=3 D$. É possível notar que os resultados gerados pelos dois modelos de domínio são bastante similares, indicando que efeitos de blocagem (motivação inicial para a construção dos modelos M1 e M2) não se mostraram presentes.

Tabela 8 - Coeficientes de arrasto médio das malhas E, utilizando os modelos M1 e M2 para o caso $s=3 D$.

\begin{tabular}{c|c|c|c|c}
\hline \hline Modelo & CF & CM & CT & CB \\
\hline \hline M1 & 0,890 & $-0,218$ & 1,203 & 1,203 \\
M2 & 0,900 & $-0,219$ & 1,219 & 1,219 \\
\hline \hline
\end{tabular}

Fonte: Autora.

A Tabela 9 mostra o número de elementos das malhas mais refinadas E para todos os casos de espaçamento $s$, com o domínio M2. 
Tabela 9 - Número de elementos das malhas E para todos os casos $s$ utilizando o domínio $\mathrm{M} 2$.

\begin{tabular}{c|c}
\hline \hline$s$ & Número de elementos \\
\hline \hline $3 D$ & 231.362 \\
$3,5 D$ & 295.226 \\
$4 D$ & 386.211 \\
$4,5 D$ & 481.781 \\
$5 D$ & 586.346 \\
\hline \hline
\end{tabular}

Fonte: Autora.

\subsection{Caso de cilindro isolado}

Com a obtenção dos resultados gerados pelas simulações do modelo matemático proposto, tornou-se evidente a necessidade de criar uma base de comparação para a pesquisa. Para isso, optou-se por formular um caso de escoamento bidimensional ao redor de um cilindro fixo e isolado. Nesse novo caso adotou-se os mesmo parâmetros apresentados na Tabela 1, densidade de elementos igual ao do modelo de refinamento da malha $\mathrm{E}$ em $s=3 D$ e domínio de dimensões semelhantes às do modelo $\mathrm{M} 2$, porém com fator de escala $D$ (ao invés de $H$ e $B$ ). Os resultados gerados a partir deste caso serviram como base de comparação para os resultados obtidos nas simulações do modelo de quatro cilindros investigado nesta pesquisa e estão apresentados na Tabela 10. Essa tabela apresenta, ainda, resultados gerados por outros estudos semelhantes do escoamento ao redor de um cilindro caracterizado por $R e=200$.

Tabela 10 - Comparação dos resultados obtidos para o caso de cilindro isolado a número de Reynolds $R e=200$.

\begin{tabular}{c|c|c|c|c|}
\hline \hline Referência & $\overline{C_{D}} \pm \sigma_{C_{D}}$ & $\widehat{C_{L}}$ & $\sigma_{C_{L}}$ & $S_{t}$ \\
\hline \hline Rosenfeld, Kwak e Vinokur (1991) & $1,31 \pm 0,04$ & & 0,65 & 0,20 \\
Liu, Zheng e Sung (1998) & $1,31 \pm 0,05$ & & 0,69 & 0,19 \\
Wright e Smith (2001) & $1,33 \pm 0,04$ & & 0,68 & 0,20 \\
Calhoun (2002) & $1,17 \pm 0,06$ & & 0,67 & 0,20 \\
Russell e Wang (2003) & $1,29 \pm 0,02$ & & 0,50 & 0,20 \\
Williamson (1991) & & & & 0,196 \\
Presente estudo & $1,37 \pm 0,04$ & 1,433 & 0,51 & 0,20 \\
\hline \hline
\end{tabular}

Fonte: Autora.

As Figuras 17 e 18 mostram, respectivamente, a série temporal do coeficiente de sustentação e o contorno de vorticidade em um instante de tempo do caso de cilindro isolado. Nota-se que a série temporal é livre de modulações em amplitude, atingindo o estado de regularidade das oscilações em aproximadamente $t=80$. A partir da figura de 
contorno de vorticidade, observa-se que um padrão regular de desprendimento de vórtices com o tempo, comportamento típico apresentado por cilindros estacionários na presença de um escoamento incidente, sendo tal fenômeno conhecido como esteira de von Kármán.

Figura 17 - Série temporal do coeficiente de sustentação para o caso de cilindro isolado.

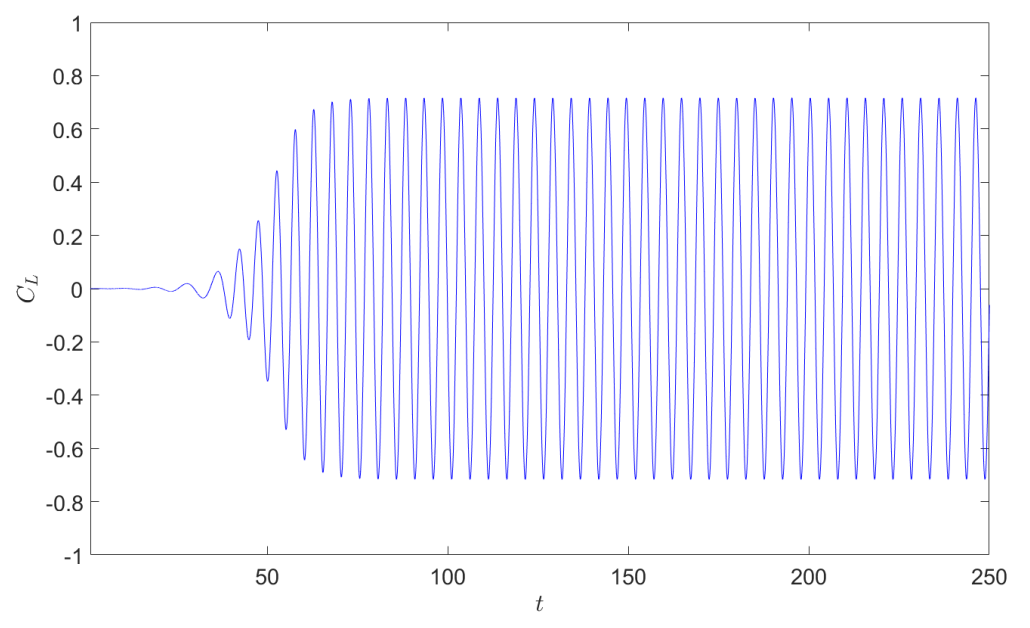

Fonte: Autora.

Figura 18 - Contorno de vorticidade no plano xy para um particular instante para o caso de cilindro isolado.

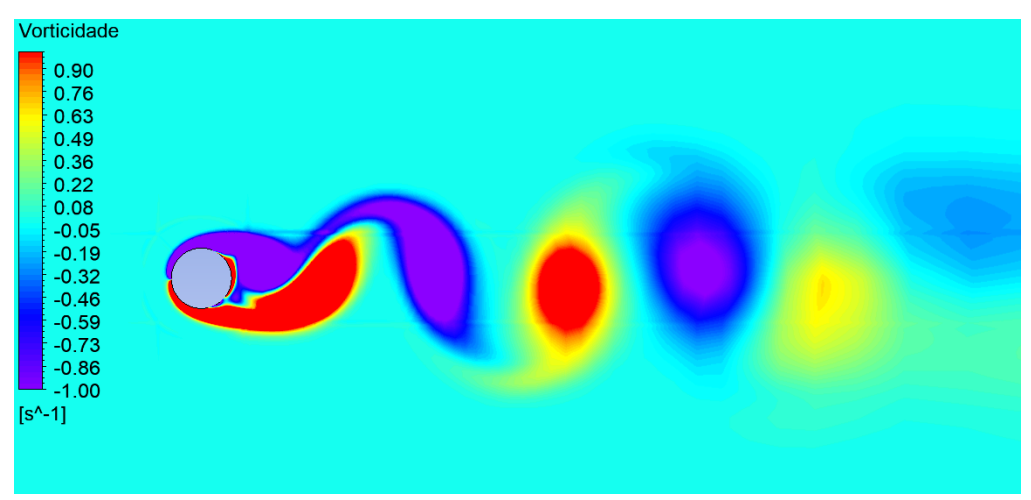

Fonte: Autora. 


\section{Resultados e discussões}

Este capítulo apresenta os resultados obtidos a partir das simulações numéricas do modelo matemático apresentado na Seção 5.1. São analisados cinco casos de espaçamento entre cilindros - $s=3 D ; 3,5 D ; 4 D ; 4,5 D$ e $5 D$ - para dois diferentes valores de ângulo de incidência - $\beta=0^{\circ}$ e $180^{\circ}$ (ver Figura 12). Com o intuito de melhor elucidar as discussões aqui contidas, este capítulo está dividido em 4 seções. A primeira, aborda as características dos padrões do escoamento do modelo matemático que estão agrupadas nas razões de espaçamento média e larga. A razão de espaçamento média abrange o caso $s=3 D$ para $\beta=0^{\circ}$ e os casos $s=3 D$ e $s=3,5 D$ para $\beta=180^{\circ}$. Já a razão de espaçamento larga aborda os casos $s=3,5 D, 4 D, 4,5 D$ e $5 D$ para $\beta=0^{\circ}$ e $s=4 D, 4,5 D$ e $5 D$ para $\beta=180^{\circ}$. Nas seções 6.2 e 6.3, são realizadas análises dos coeficientes de força em cada cilindro. Por fim, na seção 6.4, explora-se os resultados referentes aos números de Strouhal.

\subsection{Características dos padrões de escoamento}

Nesta seção, as características dos padrões do escoamento estão agrupadas em duas distintas razões de espaçamento: média e larga. O presente trabalho não aborda espaçamentos entre cilindros menores que $s=3 D$, variação na qual a autora acredita que efeitos de proximidade seriam predominantes no escoamento. Por essa razão, não há uma classificação de razão de espaçamento "pequena" neste trabalho. Assim, a classificação inicia-se pela razão de espaçamento média.

\subsubsection{Razão de espaçamento média}

A razão de espaçamento média é caracterizada por uma combinação de efeitos causados pela interferência de proximidade e pela interferência de esteira.

Para $\beta=0^{\circ}$, o caso que melhor reflete esse fenômeno é aquele caracterizado por $s=3 D$. A Figura 19 mostra o contorno de vorticidade, para um particular instante de tempo, do campo de escoamento para $s=3 D$. Nota-se que o desenvolvimento do campo de emissão de vórtices do cilindro frontal $(\mathrm{CF})$ é suprimido pelo cilindro intermediário (CM) que, por sua vez, tem seu campo suprimido pelos cilindros a jusante (CT e CB), ainda que sejam observados indícios de formação de vórtices nas esteiras de CF e CM. Tal fenômeno fica bastante evidente ao se observar as linhas de corrente do escoamento como mostra a Figura 20. Observa-se que os vórtices formados na esteira do cilindro central (CM) são menores dos que os encontram-se na esteira do cilindro frontal (CF). Essa diferença no tamanho dos vórtices parece estar relacionada com a presença tanto 
dos cilindros a jusante (CT e CB) (provocando o estreitamento de sua região de esteira) quanto de $\mathrm{CF}$, que modifica o escoamento incidente em CM.

Outro fator interessante, já relatado em pesquisas anteriores como a de Dehkordi, Moghaddam e Jafari (2011), é o fato de que as camadas cisalhantes que se desprendem do cilindro mais a montante $(\mathrm{CF})$ se incorporam à superfície de CM. Em relação aos cilindros CT e CB, nota-se a formação de esteiras de vórtices, com modos de emissão de vórtices em antífase. Tal comportamento provoca uma simetria das linhas de corrente instantâneas. Destaca-se ainda a tendência das esteiras de vórtices dos cilindros de se misturarem e se agruparem em uma única grande esteira.

Figura 19 - Contorno de vorticidade no plano xy para um particular instante para $\beta=0^{\circ}$ e $s=3 D$.

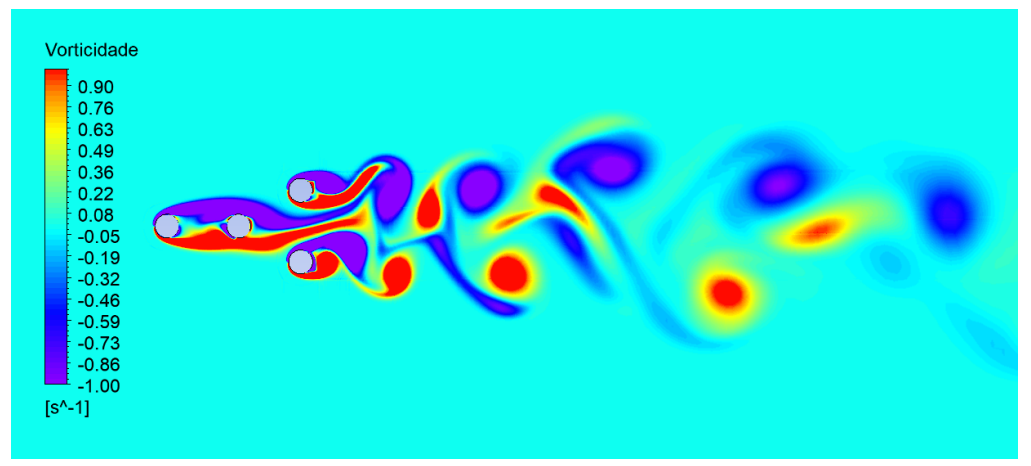

Fonte: Autora.

Figura 20 - Linhas de corrente do campo de velocidades para um particular instante para $\beta=0^{\circ}$ e $s=3 D$.

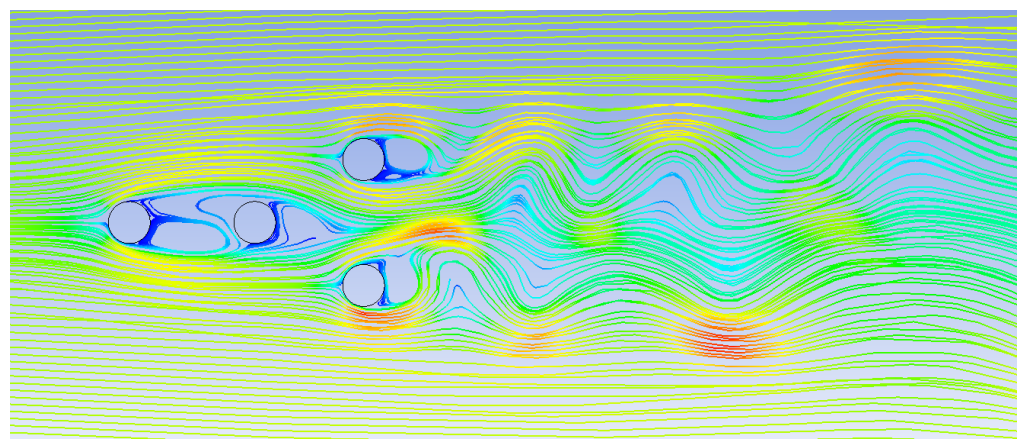

Fonte: Autora.

Para $\beta=180^{\circ}$, a razão de espaçamento média abrange os casos $s=3 D$ e $s=3,5 D$. Assim como no caso para $\beta=0^{\circ}$, é observada a supressão da emissão de vórtices dos cilindros a jusante (CM e CF), porém com indícios de sua formação, como mostra a Figura 21. Nota-se ainda que as camadas cisalhantes desses cilindros (CM e CF) são refletidas para fora, levando à formação de um escoamento simétrico (Figura 21). Por fim, com relação aos cilindros a montante (CT e CB), observa-se emissãos de vórtices em antífase para ambos os casos $s$ (Figura 22). 
Figura 21 - Linhas de corrente do campo de velocidades para um particular instante para $\beta=180^{\circ}$ e (a) $s=3 D$ e (b) $s=3,5 D$.

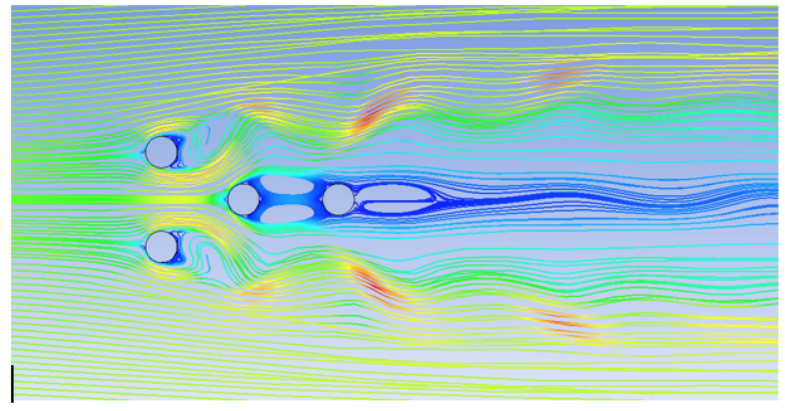

(a)

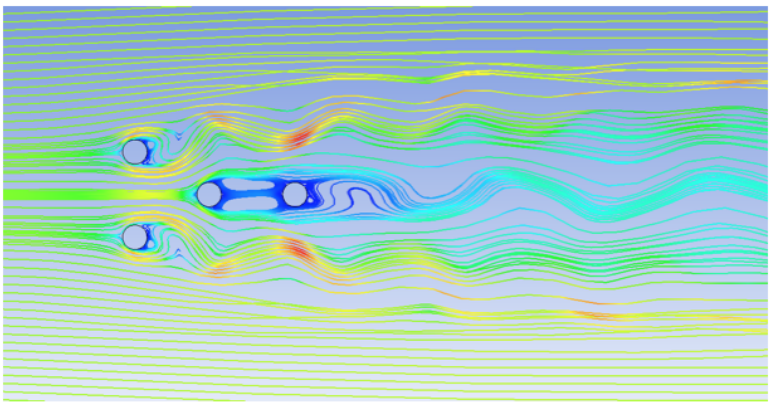

(b)

Fonte: Autora.

Figura 22 - Contorno de vorticidade no plano xy para um particular instante para $\beta=180^{\circ}$ e (a) $s=3 D$ e (b) $s=3,5 D$.

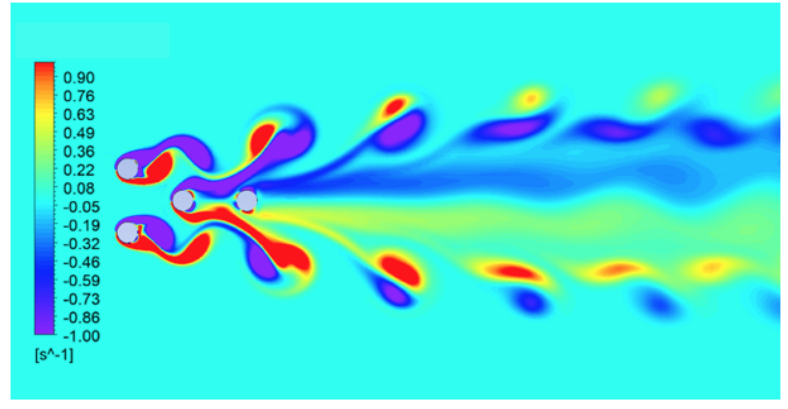

(a)

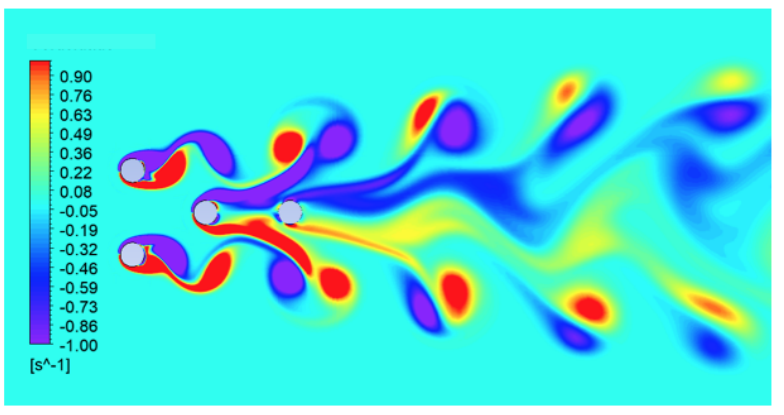

(b)

Fonte: Autora.

\subsubsection{Razão de espaçamento larga}

Esta faixa de razão de espaçamento é caracterizada pela predominância do efeito de esteira e pela diminuição do efeito de proximidade sobre o escoamento. Tal fenômeno abrange os casos $s \geq 3,5 D$ para $\beta=0^{\circ}$ e $s \geq 4 D$ para $\beta=180^{\circ}$.

Nos casos que se referem ao ângulo de incidência $\beta=0^{\circ}$, as consequências de tais efeitos podem ser observadas na Figura 23. Nela, verifica-se a formação de esteiras de von Kármán para os cilindros a montante (CF e CM). O leitor que retornar à subseção 6.1.1 notará que essas esteiras eram suprimidas para a condição de espaçamento $s=3 D$. Nota-se, também, que os vórtices gerados pelo cilindro central (CM) parecem impactar as esteiras dos cilindros a jusante (CT e CB) e que seus efeitos são minimizados com o aumento do espaçamento. Isso leva à formação de esteiras mais uniformes que deixam de se misturar entre si conforme aumenta o espaçamento entre os cilindros, com exceção das esteiras dos cilindros CF e CM que se incorporam em uma única em todos os casos $s$. No que tange às de emissões de vórtices dos cilindros a jusante, essas passam a se 
comportar em fase. O retorno à seção anterior mostra que, para $s=3 D$, essas emissões eram observadas em antífase.

Figura 23 - Contorno de vorticidade no plano xy para um particular instante para $\beta=0^{\circ}$ e (a) $s=3,5 D$; (b) $s=4 D$; (c) $s=4,5 D$ e (d) $s=5 D$.

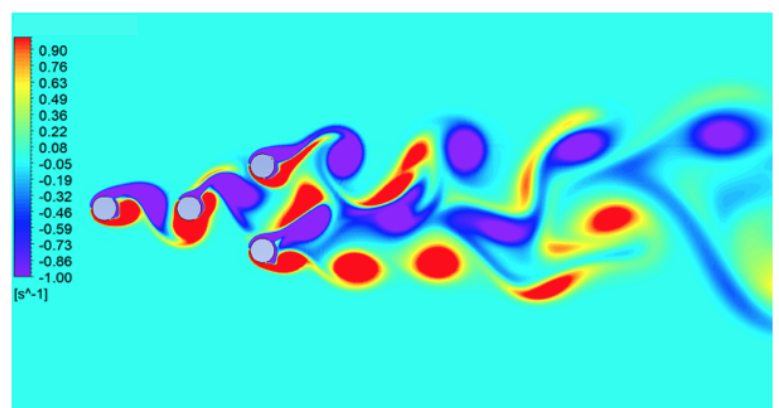

(a)

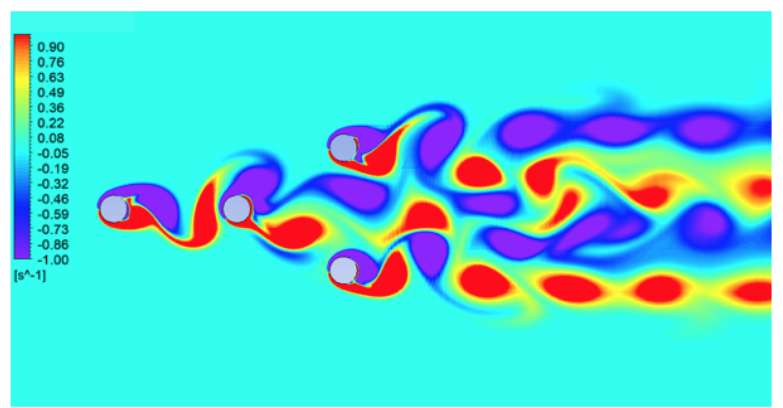

(c)

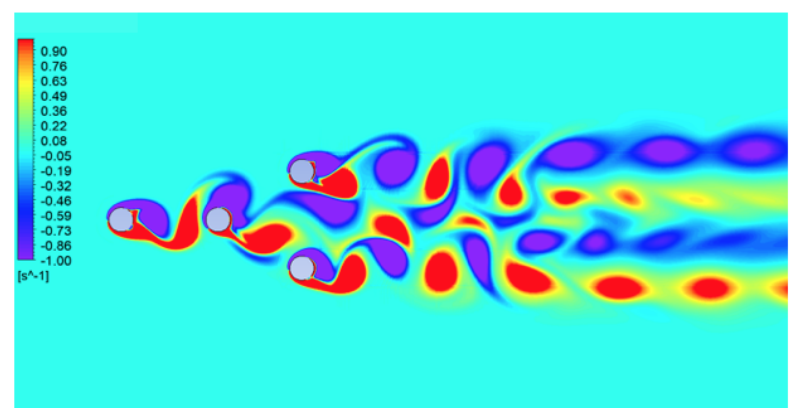

(b)

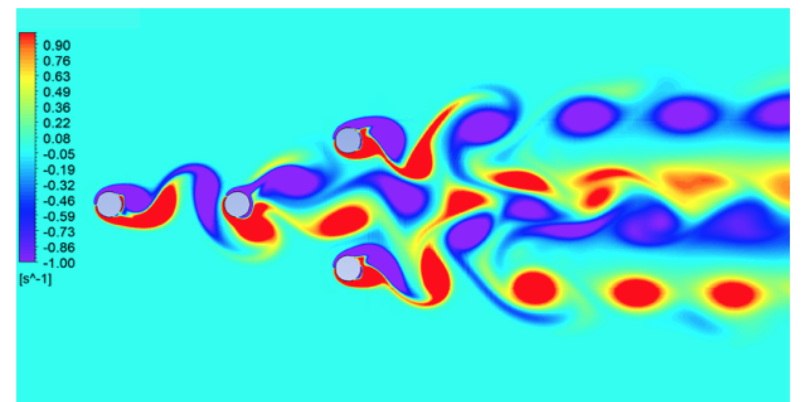

(d)

Fonte: Autora.

Já para os casos $\beta=180^{\circ}$, também observa-se a formação de esteiras de von Kármán, agora, em todos os cilindros (CT, CB, CM e CF), como pode ser observado na Figura 24. Com o aumento do espaçamento, as esteiras de vórtices dos cilindros frontais (CT e CB) deixam de interagir tão fortemente com as esteiras dos cilindros CM e CF e passam a apresentar esteiras independentes e mais regulares. Por fim, destaca-se que as emissões de vórtices de CT e CB permanecem em antífase, assim como verificado na subseção anterior 6.1.1. 
Figura 24 - Contorno de vorticidade no plano xy para um particular instante para $\beta=180^{\circ}$ e (a) $s=4 D$; (b) $s=4,5 D$ e (c) $s=5 D$.

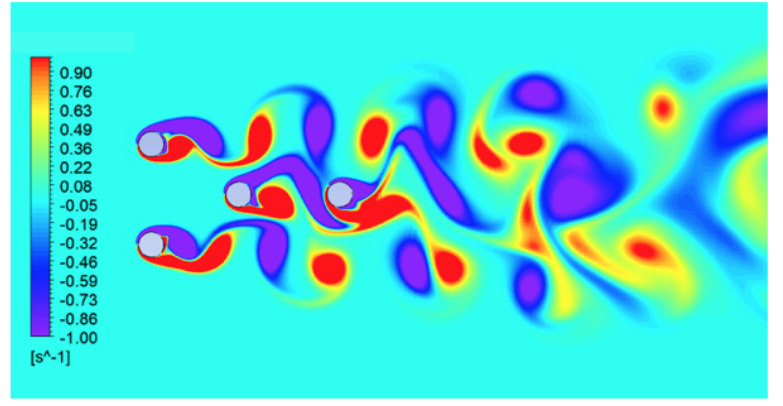

(a)

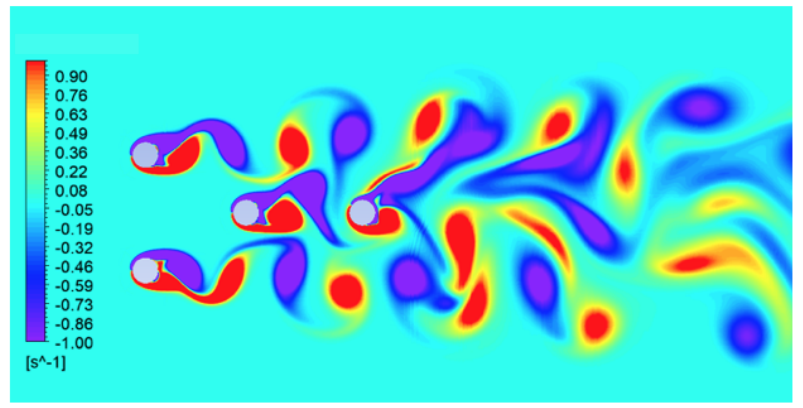

(b)

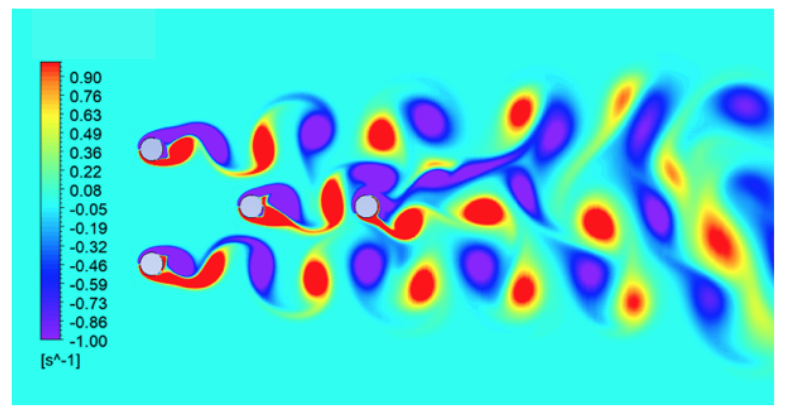

(c)

Fonte: Autora.

\subsection{Coeficiente de arrasto médio}

Esta seção é dividida em duas partes, nas quais serão analisados os coeficientes de arrasto médio por cilindro (subseção 6.2.1) e os coeficientes de arrasto médio do sistema (subseção 6.2.2) para os ângulos de incidência $\beta=0^{\circ}$ e $\beta=180^{\circ}$.

\subsubsection{Coeficiente de arrasto médio por cilindro}

Para os casos com ângulo de incidência $\beta=0^{\circ}$, a Figura 25(a) mostra a variação do coeficiente de arrasto médio em relação ao espaçamento entre cilindros. Como base de comparação, apresenta-se também o resultado obtido com o cilindro isolado, identificado por CI.

Nota-se que, para $s=3 D$, os cilindros a montante (CF e $\mathrm{CM}$ ) apresentam valores de coeficiente de arrasto médio consideravelmente inferiores àqueles observados para os outros espaçamentos aqui estudados e também do valor encontrado para o caso de cilindro isolado. Tal análise será conduzida com o auxílio dos contornos de pressão ilustrados na Figura 26. 
Figura 25 - Variação do coeficiente de arrasto médio com o espaçamento $s$ para (a) $\beta=0^{\circ}$ e (b) $\beta=180^{\circ}$.

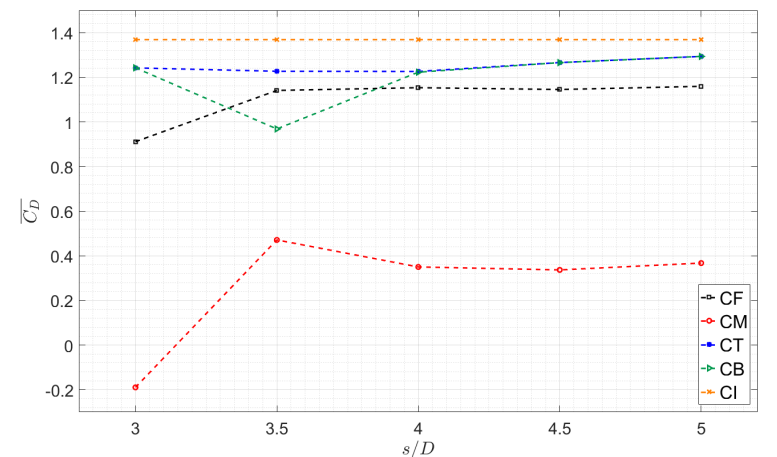

(a)

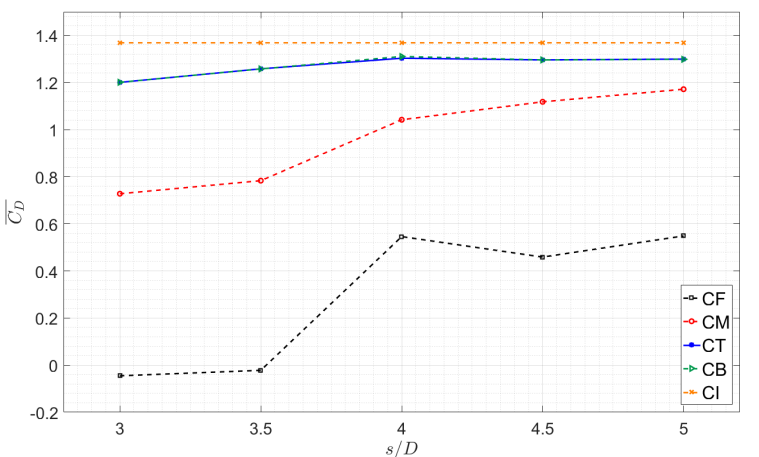

(b)

Fonte: Autora.

O baixo valor do coeficiente de arrasto dos cilindros CF e CM ocorre devido ao desenvolvimento de uma região de esteira de baixa pressão que se forma a jusante de CF. A presença do cilindro central (CM) leva, então, a um aumento de pressão nessa região, provocando uma diminuição da força de arrasto no cilindro frontal (CF). Já o baixo valor verificado em CM deve-se ao fato da pressão em sua região posterior ser ligeiramente mais elevada do que a pressão em sua região frontal, como pode ser visto na Figura 26. Tais fenômenos também foram observados no trabalho de Dehkordi, Moghaddam e Jafari (2011), que realizaram simulações numéricas ao redor de dois cilindros em configuração tandem. Além disso, um outro fator que pode estar envolvido no baixo valor do coeficiente de arrasto médio de CM está relacionado com a interferência que a presença dos cilindros a jusante (CT e CB) causa à região de esteira de CM (Figura 20).

Figura 26 - Contorno de pressão ao redor dos cilindros para $\beta=0^{\circ}$ e $s=3 D$.

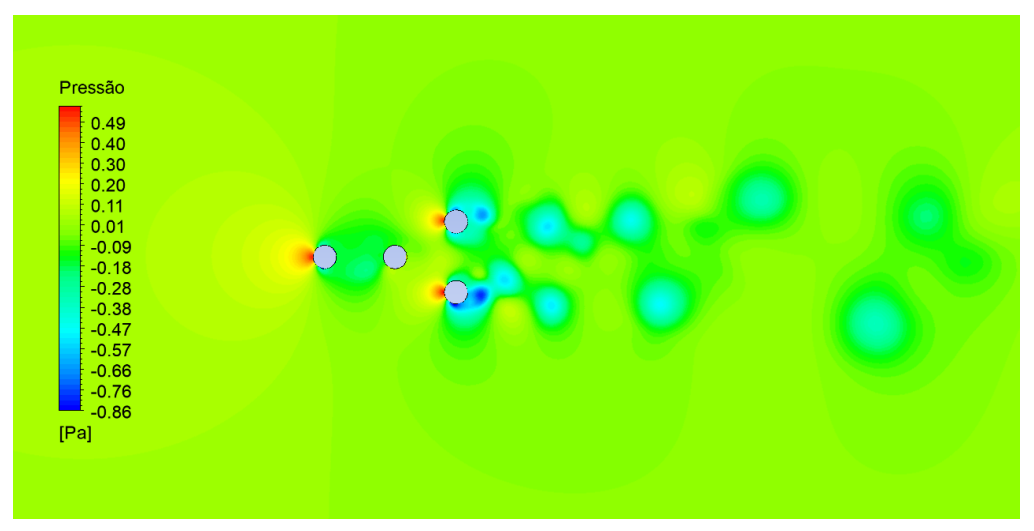

Fonte: Autora.

Com o aumento da distância entre cilindros, os efeitos de interferência de proximidade tendem a diminuir, levando a um aumento nos valores do coeficiente de arrasto médio. O aumento do espaçamento $s$ modifica ainda o escoamento de modo que as camadas 
cisalhantes que se desprendem de CF e CM passam a obedecer um comportamento oscilatório de emissão de vórtices (Figura 23), provocando um aumento do coeficiente médio de arrasto de seus cilindros a jusante.

Outro ponto interessante é a diferença entre coeficientes de arrasto observada nos cilindros a jusante $(\mathrm{CT}$ e $\mathrm{CB}$ ) para o caso $s=3,5 \mathrm{D}$. Tal fato pode estar relacionado com o comportamento descrito na Subseção 6.1.2, no qual as esteiras desses cilindros deixam de se misturar com as esteiras de CF e CM com o aumento do espaçamento entre cilindros. O impacto causado pelas esteiras dos cilindros CF e CM nas esteiras dos cilindros a jusante deixaria de ocorrer primeiramente em um dos cilindros e posteriormente no outro, conforme mostra a Figura 23(a). Isso provocaria a quebra de simetria do escoamento, bem como uma diferença nas forças hidrodinâmicas sobre os cilindros CT e CB.

Por fim, observa-se que o coeficiente de arrasto médio do cilindro central (CM) passa a ser positivo para $s \geq 3,5 D$. Tal fato se deve ao aumento da pressão na sua região de estagnação frontal, que passa a ser maior que a região do seu lado oposto (base), conforme mostra a Figura 27.

Figura 27 - Contorno de pressão ao redor dos cilindros para $\beta=0^{\circ}$ e (a) $s=3,5 D$; (b) $s=4 D ;(\mathrm{c}) s=4,5 D$ e (d) $s=5 D$.

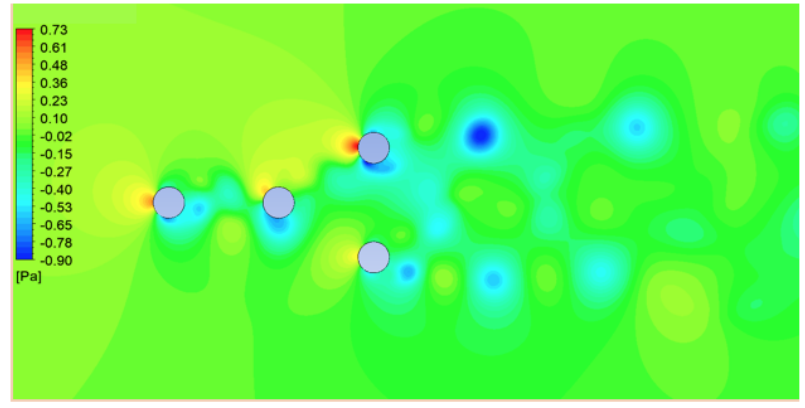

(a)

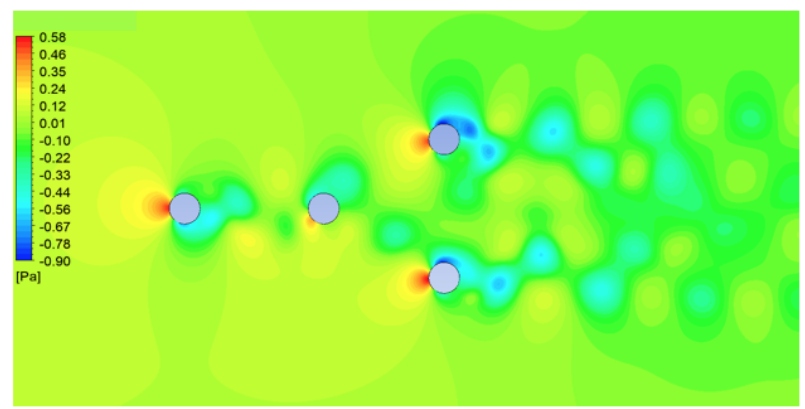

(c)

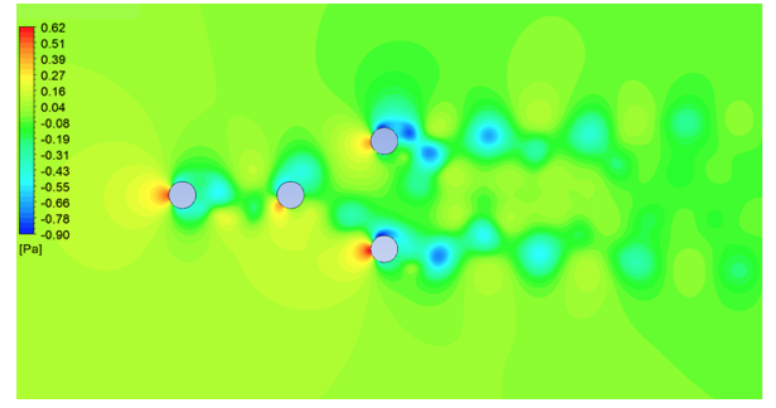

(b)

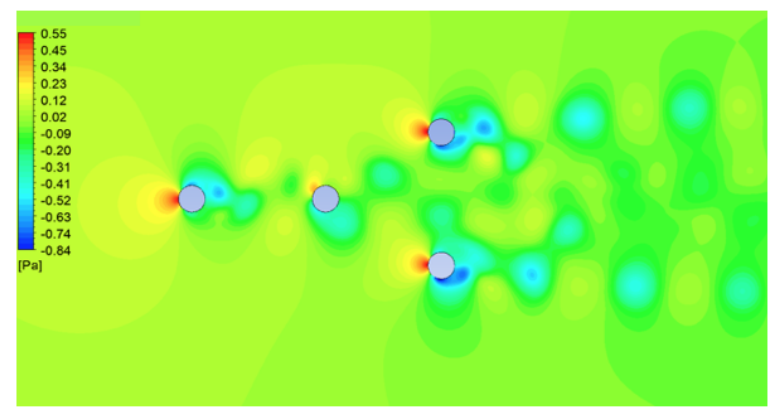

(d)

Fonte: Autora.

Já a Figura 25(b) apresenta a variação do coeficiente de arrasto médio em relação ao espaçamento entre cilindros para os casos $\beta=180^{\circ}$. É nítida a presença de dois padrões nos valores dos coeficientes de arrasto dos cilindros a jusante (CM e CF). O primeiro padrão 
é observado nos casos $s=3 D$ e $s=3,5 D$, caracterizado pela presença de coeficientes de arrasto negativos e próximos a zero para o cilindro mais a jusante $(\mathrm{CF})$ e coeficientes de arrasto menores que 0,8 para o cilindro central (CM). O segundo padrão de comportamento contempla os casos $s=4 D ; 4,5 D$ e $5 D$. Para esses casos, há um repentino aumento dos valores dos coeficientes de arrasto para ambos os cilindros, atingindo valores próximos de 0,5 para o cilindro $\mathrm{CF}$ e valores maiores que 1 para $\mathrm{CM}$.

Com relação aos cilindros a montante (CT e CB), nota-se que seus valores são iguais em intensidade em todos os casos de espaçamento estudados. Além disso, para os mesmos grupos de casos $s$ discutidos anteriormente $(s=3 D$ e $3,5 D$ e $s=4 D ; 4,5 D$ e $5 D$ ), observa-se que nos casos do primeiro grupo, os coeficientes de arrasto de CT e CB tendem a aumentar à medida que aumenta o espaçamento entre cilindros. Já no segundo grupo, os coeficientes de arrasto tendem a manterem-se constantes à medida que a distância aumenta.

\subsubsection{Coeficiente de arrasto médio do sistema}

As Figuras 28(a) e (b) apresentam a variação do coeficiente de arrasto médio do sistema composto pelos quatro cilindros em relação ao espaçamento entre cilindros $s$ para $\beta=0^{\circ}$ e $\beta=180^{\circ}$, respectivamente. Note que, em uma aplicação relacionada a uma plataforma flutuante offshore, esse parâmetro é de fundamental importância em uma série de aspectos do projeto.

Figura 28 - Variação do coeficiente de arrasto médio do sistema com o espaçamento $s$ para (a) $\beta=0^{\circ}$ e (b) $\beta=180^{\circ}$.

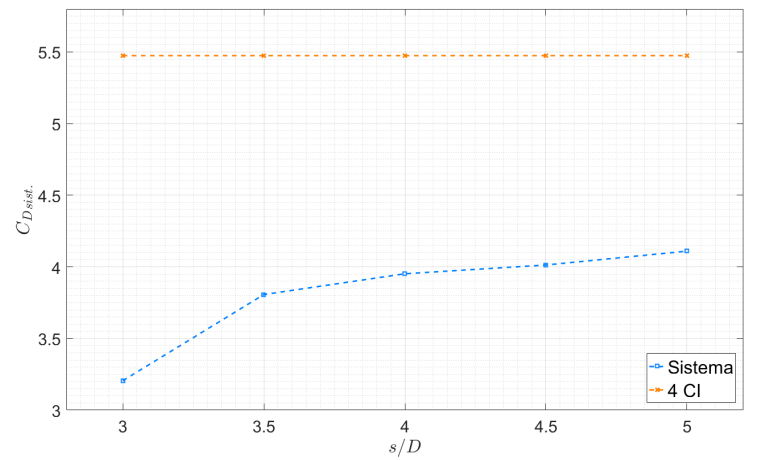

(a)

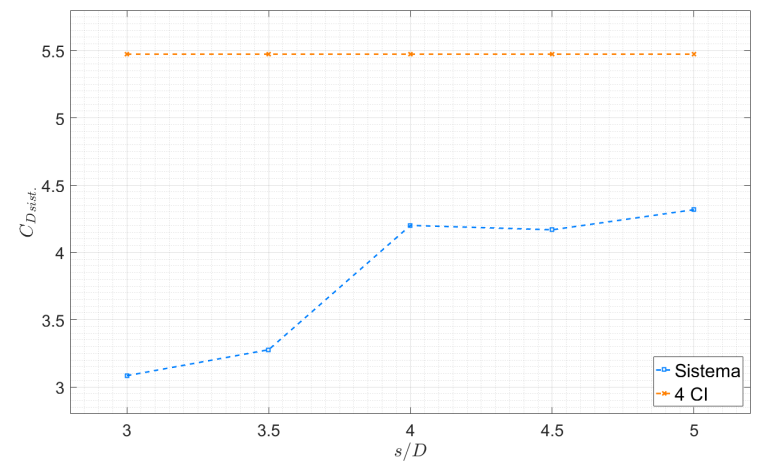

(b)

Fonte: Autora.

Em ambos os casos de ângulos de ataque $\beta$ apresentados, o coeficiente de arrasto médio do sistema é consideravelmente maior do que o coeficiente de arrasto de um cilindro isolado (CI) (1,34, ver Tabela 10), em todos os casos de espaçamento $s$. Tal resultado já era esperado, uma vez que estamos somando forças de quatro cilindros e dividindo pela 
área de 1. No entanto, a Figura 28 mostra que esses coeficientes de arrasto são também menores do que a soma dos coeficientes de arrasto de quatro cilindros isolados.

Além disso, há uma tendência de aumento coeficiente de arrasto médio do sistema à medida que o espaçamento entre cilindros aumenta. Esse comportamento vem acompanhado de um súbito salto do valor do coeficiente de arrasto do sistema. Tal fato ocorre entre $s=3 D$ e $s=3,5 D$ para $\beta=0^{\circ}$, sendo o salto partindo de um valor próximo de 3,2 para aproximadamente 4 . Para $\beta=180^{\circ}$, o mesmo fenômeno ocorre, porém com diferente intervalo de espaçamento $s$, entre $s=3,5 D$ e $s=4 D$, saltando o coeficiente de um valor de 3,3 para, aproximadamente, 4,2.

\subsection{Coeficiente de sustentação}

As Figuras 29(a), 30(a) e 31(a), apresentam as variações da média temporal, do root-mean square (r.m.s.) e dos valores pico-a-pico das séries temporais do coeficiente de sustentação (respectivamente) em função do espaçamento entre cilindros $s$ e para o caso de ângulo de incidência $\beta=0^{\circ}$. As séries temporais do coeficiente de sustentação de cada caso de espaçamento são ilustradas na Figura 32. Vale ressaltar que os valores dos coeficientes de sustentação e de suas estatísticas são referentes aos instantes de tempo no qual eram observados estados de regularidade das oscilações, sendo que para alguns casos este estado refere-se ao regime 2 que será apresentado mais adiante.

Conforme pode ser observado pela Figura 29(a) o valor do coeficiente de sustentação médio dos cilindros a montante ( $\mathrm{CF}$ e $\mathrm{CM})$ é próximo a zero, situação semelhante ao caso de cilindro isolado (CI). Isso se deve à geometria simétrica do modelo e ao fato de CF e CM estarem posicionados em seu eixo de simetria. Contudo, a influência do cilindro central (CM) sobre a região de esteira do cilindro frontal (CF) e a influência dos cilindros a jusante (CT e CB) na região de esteira do cilindro central CM causam uma flutuação nesses valores à medida que varia o espaçamento entre cilindros $s$.

Uma outra característica bastante interessante observada na Figura 29(a) é a inversão de sinais observada nos cilindro a jusante, verificada entre $s=3 D$ e $s=4 D$. Em $s=3,5 D$ as médias dos coeficientes de sustentação de CT e CB convergem para um valor próximo de 0,05 e então, com o aumento do espaçamento, eles tendem para valores de sinais contrários aos encontrados em $s=3 D$. Tal fenômeno de inversão de sinais também foi relatado por Zheng, Zhang e Lv (2016), em seu estudo do escoamento ao redor de três cilindros com configuração de triângulo equilátero, no qual atribuíram o fenômeno à relação entre pressão e força na região entre os cilindros a jusante em configuração tandem.

No caso $s=3 D$, a região de pressão negativa criada entre os cilindros a jusante (CT e CB) (Figura 26), seria responsável pelo desenvolvimento de forças de atração. Com o aumento da pressão, ela torna-se positiva (Figura 27), gerando forças de repulsão. Essa 
Figura 29 - Variação do coeficiente de sustentação médio com o espaçamento $s$ para (a) $\beta=0^{\circ}$ e (b) $\beta=180^{\circ}$.

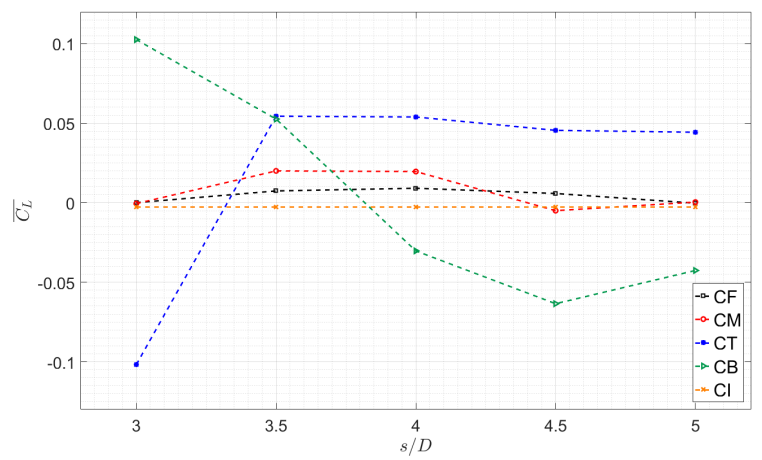

(a)

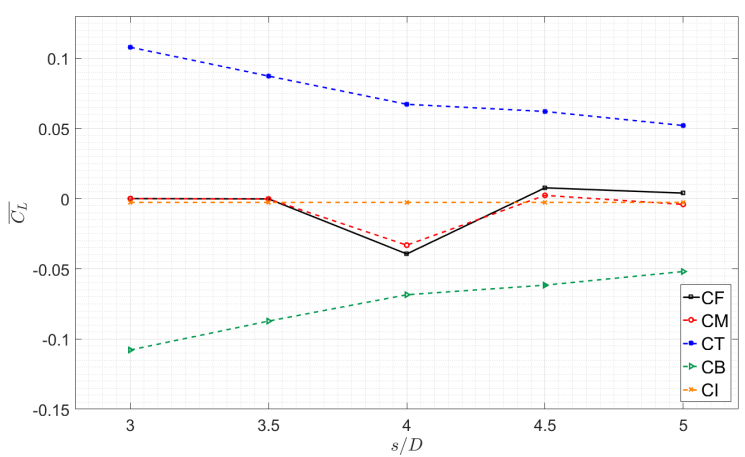

(b)

Fonte: Autora.

mudança de forças seria, então, responsável pela inversão de sinais entre os coeficiente de sustentação médio dos cilindros a jusante.

Com relação ao r.m.s., observa-se que, para os cilindros posicionados mais a montante ( $\mathrm{CF}$ e $\mathrm{CM}$ ), seu valor é zero em $s=3 D$, indicando a supressão do desenvolvimento de seus vórtices (Figura 19), devido ao efeito da interferência de proximidade. Já o aumento de espaçamento provoca uma elevação significativa em seus valores e está relacionada à formação de esteiras de vórtices desses cilindros (Figura 23). Tal comportamento também é refletido nos cilindros a jusante (CT e CB), que têm um considerável aumento de seus valores de r.m.s. entre $s=3 D$ e $s=3,5 D$. Por fim, nota-se a tendência do valor do r.m.s. do coeficiente de sustentação do cilindro frontal ( $\mathrm{CF}$ ) de aproximar-se ao valor encontrado no caso de cilindro isolado (CI) para $s \geq 3,5 D$.

Figura 30 - Variação do r.m.s. do coeficiente de sustentação com o espaçamento $s$ para (a) $\beta=0^{\circ}$ e (b) $\beta=180^{\circ}$.

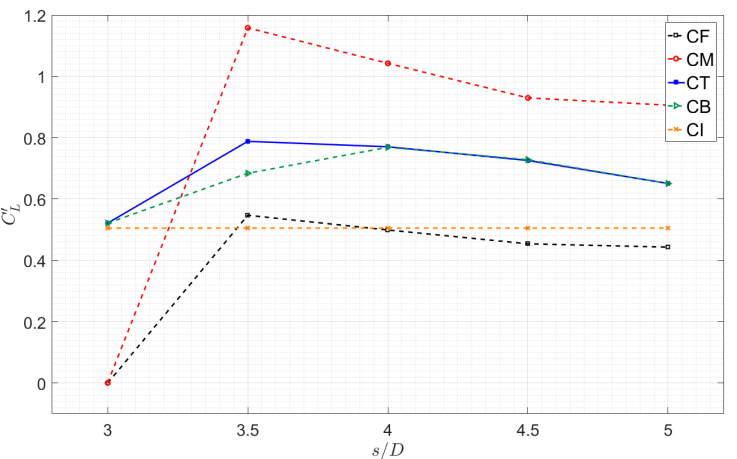

(a)

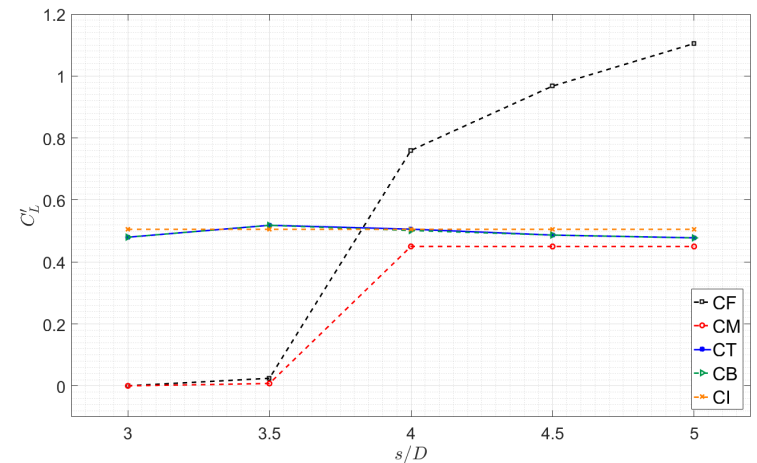

(b)

Fonte: Autora.

A análise da variação dos valores pico-a-pico das séries temporais do coeficiente de 
sustentação (Figura 31(a)), bem como de suas séries temporais (Figura 32), corroboram com tais observações. Entre $s=3 D$ e $s=3,5 D$, observa-se uma alteração significativa no comportamento das oscilacões das séries temporais dos coeficientes de sustentação de todos os cilindros. Isso é devido ao fato das forças de sustentação dos cilindros CF e CM não apresentarem oscilações expressivas para o caso de espaçamento $s=3 D$, ao passo que, com o aumento da distância entre os corpos, esses cilindros passam a ter esteiras de vórtices que oscilam consideravelmente. Tal comportamento ilustra, portanto, a íntima relação entre a flutuação do coeficiente de sustentação e as emissões de vórtices.

Figura 31 - Variação dos valores pico-a-pico do coeficiente de sustentação com o espaçamento $s$ para (a) $\beta=0^{\circ}$ e (b) $\beta=180^{\circ}$.

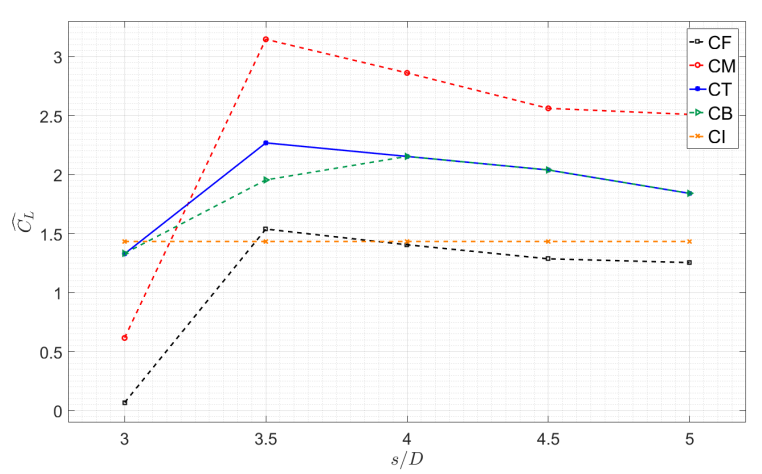

(a)

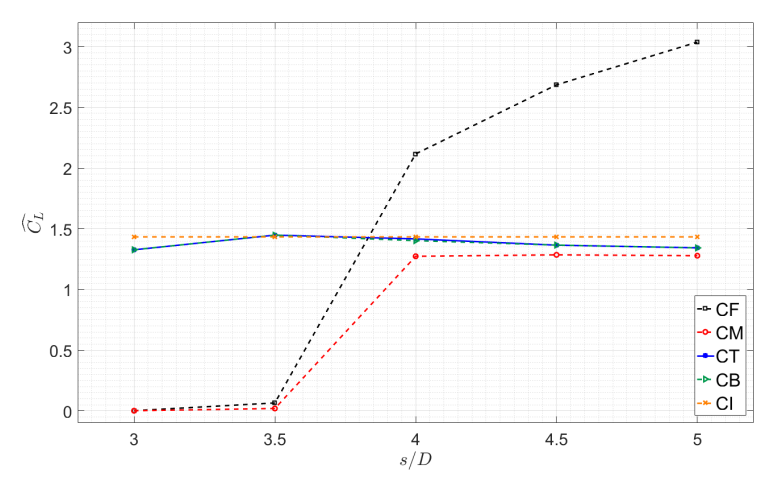

(b)

Fonte: Autora.

Ao se analisar as séries temporais dos coeficientes de sustentação do sinal completo, nota-se que para o caso $s=3 D$ (Figura 32(a)) foi necessário um longo número de ciclos (ultrapassando $t=200 \mathrm{~s}$ ) para que fosse observado o início das oscilações dos coeficientes de sustentação relacionados aos cilindros frontais CF e CM. A Figura 35 apresenta a série temporal do coeficiente de arrasto desse caso em particular (as séries dos demais casos podem ser vistas no Apêndice A). Nessa figura, observa-se a presença de dois regimes de oscilação bastante bem definidos, um anterior a $t=300$ e outro posterior a esse instante de tempo (Figura 33). Com o aumento do espaçamento $s$, apesar de ainda se destacar a presença de dois regimes distintos, os regimes iniciais têm um intervalo de duração bastante reduzido quando comparado ao do caso $s=3 D$, atingindo o segundo regime mais rapidamente. A Figura 34 exemplifica essa redução no período de duração do primeiro regime, no qual termina próximo de $t=100$ para $s=3,5 D$. Outro ponto relevante, é o fato de que as oscilações de força de sustentação associadas ao cilindro central (CM) iniciam-se antes daquelas do cilindro a montante $(\mathrm{CF})$. A oscilação nas forças de sustentação desses dois cilindros provoca uma mudança no comportamento das oscilações dessa componente de força nos cilindros a jusante (CT e CB), alterando o comportamento de todo o sistema.

Com relação aos demais casos de espaçamento $s$ (Figuras 32(b), (c), (d) e (e)), 
nota-se que apesar existir um regime regime ocilatórios dos coeficientes de sustentação dos cilindros semelhante ao observado na Figuras 32(a), esse regime transitório é menor e tende a ser menos expressivo com o aumento do espaçamento entre cilindros. Além disso, o regime posterior valores de pico-a-pico do coeficiente de sustentação dos cilindros são significativamente maiores, principalmente para os cilindros a montante ( $\mathrm{CF}$ e $\mathrm{CM})$.

Figura 32 - Séries temporais do coeficiente de sustentação para $\beta=0^{\circ}$ e (a) $s=3 D$; (b) $s=3,5 D ;(\mathrm{c}) s=4 D ;(\mathrm{d}) s=4,5 D$ e (e) $s=5 D$.

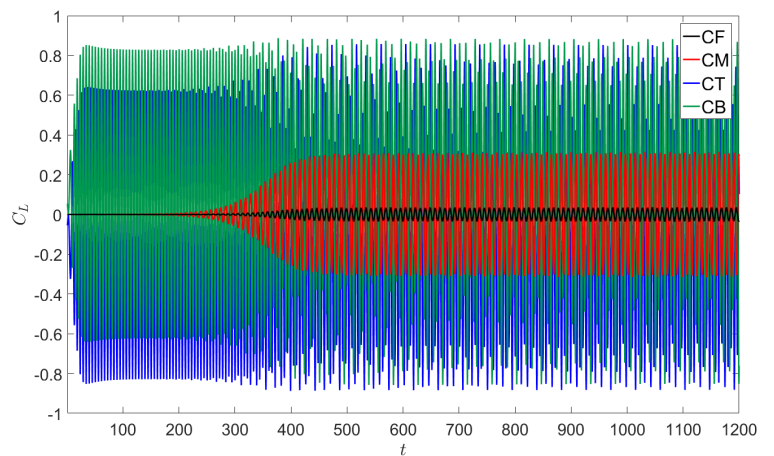

(a)

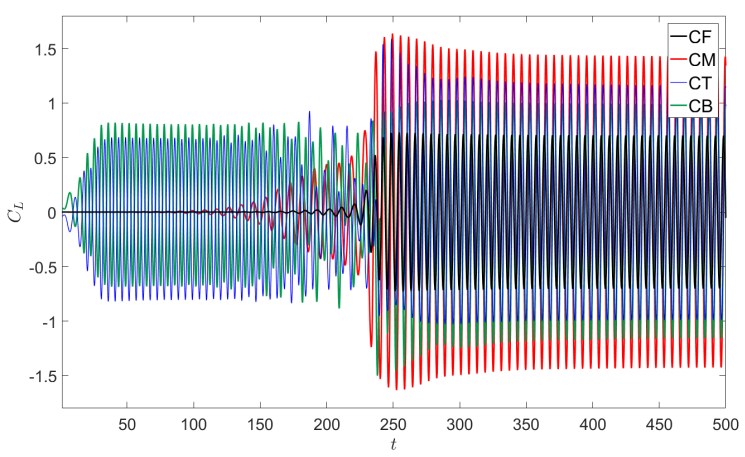

(c)

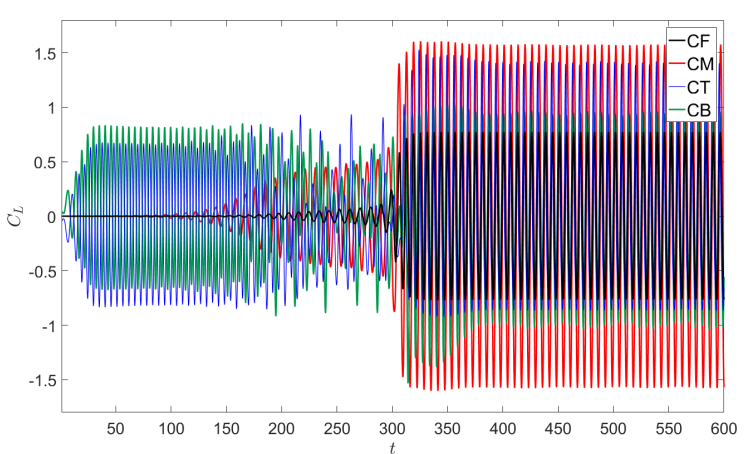

(b)

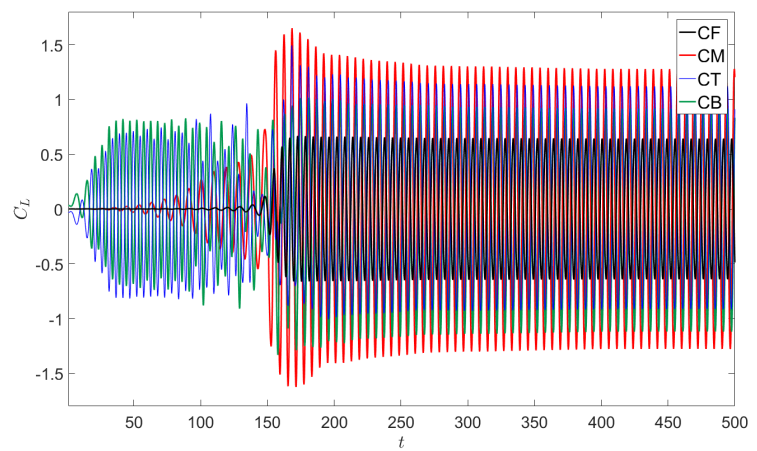

(d)

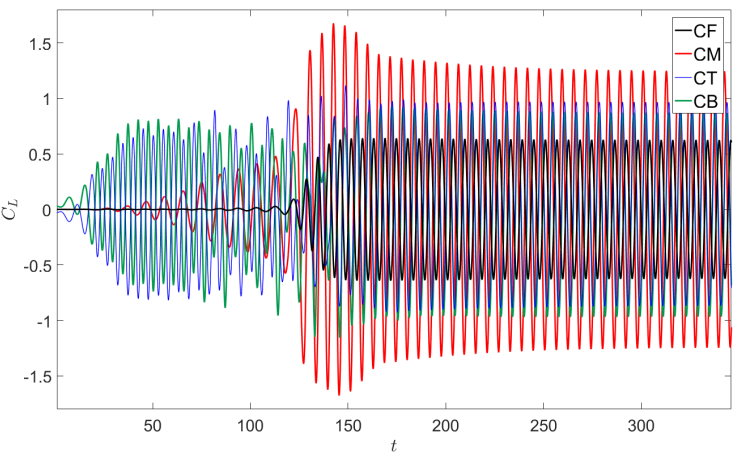

(e)

Fonte: Autora. 
Figura 33 - Séries temporais do coeficiente de sustentação para $\beta=0^{\circ}$ e $s=3 D$ para (a) $t=0$ a $300 \mathrm{~s}$ e (b) $t=300$ a $1200 s$.

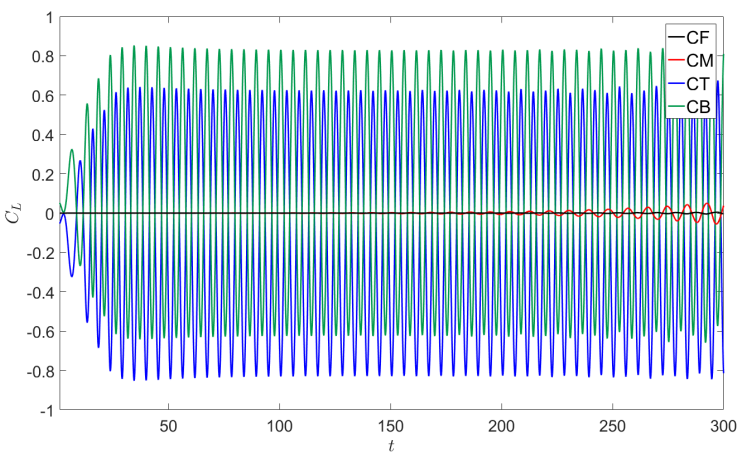

(a)

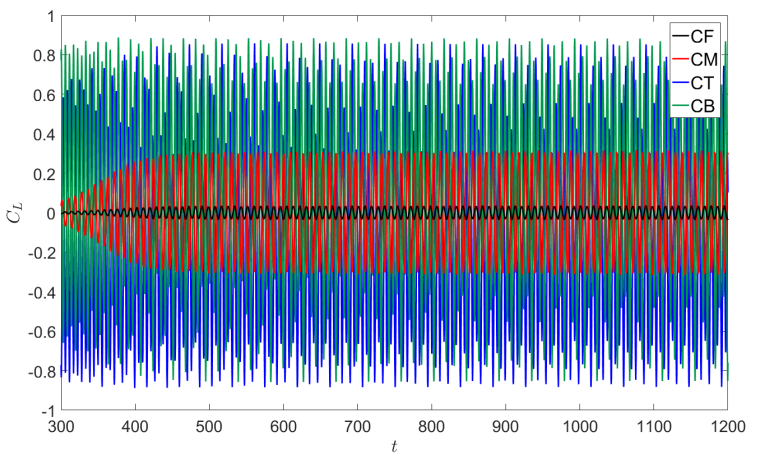

(b)

Fonte: Autora.

Figura 34 - Séries temporais do coeficiente de sustentação para $\beta=0^{\circ}$ e $s=3,5 D$ para (a) $t=0$ a $100 \mathrm{~s}$ e (b) $t=100$ a $600 \mathrm{~s}$.

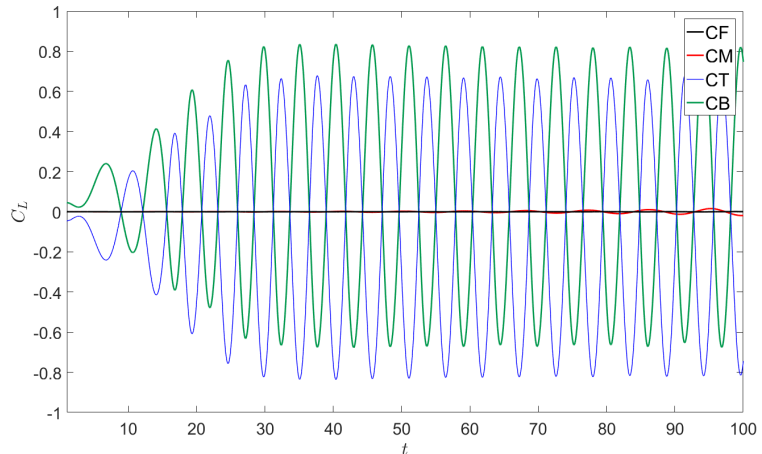

(a)

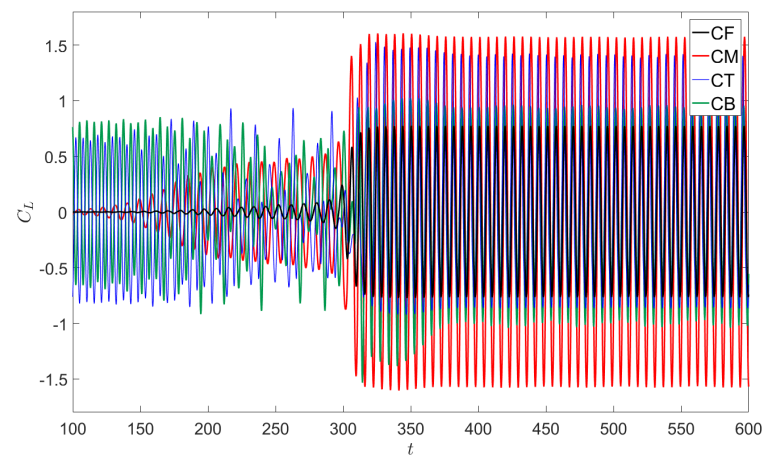

(b)

Fonte: Autora.

O caso com ângulo de incidência da correnteza $\beta=180^{\circ}$ é ilustrado nas Figuras 29(b), 30(b) e 31(b) que representam, respectivamente, as variações da média temporal, do valor r.m.s. e dos valores pico-a-pico das séries temporais do coeficiente de sustentação em função do espaçamento entre cilindros $s$. As séries temporais do coeficiente de sustentação de cada caso $s$ são apresentadas na Figura 36 e consideram todo o sinal.

Assim como no caso caracterizado por um ângulo de incidência $\beta=0^{\circ}$, as médias dos coeficientes de sustentação dos cilindros a jusante (agora, CM e CF) variam entre valores próximos a zero à medida que o espaçamento entre cilindros aumenta. Contudo, um pequeno desvio desse comportamento ocorre em $s=4 D$ (Figura 29(b)), ponto no qual coincide com o súbito aumento do coeficiente de arrasto do sistema (Figura 28(b)).

Outro fato interessante é observado entre as médias dos coeficientes de sustentação de cilindros frontais (agora, CT e CB), nos quais possuem valores próximos em intensidade 
Figura 35 - Série temporal do coeficiente de arrasto para $s=3 D$ e $\beta=0^{\circ}$.

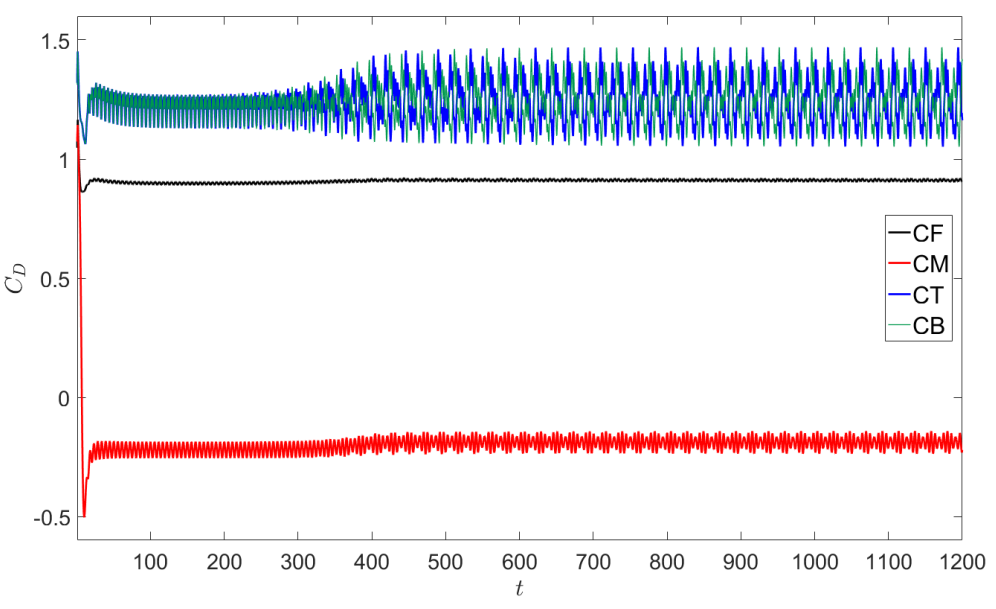

Fonte: Autora.

e de sinais opostos entre si. Nota-se ainda a tendência de convergência para zero à medida que aumenta o espaçamento entre cilindros.

Com relação ao valor r.m.s do coeficiente de sustentação, nota-se que para os casos $s=3 D$ e $s=3,5 D$ os valores desse parâmetro para os cilindros a jusante (CM e CF) situam-se próximos à zero, indicando a supressão da emissão de seus vórtices, como foi relatado na seção 6.1 (ver Figura 21). Tal observação é ainda reforçada ao se analisar as séries temporais do coeficiente de sustentação desses cilindros (Figura 36).

Com o aumento do espaçamento $s$ entre cilindros, há então o desenvolvimento da esteiras de vórtices desses cilindros (CM e CF), aumentando consideravelmente o r.m.s. e, por consequência, as oscilações dos coeficientes de sustentação de ambos os cilindros. Essa mudança de comportamento é evidente especialmente entre os casos $s=3,5 D$ e $s=4 D$ (Figuras 36(b) e (c)).

Entre $s=4 D$ e $s=5 D$, a emissão de vórtices dos cilindros CM e CF modifica o comportamento do escoamento. Com isso, observa-se que a frequência das oscilações dos coeficientes de sustentação dos cilindros a jusante (CM e CF) altera-se para diferentes valores de espaçamento $s$, principalmente para o cilindro CF, que apresenta picos de oscilação bastante irregulares e de valores crescentes. Ainda para o cilindro CF, nota-se uma tendência de crescimento linear do r.m.s., bem como de seus valores pico-a-pico do coeficiente de sustentação. Já para o cilindro central (CM), os valores de r.m.s. do coeficiente de sustentação tendem a se aproximar do valor encontrado para o caso do cilindro isolado (CI). O mesmo comportamento é observado para os cilindros a montante (CT e CB), porém, para todo o intervalo estudado. 
Figura 36 - Série temporal do coeficiente de sustentação para $\beta=180^{\circ}$ e (a) $s=3 D$; (b) $s=3,5 D ;$ (c) $s=4 D ;$ (d) $s=4,5 D$ e (e) $s=5 D$.

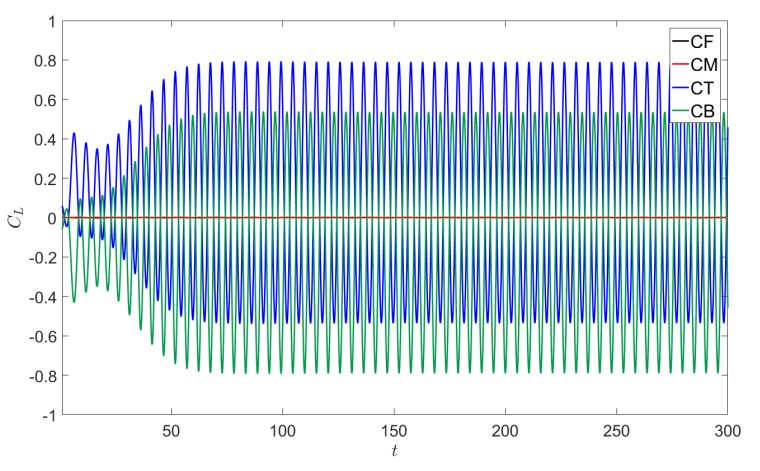

(a)

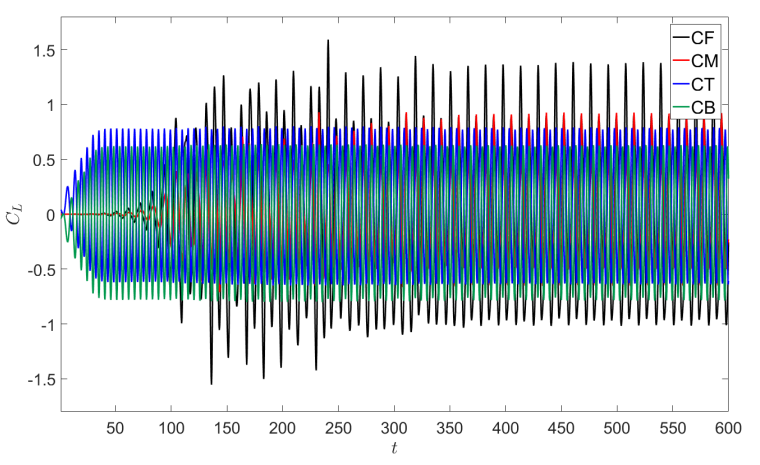

(c)

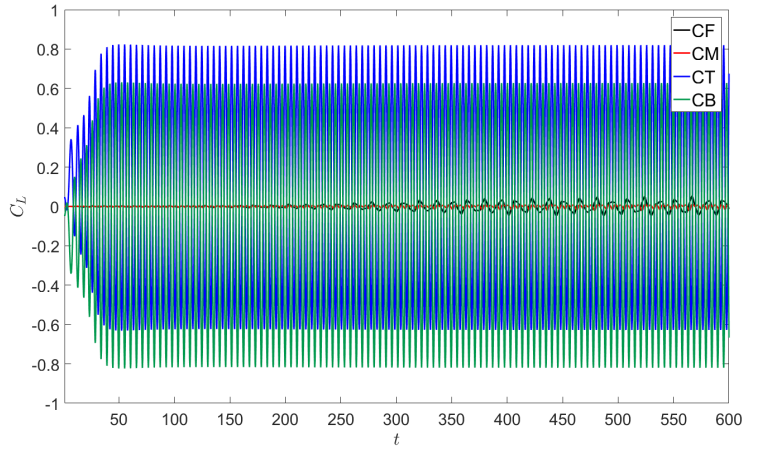

(b)

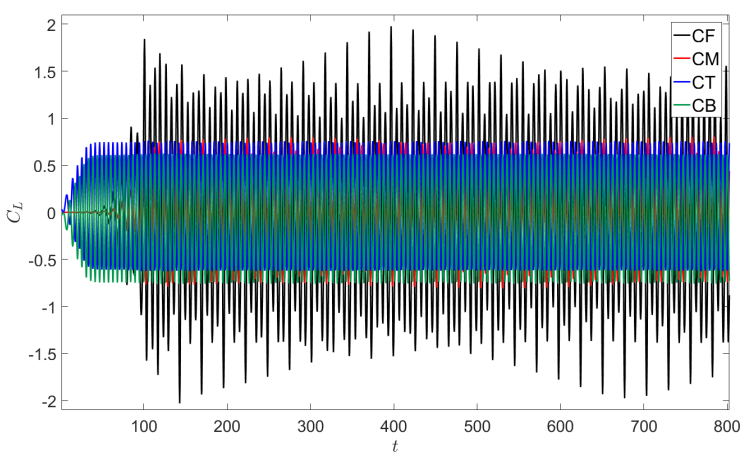

(d)

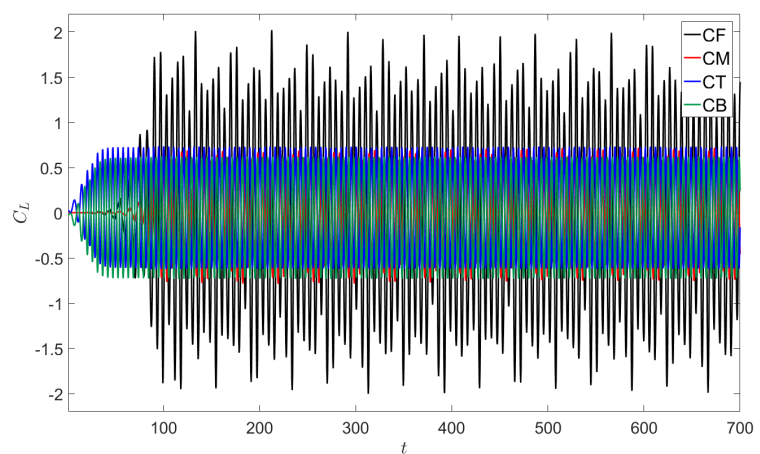

(e)

Fonte: Autora.

\subsection{Número de Strouhal}

O número de Strouhal foi calculado a partir das séries temporais dos coeficientes de sustentação de cada cilindro do sistema. Para cada série, construiu-se o espectro de amplitude utilizando-se a função fft (Fast Fourier Transform), da ferramenta comercial $M A T L A B^{\circledR}$, para se obter a frequência dominante (aquele que apresenta maior energia) e sua correspondente amplitude.

A Figura 37(a) mostra a variação do número de Strouhal como função do espaçamento 
entre cilindros $s$ e para $\beta=0^{\circ}$. Nota-se que, para $s=3 D$, o número de Strouhal apresenta dois valores distintos, sendo $S_{t}=0,114$ para os cilindros a montante $\left(\mathrm{CF}\right.$ e CM) e $S_{t}=0,182$ para os cilindros a jusante (CB e CT). Contudo, com o aumento do espaçamento de $s=3 D$ para $s=3,5 D$, é observado um padrão no qual todos os cilindros passam a apresentar um único valor de número de Strouhal, $S_{t}=0,159$. Tal comportamento repete-se para os casos $s=4 D, s=4,5 D$ e $s=5 D$. Nota-se ainda que, em todos esses casos, o número de Strouhal é menor do que aquele encontrado para o caso de cilindro isolado (CI), $S_{t}=0,195$.

Figura 37 - Variação do número de Strouhal com o espaçamento $s$ para (a) $\beta=0^{\circ}$ e (b) $\beta=180^{\circ}$.

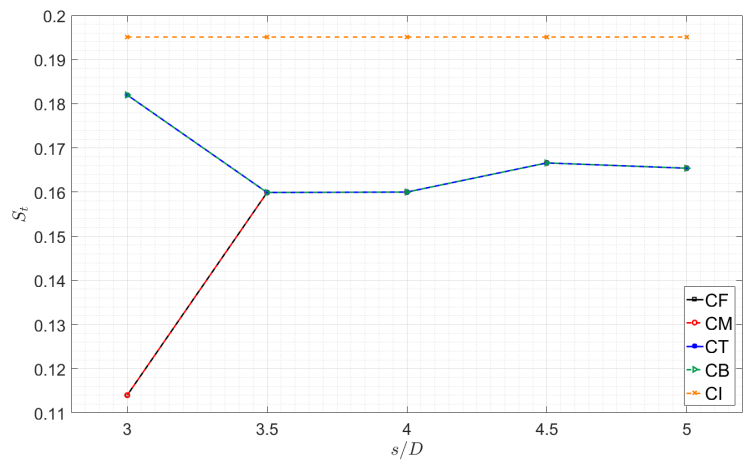

(a)

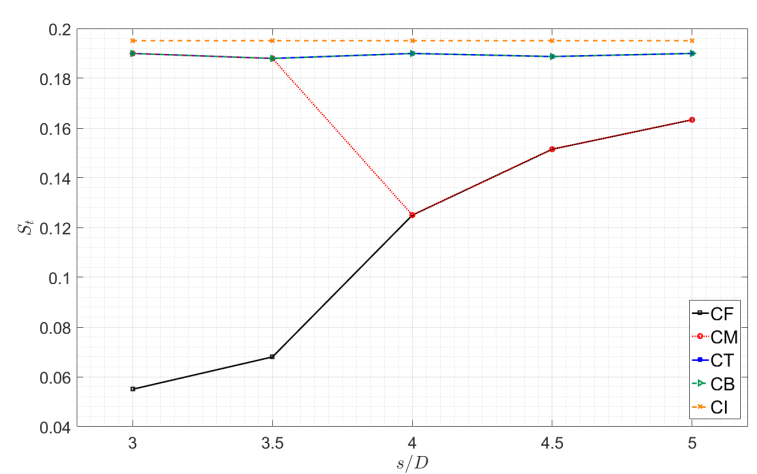

(b)

Fonte: Autora.

Essa diferença de comportamento entre os casos $s$ estudados pode estar relacionada à mudança no padrão de escoamento do que ocorre entre $s=3 D$ e $s=3,5 D$. Retornando a Figura 19, observa-se que, devido ao efeito de proximidade, as esteiras de vórtices dos cilindros de montante ( $\mathrm{CF}$ e $\mathrm{CM}$ ) não se desenvolvem totalmente, configurando padrões bastante diferentes das esteiras formadas pelos cilindros a jusante (CT e CB). Portanto, dois padrões de escoamento distintos são observados para $s=3 D$, um para os cilindros CF e CM e outro para CT e CB. Cada um desses padrões é caracterizado por um número de Strouhal distinto.

Ao se aumentar o espaçamento entre cilindros, padrões de comportamento de emissão de vórtices são observados nas regiões de esteira de todos os cilindros, conforme pode ser visto na Figura 23. Nota-se, de forma clara, a formação de vórtices em todas as regiões de esteira dos cilindros, indicando a formação campos de vorticidade bem desenvolvidos.

O caso para $\beta=180^{\circ}$ é apresentado na Figura 37(b). Nessa figura, três pontos podem ser destacados. Primeiro, observa-se dois padrões no comportamento do número de Strouhal, um para $s=3 D$ e $s=3,5 D$ e outro entre $s=4 D$ e $s=5 D$. No primeiro intervalo de espaçamento $s$, o número de Strouhal dos cilindros CT, CB e CM coincidem. Já no segundo intervalo, os cilindros frontais (CT e CB) apresentam o mesmo número 
de Strouhal, enquanto que, o valor de $S_{t}$ do cilindro central (CM) passa a coincidir com aquele obtido no cilindro a jusante $(\mathrm{CF})$. Segundo ponto, o número de Strouhal do cilindro a jusante $(\mathrm{CF})$ tende a aumentar durante todo o intervalo analisado e a partir de $s=4 D$, tal comportamento passa a coincidir com o do cilindro central (CM). Por fim, o terceiro ponto diz respeito aos valores de número de Strouhal dos cilindros a montante (CT e $\mathrm{CB})$, que permanecem praticamente constantes durante todo o intervalo de espaçamento estudado.

Comparando-se agora os espectros de amplitude calculados para os cilindros para ambos os valores de ângulo de incidência $\beta$ do escoamento, é interessante notar que em alguns casos são observados mais do que um pico de amplitude, ou seja, picos de amplitude secundários. Tal comportamento parece ser predominante nos cilindros a jusante do escoamento e para valores baixos de espaçamento $s$. À medida que o espaçamento entre cilindros aumenta, a amplitude desses picos secundários tendem a diminuir de tamanho. Além disso, a orientação do modelo geométrico parece também possuir importância para o aparecimento desses picos. Observa-se que o efeito tende a ser mais expressivo nos casos onde o ângulo de incidência é $\beta=180^{\circ}$. Todos esses casos apresentam um conjunto de picos de amplitude para os cilindros a jusante (CF e CM) (ver Figura 38), ainda que esses picos de amplitude se tornem menos predominantes com o aumento do espaçamento $s$ entre cilindros. Já com relação aos casos $\beta=0^{\circ}$, o fenômeno é observado com mais intensidade no caso $s=3 D$ para os cilindros a jusante (CT e CB), como mostra a Figura 39.

De fato, é intuitivo que o aumento do espaçamento entre os cilindros reduza o número de picos observado nos espectros de amplitude. O aumento do espaçamento faz com que os efeitos de interferência sejam diminuídos, o que aproxima o escoamento ao redor de cada cilindro do caso de um cilindro isolado, o qual apresenta espectro de amplitude do coeficiente de sustentação caracterizado por uma única frequência relevante. 
Figura 38 - Espectro de amplitude do coeficiente de sustentação em cada cilindro para $\beta=180^{\circ}$ e (a) $s=3 D$; (b) $s=3,5 D$; (c) $s=4 D$; (d) $s=4,5 D$ e (e) $s=5 D$.
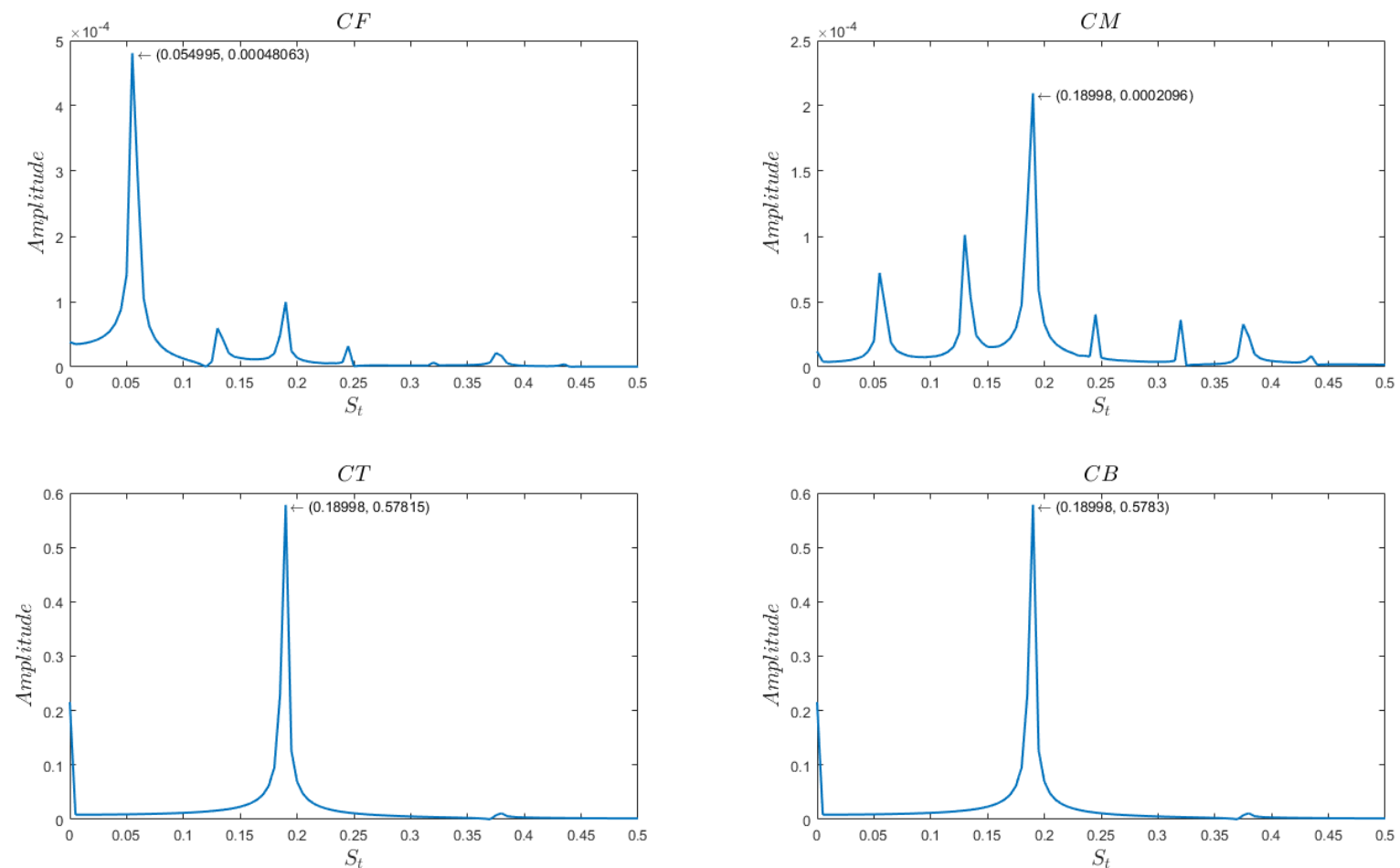

(a)
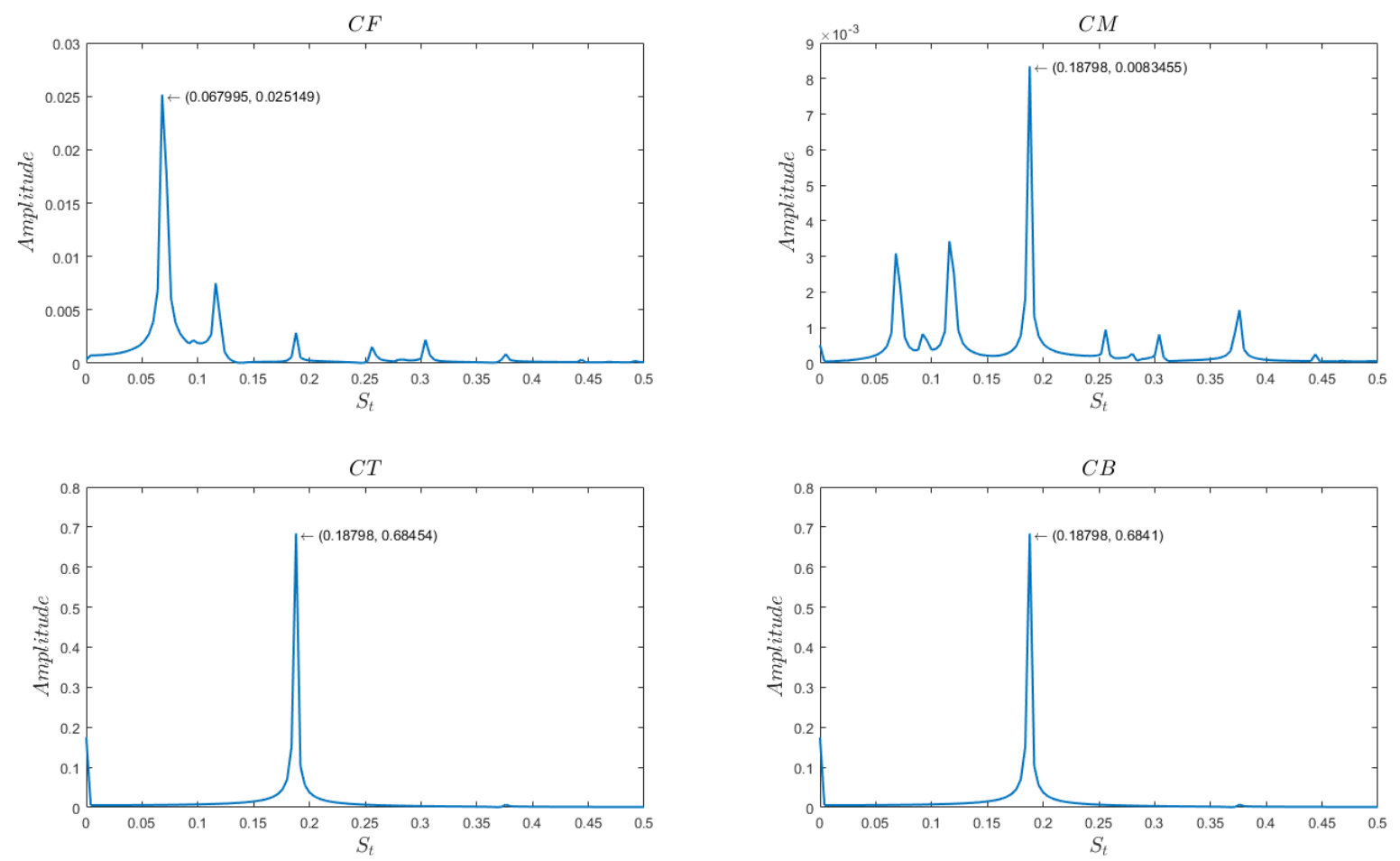

(b) 

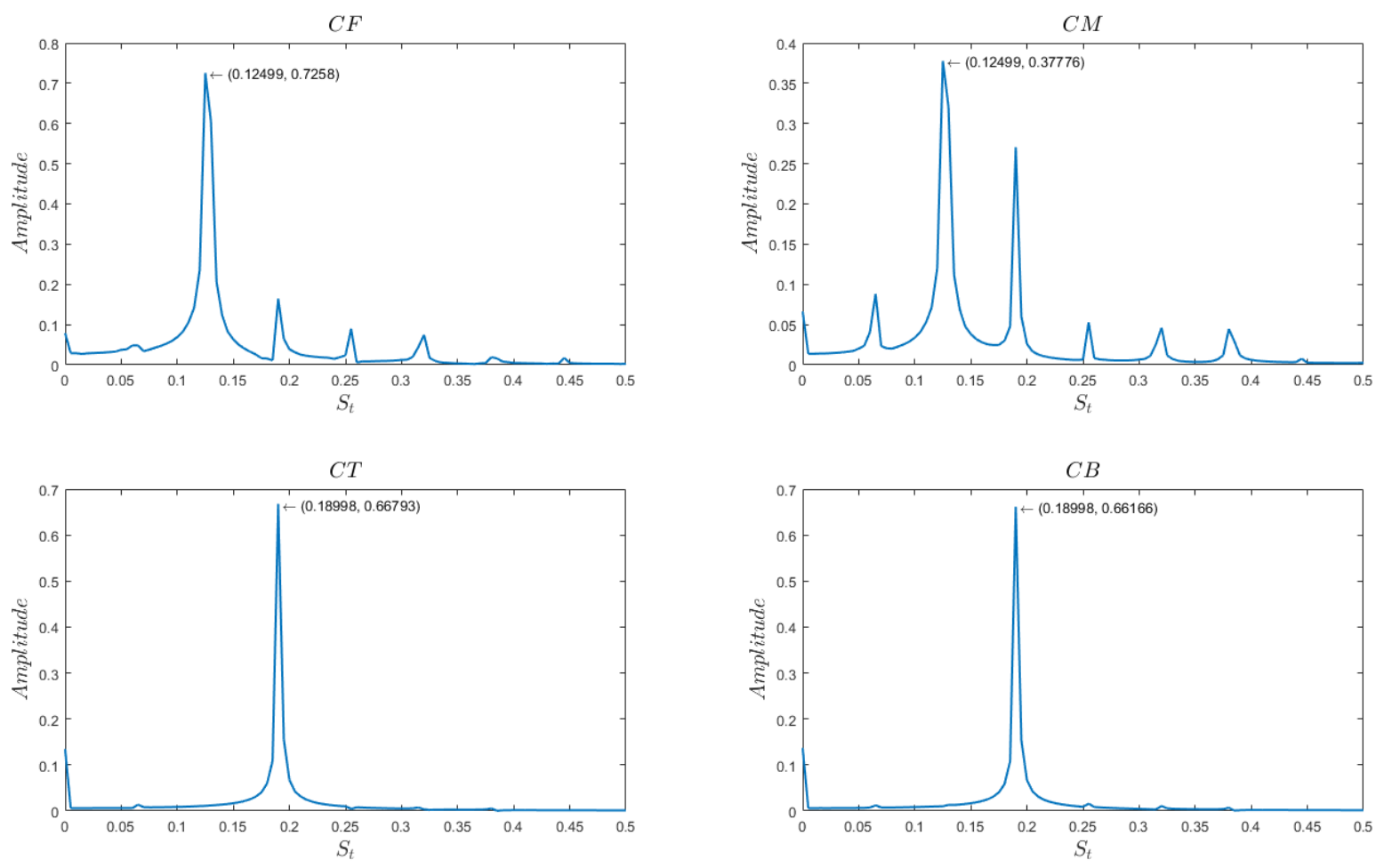

(c)
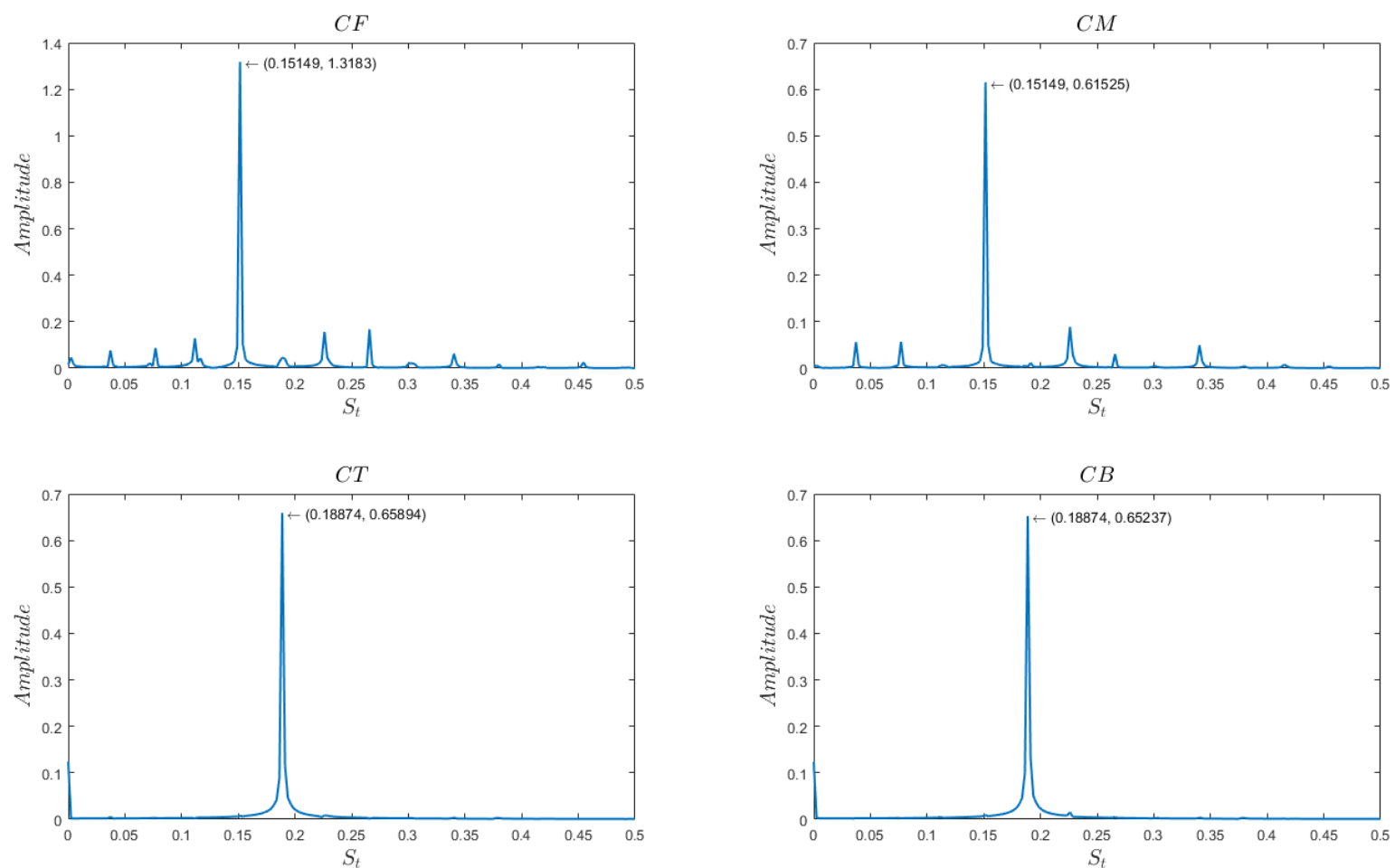

(d) 

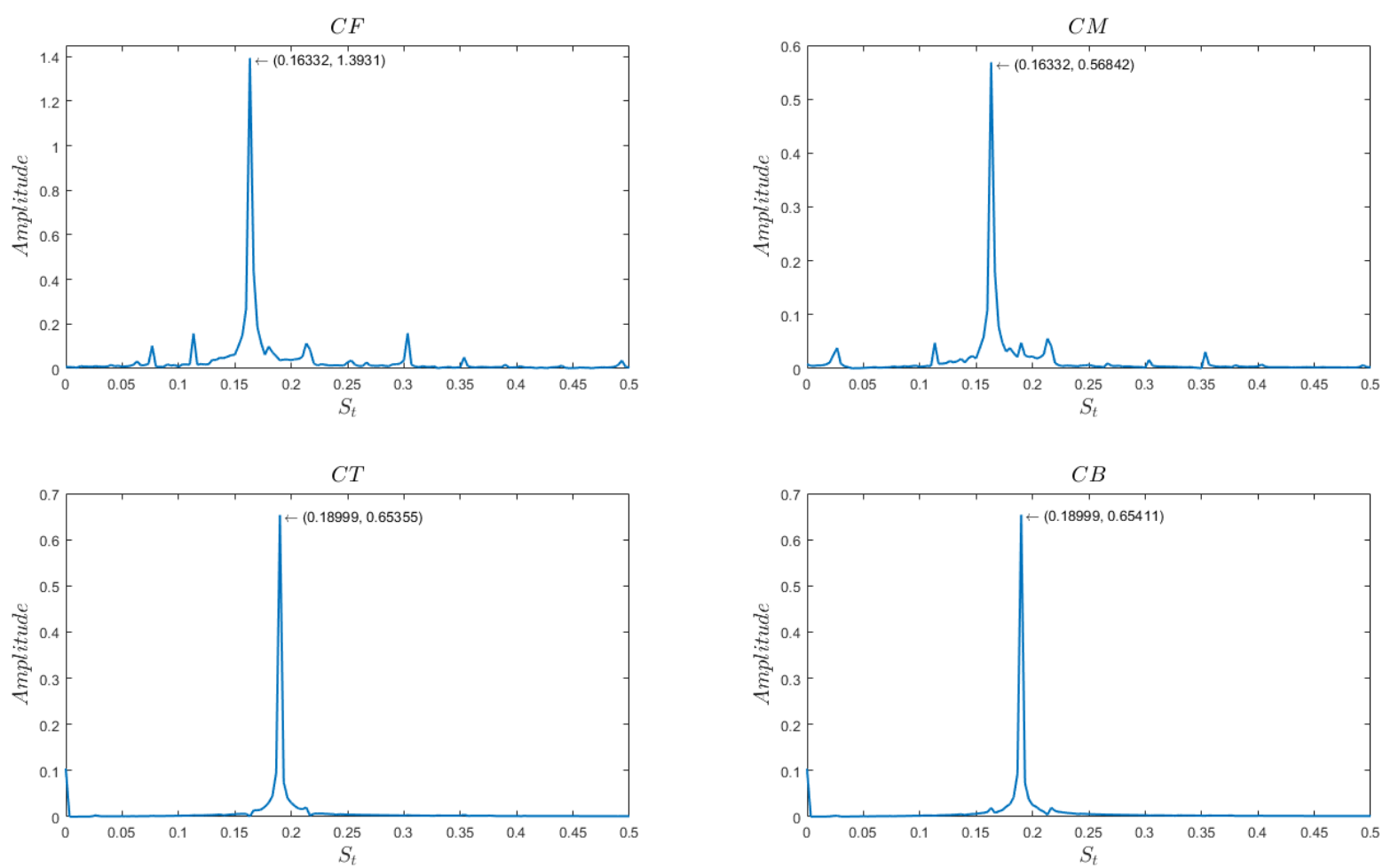

(e)

Fonte: Autora.

Figura 39 - Espectro de amplitude do de sustentação em cada cilindro para $\beta=0^{\circ}$ e (a) $s=3 D$; (b) $s=3,5 D$; (c) $s=4 D$;

(d) $s=4,5 D$ e (e) $s=5 D$.
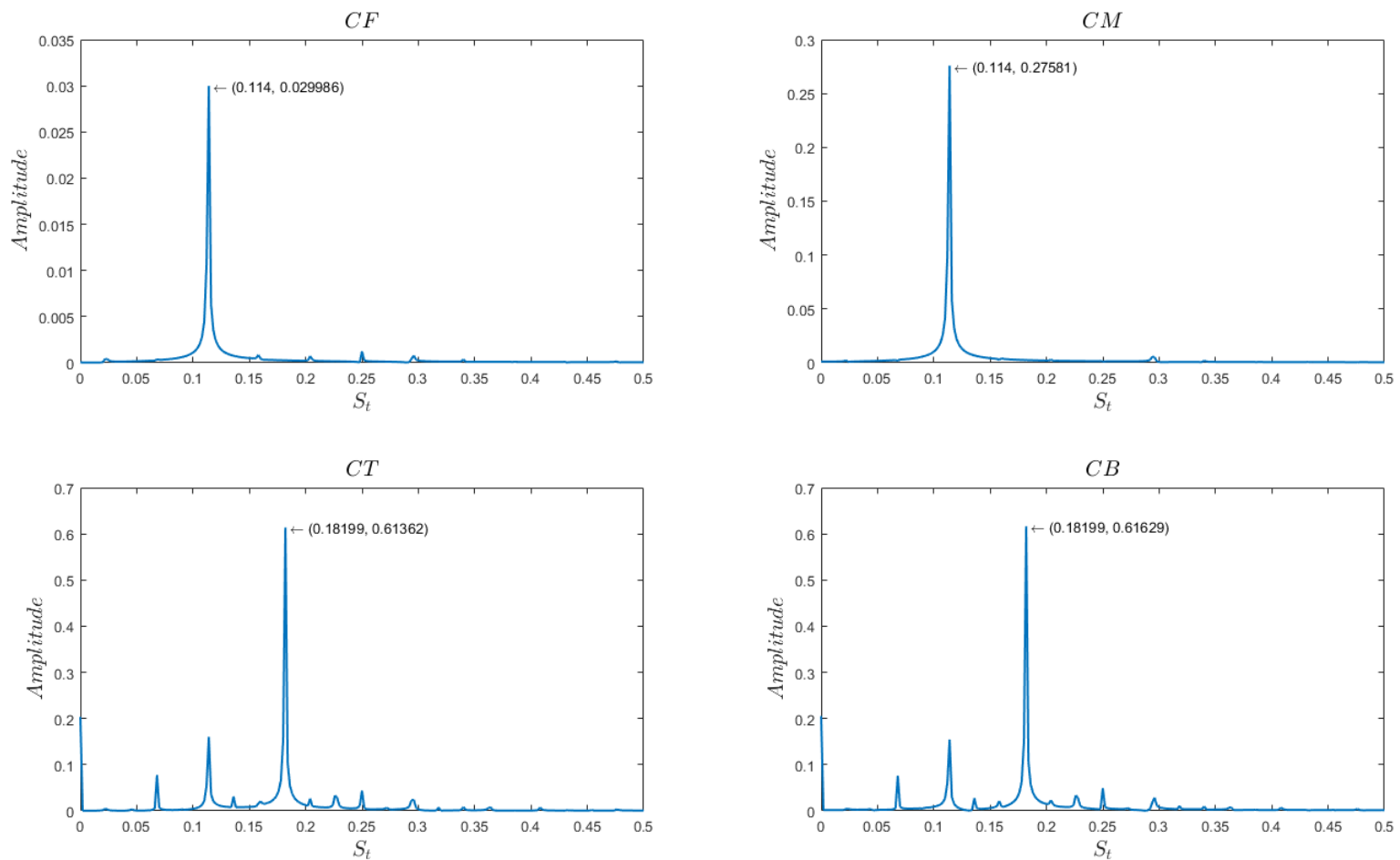

(a) 

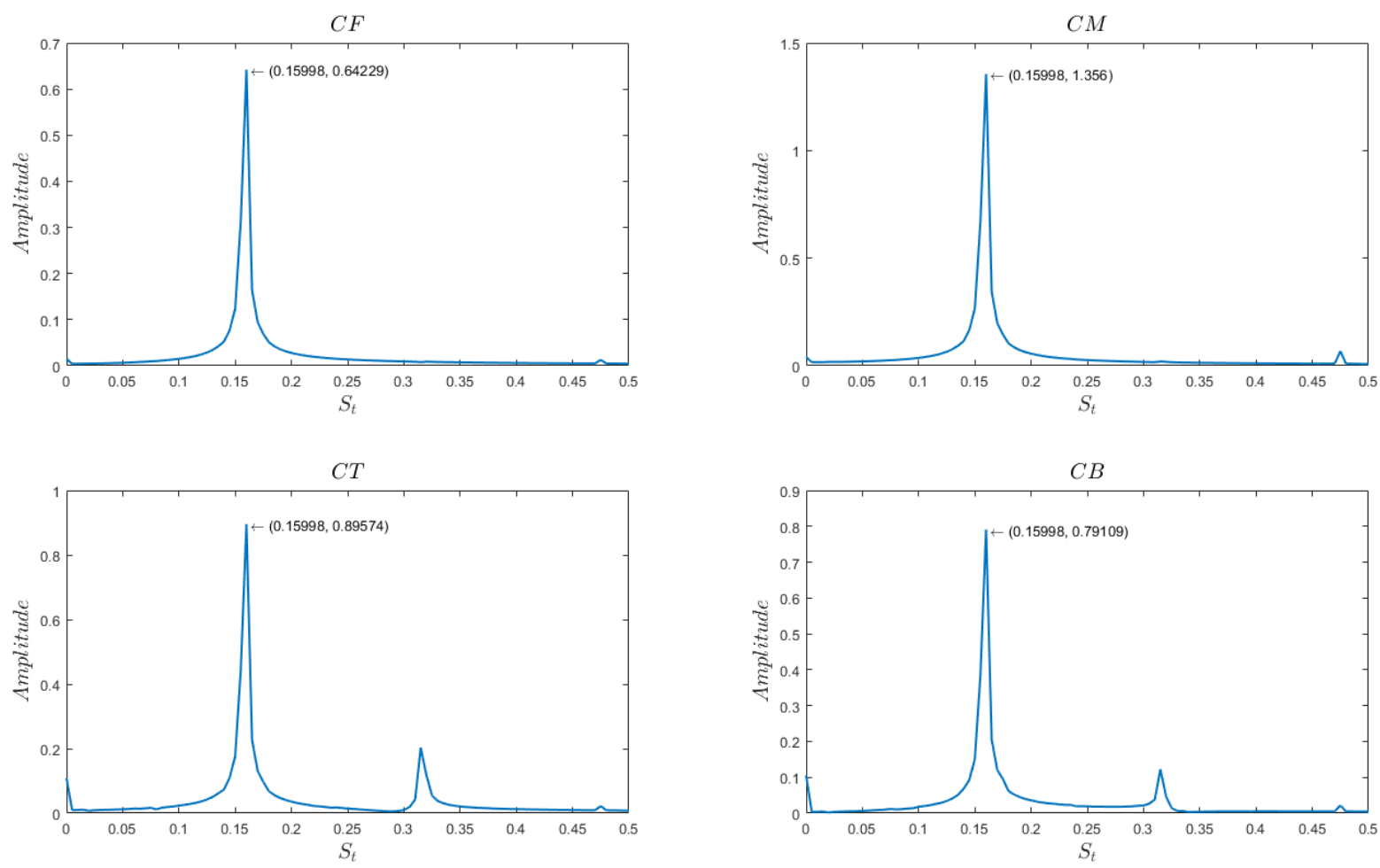

(b)
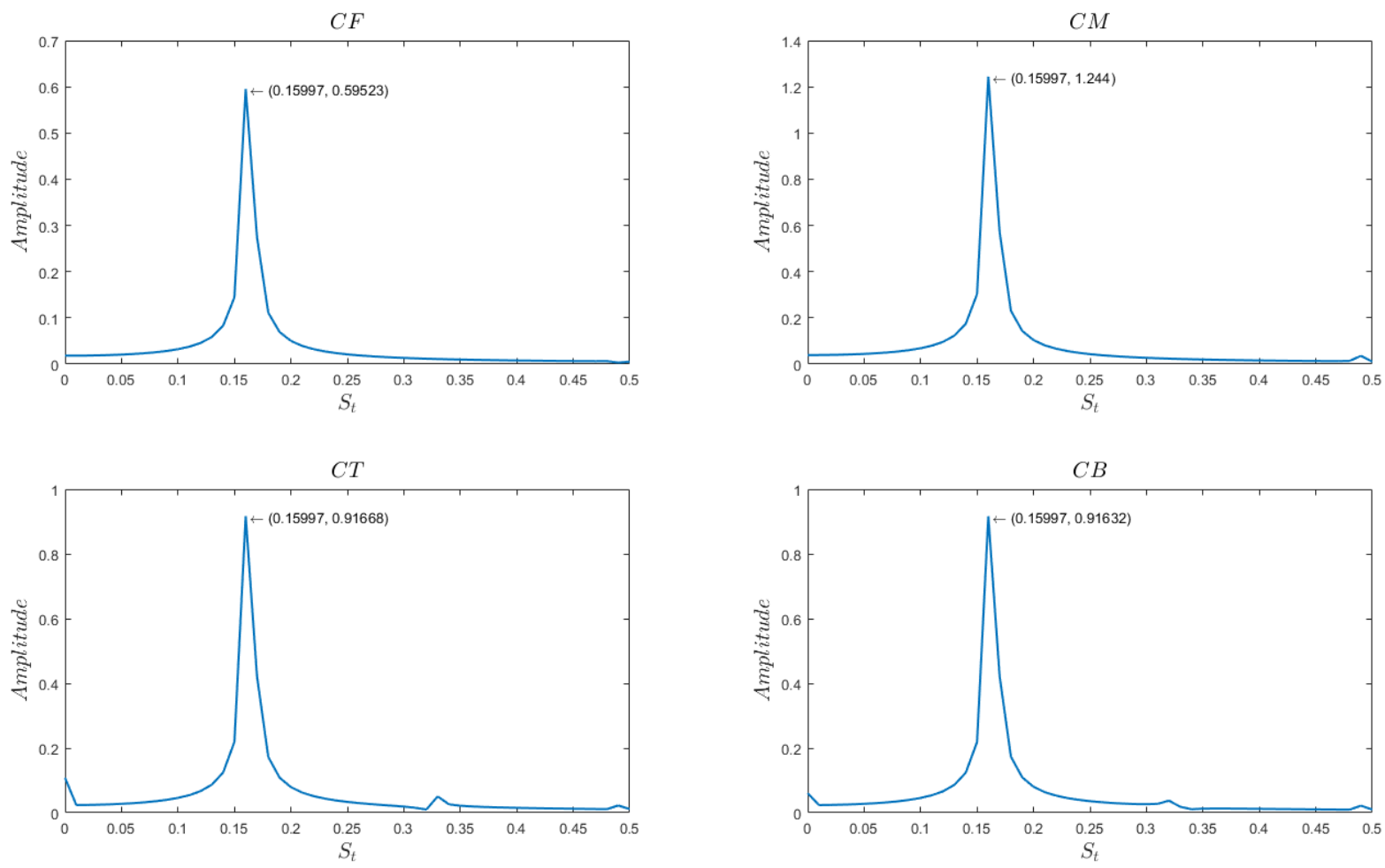

(c) 
$C F$
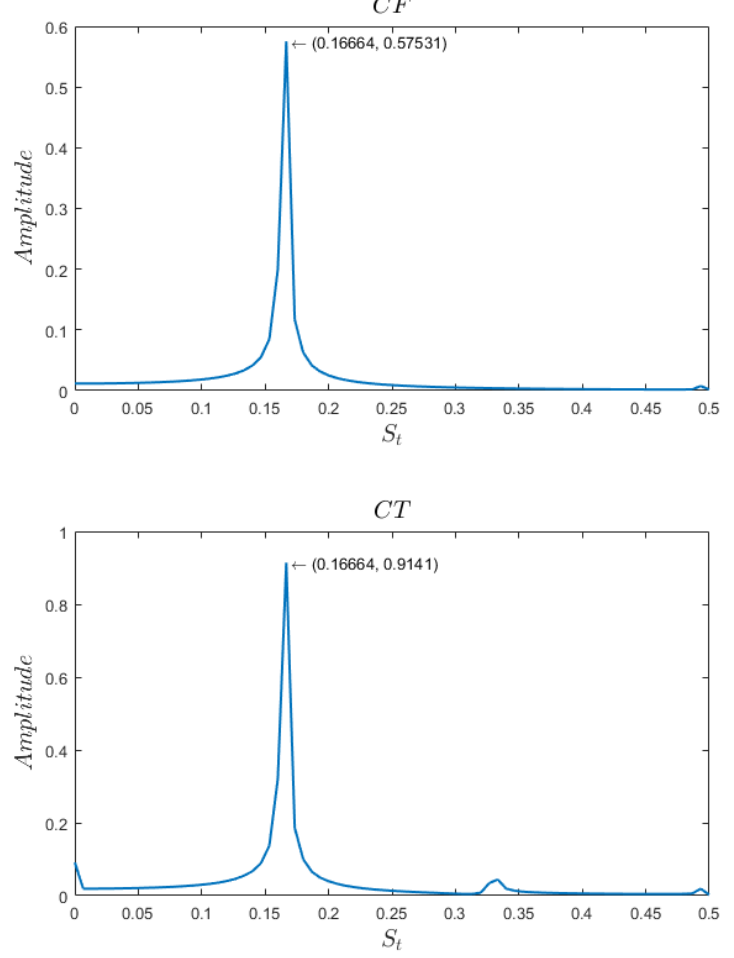

(d)
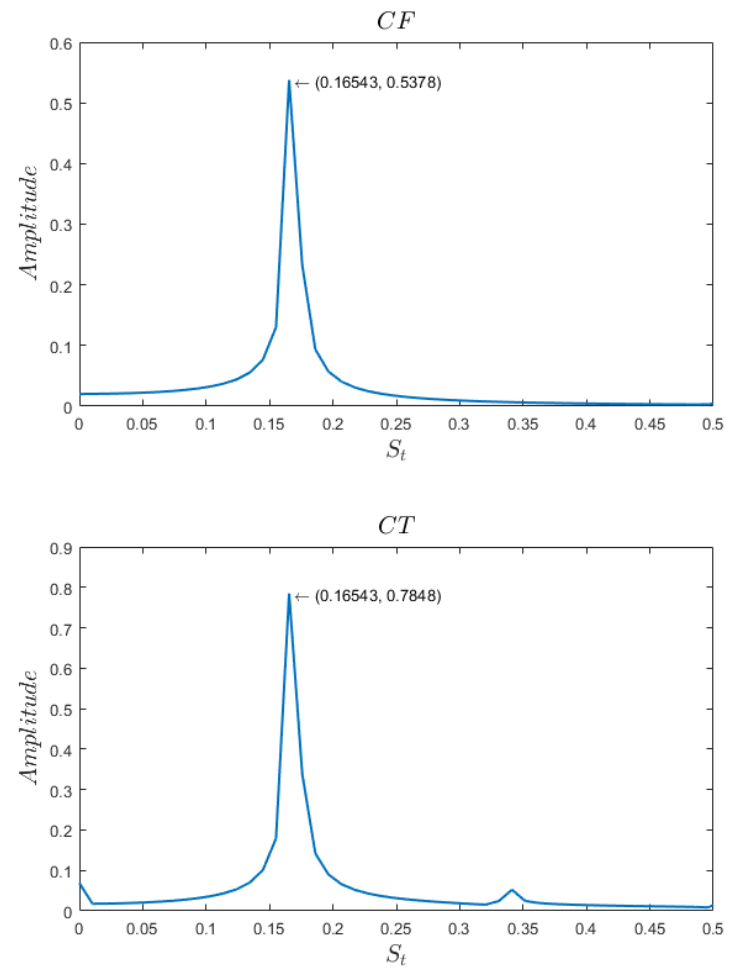
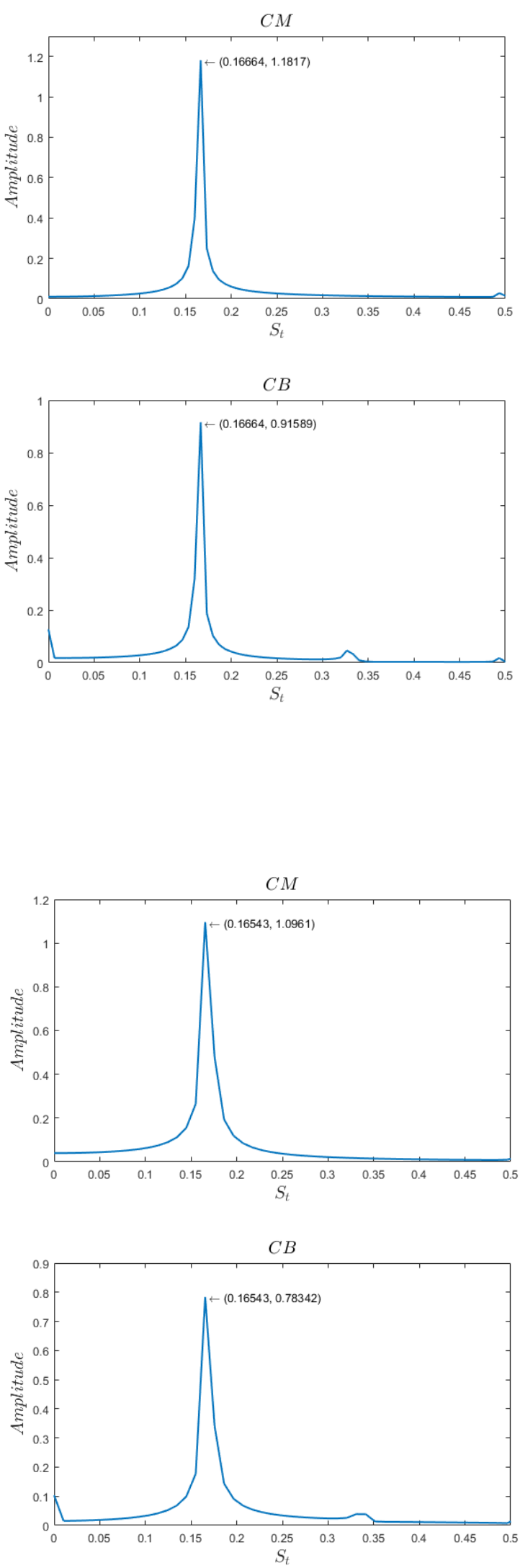

(e)

Fonte: Autora. 


\subsection{Resumo dos resultados}

As Tabelas 11 e 12 resumem os resultados obtidos a partir do conjunto de simulações que foi objeto da dissertação.

Tabela 11 - Resumo dos resultados para todos os casos $s$ e $\beta=0^{\circ}$.

\begin{tabular}{|c|c|c|c|c|c|c|c|}
\hline$s$ & $C_{D \text { sist. }} \pm \sigma_{C_{D} \text { sist. }}$ & Cilindro & $\overline{C_{D}} \pm \sigma_{C_{D}}$ & $\widehat{C_{L}}$ & $\overline{C_{L}} \pm \sigma_{C_{L}}$ & $C_{L}^{\prime}$ & $S_{t}$ \\
\hline $3 D$ & $3,206 \pm 0,067$ & $\begin{array}{l}\mathrm{CF} \\
\mathrm{CM} \\
\mathrm{CT} \\
\mathrm{CB}\end{array}$ & $\begin{array}{c}0,911 \pm 0,005 \\
-0.189 \pm 0,026 \\
1,242 \pm 0,095 \\
1,242 \pm 0,095\end{array}$ & $\begin{array}{l}0,068 \\
0,616 \\
1,329 \\
1,332\end{array}$ & $\begin{array}{c}3,5 \mathrm{E}-5 \pm 0,024 \\
-5,6 \mathrm{E}-4 \pm 0,219 \\
-0,102 \pm 0,488 \\
0,103 \pm 0,488\end{array}$ & $\begin{array}{l}0,024 \\
0,219 \\
0,498 \\
0,499\end{array}$ & $\begin{array}{l}0,114 \\
0,114 \\
0,182 \\
0,182\end{array}$ \\
\hline $3,5 D$ & $3,807 \pm 0,152$ & $\begin{array}{l}\mathrm{CF} \\
\mathrm{CM} \\
\mathrm{CT} \\
\mathrm{CB}\end{array}$ & $\begin{array}{l}1,141 \pm 0,047 \\
0,471 \pm 0,212 \\
1,227 \pm 0,217 \\
0,968 \pm 0,229\end{array}$ & $\begin{array}{l}1,538 \\
3,146 \\
2,268 \\
1,954\end{array}$ & $\begin{array}{l}0,007 \pm 0,547 \\
0,020 \pm 1,158 \\
0,054 \pm 0,786 \\
0,053 \pm 0,684\end{array}$ & $\begin{array}{l}0,547 \\
1,158 \\
0,788 \\
0,684\end{array}$ & $\begin{array}{l}0,159 \\
0,159 \\
0,159 \\
0,159\end{array}$ \\
\hline $4 D$ & $3,952 \pm 0,244$ & $\begin{array}{l}\mathrm{CF} \\
\mathrm{CM} \\
\mathrm{CT} \\
\mathrm{CB}\end{array}$ & $\begin{array}{l}1,153 \pm 0,037 \\
0,350 \pm 0,120 \\
1,226 \pm 0,141 \\
1,223 \pm 0,139\end{array}$ & $\begin{array}{l}1,405 \\
2,861 \\
2,154 \\
2,154\end{array}$ & $\begin{array}{c}0,009 \pm 0,499 \\
0,020 \pm 1,042 \\
0,054 \pm 0,769 \\
-0,030 \pm 0,768\end{array}$ & $\begin{array}{l}0,499 \\
1,043 \\
0,770 \\
0,769\end{array}$ & $\begin{array}{l}0,160 \\
0,160 \\
0,160 \\
0,160\end{array}$ \\
\hline $4,5 D$ & $4,013 \pm 0,092$ & $\begin{array}{l}\mathrm{CF} \\
\mathrm{CM} \\
\mathrm{CT} \\
\mathrm{CB}\end{array}$ & $\begin{array}{l}1,145 \pm 0,034 \\
0,337 \pm 0,100 \\
1,266 \pm 0,059 \\
1,266 \pm 0,059\end{array}$ & $\begin{array}{l}1,286 \\
2,561 \\
2,039 \\
2,039\end{array}$ & $\begin{array}{c}0,006 \pm 0,454 \\
-0,005 \pm 0,930 \\
0,046 \pm 0,724 \\
-0,064 \pm 0,725\end{array}$ & $\begin{array}{l}0,454 \\
0,930 \\
0,726 \\
0,728\end{array}$ & $\begin{array}{l}0,167 \\
0,167 \\
0,167 \\
0,167\end{array}$ \\
\hline $5 D$ & $4,110 \pm 0,094$ & $\begin{array}{l}\mathrm{CF} \\
\mathrm{CM} \\
\mathrm{CT} \\
\mathrm{CB}\end{array}$ & $\begin{array}{l}1,159 \pm 0,034 \\
0,368 \pm 0,100 \\
1,293 \pm 0,051 \\
1,293 \pm 0,051\end{array}$ & $\begin{array}{l}1,254 \\
2,510 \\
1,840 \\
1,841\end{array}$ & $\begin{array}{c}-3,3 \mathrm{E}-4 \pm 0,443 \\
3,9 \mathrm{E}-4 \pm 0,906 \\
0,044 \pm 0,649 \\
-0,043 \pm 0,649\end{array}$ & $\begin{array}{l}0,443 \\
0,906 \\
0,651 \\
0,651\end{array}$ & $\begin{array}{l}0,165 \\
0,165 \\
0,165 \\
0,165\end{array}$ \\
\hline
\end{tabular}


Tabela 12 - Resumo dos resultados para todos os casos $s$ e $\beta=180^{\circ}$.

\begin{tabular}{|c|c|c|c|c|c|c|c|}
\hline$s$ & $C_{\text {Dsist. }} \pm \sigma_{C_{D} \text { sist. }}$ & Cilindro & $\overline{C_{D}} \pm \sigma_{C_{D}}$ & $\widehat{C_{L}}$ & $\overline{C_{L}} \pm \sigma_{C_{L}}$ & $C_{L}^{\prime}$ & $S_{t}$ \\
\hline $3 D$ & $3,084 \pm 0,222$ & $\begin{array}{l}\mathrm{CF} \\
\mathrm{CM} \\
\mathrm{CT} \\
\mathrm{CB}\end{array}$ & $\begin{array}{c}-0,045 \pm 0,158 \\
0,728 \pm 0,323 \\
1,201 \pm 0,054 \\
1,201 \pm 0,054\end{array}$ & $\begin{array}{l}0,001 \\
0,001 \\
1,326 \\
1,327\end{array}$ & $\begin{array}{c}1,9 \mathrm{E}-5 \pm 0,001 \\
0,6 \mathrm{E}-5 \pm 0,000 \\
0,108 \pm 0,468 \\
-0,108 \pm 0,468\end{array}$ & $\begin{array}{c}4,5 \mathrm{E}-4 \\
2,2 \mathrm{E}-4 \\
0,480 \\
0,480\end{array}$ & $\begin{array}{l}0,055 \\
0,190 \\
0,190 \\
0,190\end{array}$ \\
\hline $3,5 D$ & $3,277 \pm 0,245$ & $\begin{array}{l}\mathrm{CF} \\
\mathrm{CM} \\
\mathrm{CT} \\
\mathrm{CB}\end{array}$ & $\begin{array}{c}-0,022 \pm 0,085 \\
0,783 \pm 0,302 \\
1,258 \pm 0,046 \\
1,258 \pm 0,046\end{array}$ & $\begin{array}{l}0,065 \\
0,019 \\
1,447 \\
1,447\end{array}$ & $\begin{array}{c}-1,7 \mathrm{E}-4 \pm 0,025 \\
-2,5 \mathrm{E}-4 \pm 0,008 \\
0,087 \pm 0,511 \\
-0,087 \pm 0,511\end{array}$ & $\begin{array}{l}0,025 \\
0,008 \\
0,518 \\
0,518\end{array}$ & $\begin{array}{l}0,068 \\
0,188 \\
0,188 \\
0,188\end{array}$ \\
\hline $4 D$ & $4,201 \pm 0,379$ & $\begin{array}{l}\mathrm{CF} \\
\mathrm{CM} \\
\mathrm{CT} \\
\mathrm{CB}\end{array}$ & $\begin{array}{l}0,546 \pm 0,271 \\
1,042 \pm 0,281 \\
1,303 \pm 0,042 \\
1,311 \pm 0,037\end{array}$ & $\begin{array}{l}2,116 \\
1,273 \\
1,416 \\
1,402\end{array}$ & $\begin{array}{c}-0,039 \pm 0,759 \\
-0,033 \pm 0,449 \\
0,067 \pm 0,501 \\
-0,069 \pm 0,497\end{array}$ & $\begin{array}{l}0,760 \\
0,450 \\
0,506 \\
0,502\end{array}$ & $\begin{array}{l}0,125 \\
0,125 \\
0,190 \\
0,190\end{array}$ \\
\hline $4,5 D$ & $4,168 \pm 0,319$ & $\begin{array}{l}\mathrm{CF} \\
\mathrm{CM} \\
\mathrm{CT} \\
\mathrm{CB}\end{array}$ & $\begin{array}{l}0,460 \pm 0,233 \\
1,119 \pm 0,233 \\
1,297 \pm 0,037 \\
1,297 \pm 0,037\end{array}$ & $\begin{array}{l}2,686 \\
1,285 \\
1,365 \\
1,365\end{array}$ & $\begin{array}{c}0,008 \pm 0,967 \\
0,002 \pm 0,450 \\
0,062 \pm 0,483 \\
-0,062 \pm 0,483\end{array}$ & $\begin{array}{l}0,967 \\
0,450 \\
0,487 \\
0,487\end{array}$ & $\begin{array}{l}0,151 \\
0,151 \\
0,189 \\
0,189\end{array}$ \\
\hline $5 D$ & $4,318 \pm 0,285$ & $\begin{array}{l}\mathrm{CF} \\
\mathrm{CM} \\
\mathrm{CT} \\
\mathrm{CB}\end{array}$ & $\begin{array}{l}0,548 \pm 0,213 \\
1,171 \pm 0,182 \\
1,299 \pm 0,035 \\
1,299 \pm 0,035\end{array}$ & $\begin{array}{l}3,037 \\
1,278 \\
1,343 \\
1,342\end{array}$ & $\begin{array}{c}0,004 \pm 1,105 \\
-0,004 \pm 0,450 \\
0,052 \pm 0,475 \\
-0,052 \pm 0,475\end{array}$ & $\begin{array}{l}1,105 \\
0,450 \\
0,478 \\
0,478\end{array}$ & $\begin{array}{l}0,163 \\
0,163 \\
0,190 \\
0,190\end{array}$ \\
\hline
\end{tabular}




\section{Considerações finais}

Neste trabalho, foi utilizado o método de volumes finitos por meio do software FLUENT ANSYS ${ }^{\circledR}$, para simular o escoamento ao redor de quatro cilindros não alinhados. As simulações, de caráter bidimensional, foram conduzidas sob número de Reynolds $R e=200$. O estudo teve como objetivo melhor compreender os efeitos do fenômeno de interferência sobre o escoamento ao redor do arranjo de cilindros proposto. Para tanto, cinco casos de espaçamento entre cilindros foram realizados - $s=3 D ; 3,5 D ; 4 D ; 4,5 D$ e $5 D$-, para dois valores de ângulos de incidência - $\beta=0^{\circ}$ e $180^{\circ}$.

Ao se analisar as razões de espaçamento entre os cilindros, dois padrões de comportamento distintos foram observados, nomeados como razão de espaçamento média e larga. A razão de espaçamento pequena não foi contemplada nos casos estudados neste trabalho. Conforme foi observado no capítulo 6, essas duas classificações passam a ser dominantes nos padrões dos resultados encontrados para todos os parâmetros estudados - forças hidrodinâmicas, número de Strouhal, linhas de corrente e campos de vorticidade. Essa mudança nos padrões de escoamento são bastante evidentes ao se analisar as séries temporais dos coeficientes de sustentação entre uma classificação e outra. Além do espaçamento entre cilindros, notou-se ainda que a direção do ângulo de incidência é um fator condicionante no comportamento do escoamento ao redor de um arranjo de cilindros. É interessante notar ainda que, para ambos os valores de ângulo de incidência estudados, o aumento do espaçamento $s$ entre cilindros leva a padrões de comportamento do escoamento mais regulares e os coeficientes analisados tendem a um valor único, variando menos entre si.

Para os casos com ângulo de incidência do escoamento $\beta=0^{\circ}$, o limite entre as duas classificações de razão de escoamento ocorreu entre $s=3 D$ e $s=3,5 D$. Para a primeira classificação, observou-se a supressão da emissão de vórtices dos cilindros à montante e a tendência de recolamento das camadas cisalhantes do cilindro frontal $(\mathrm{CF})$ sobre o cilindro central (CM). Em termos de forças hidrodinâmicas, esses mesmos cilindros apresentaram valores bastante baixos de coeficientes de arrasto médio quando comparados com os outros cilindros e também com o caso de cilindro isolado, devido à dinâmica de pressão encontrada ao redor de CF e CM. Ao se analisar o sistema como um todo, obtiveram-se valores de coeficiente de arrasto do sistema menores do a soma do coeficiente de arrasto de quatro cilindros isolados. Quanto ao coeficiente de sustentação médio, a simetria do modelo geométrico leva a valores próximos à zero para os cilindros frontais (CF e $\mathrm{CM})$ e valores próximos em intensidade, porém de sinais opostos para os cilindros à jusante (CT e CB). Com relação ao número de Strouhal, foram encontrados dois valores distintos, um para os cilindros CF e CM e outro para CT e CB, sendo ambos menores 
que o valor obtido para o caso de cilindro isolado (CI). Por fim, a análise dos espectros de amplitude calculados a partir do coeficiente de sustentação dos cilindros do caso $s=3 D$ mostrou a formação de mais de um pico de amplitude significativo para os cilindros à jusante (CT e CB).

Com o aumento do espaçamento entre cilindros, casos $s \geq 3,5 D$, observou-se o desenvolvimento completo das esteiras de von Kármán para os cilindros à montante (CF e $\mathrm{CM})$. As emissões de vórtices do cilindro central (CM) passam então a impactar as esteiras de vórtices dos cilindros à jusante $(\mathrm{CT}$ e $\mathrm{CB})$. Contudo, tal fenômeno é minimizado com o aumento do espaçamento entre cilindros. $\mathrm{O}$ valor dos coeficientes de arrasto médio dos cilindros à montante aumenta consideravelmente, mantendo-se quase que constantes à medida que o espaçamento entre cilindros aumenta.

De modo similar, o coeficiente de arrasto médio do sistema apresentou um aumento em seus valores, contudo mantendo-se ainda abaixo do valor de referência de quatro cilindros isolados. A análise do coeficiente de sustentação médio levou a observação de um ponto bastante interessante, a saber, a inversão de sinais desse parâmetro para os cilindros a jusante (CT e CB). Tal fenômeno é consequência da relação entre pressão e força na região entre esses cilindros. O aumento do espaçamento entre os cilindros provocou também uma alteração dos valores de número de Strouhal, que passou a apresentar somente um valor para todos os cilindros do sistema em cada caso de espaçamento. Além disso, não foram observados outros picos de amplitude significativos na análise de frequência da força de sustentação.

Considerando a mudança do ângulo de incidência para $\beta=180^{\circ}$, alteram-se os casos que cada razão de espaçamento abrange. Os casos $s=3 D$ e $s=3,5 D$ passam a compor a classificação "média" e o mesmo efeito de supressão da emissão de vórtices é observado nos cilindros, agora à jusante, CM e CF. Porém, nesses casos, as camadas cisalhantes que se desprendem de CM e CF são refletidas para fora do arranjo. O coeficiente de arrasto desses cilindros, bem como do sistema apresentam valores bastante baixos em relação aos seus valores de referência de cilindros isolado e aos valores dos outros casos de espaçamento $s$.

Novamente, devido à simetria do modelo matemático, os coeficientes de sustentação médio dos cilindros a jusante $(\mathrm{CM}$ e $\mathrm{CF}$ ) apresentam valores próximos à zero e dos cilindros a montante (CT e CB), próximos em intensidade, porém de sinais opostos. Quanto ao número de Strouhal, notou-se que o o cilindro mais a jusante (CF) apresentou valores distintos e bastante inferiores àquele encontrado para os outros cilindros nos casos estudados. Além disso, os valores de número de Strouhal dos cilindros CM, CT e CB, que coincidem em intensidade em cada caso $s$, são bastante próximos ao obtido para o caso se cilindro isolado (CI). Já com relação aos espectros de amplitude calculados a partir das séries temporais do coeficiente de sustentação, observou-se a formação de outros picos de 
amplitude predominantes para os cilindros a jusante (CM e $\mathrm{CF})$.

O aumento do espaçamento entre cilindros de $s=3,5 D$ para $s=4 D$ leva ao desenvolvimento completo das esteiras de von Kármán dos cilindros à jusante (CM e $\mathrm{CF}$ ). Os coeficientes de arrasto médio desses cilindros (CM e CF) sofrem, então, um significativo aumento de seus valores. Já o coeficiente de arrasto médio do sistema, ainda continua bastante abaixo do valor de referência da soma de quatro cilindros isolados. Quanto ao coeficiente de sustentação médio, observou-se, em todos os cilindros, uma tendência de convergência para zero com o aumento do espaçamento $s$. Além disso, notou-se um pequeno desvio desse comportamento, para os cilindros à jusante (CM e CF) e no caso $s=4 D$. Ainda com relação a esses cilindros, suas séries temporais do coeficiente de sustentação revelaram padrões de frequência de oscilação bastante diferentes para cada caso entre $s=4 D$ e $s=5 D$. Por fim, permaneceram ainda: a observação de dois números de Strouhal distintos, porém para diferentes grupos de cilindros, um para os cilindros à montante (CT e $\mathrm{CB}$ ) e outro para os cilindros à jusante $(\mathrm{CM}$ e $\mathrm{CF})$ e a aparição de outros picos de amplitude significativos, na análise dos espectros de frequência da força de sustentação, nos casos dos cilindros a jusante (CM e $\mathrm{CF}$ ).

Para trabalhos futuros sugere-se explorar casos menores e maiores de espaçamento entre cilindros que não foram contemplados nessa pesquisa. Tal sugestão decorre do fato de ter-se observado em alguns trabalhos da literatura razões de espaçamento menores e maiores daqueles aqui abordados, levando ao aparecimento de fenômenos específicos destas situações. Além disso, podem ser realizadas análises com diferentes seções geométricas, como por exemplo triangulares ou quadradas, nas quais poderia ser estudado casos de diferentes ângulos de incidência tanto sobre o sistema de cilindros como sobre cada cilindro individualmente. Outro interessante tema de pesquisa é o estudo da influência da variação de raios dos cilindros sobre o escoamento. Por fim, sugere-se também abordagens de de pesquisa com diferentes números de Reynolds. Essas alterações no modelo matemático auxiliariam no entendimento do estudo do escoamento ao redor de múltiplos cilindros. Estudos similares já foram realizados, porém para conjuntos com menos cilindros e de arranjos diferentes. 


\section{Referências}

ALAM, M. M.; ZHENG, Q.; HOURIGAN, K. The wake and thrust by four side-by-side cylinders at a low re. Journal of Fluids and Structures, Elsevier BV, v. 70, p. 131-144, apr 2017.

BAO, Y.; WU, Q.; ZHOU, D. Numerical investigation of flow around an inline square cylinder array with different spacing ratios. Computers $\&$ Fluids, Elsevier BV, v. 55, p. 118-131, feb 2012.

BAO, Y.; ZHOU, D.; HUANG, C. Numerical simulation of flow over three circular cylinders in equilateral arrangements at low reynolds number by a second-order characteristic-based split finite element method. Computers $\&$ Fluids, Elsevier BV, v. 39, n. 5, p. 882-899, may 2010.

CALHOUN, D. A cartesian grid method for solving the two-dimensional streamfuntionvorticity equations in ireegular regions. Journal of Computational Physics, 2002.

CARMO, B. S. Estudo numérico do escoamento de cilindros alinhados. Dissertação de Mestrado. 2005.

DEHKORDI, B. G.; MOGHADDAM, H. S.; JAFARI, H. H. Numerical simulation of flow over two circular cylinders in tandem arrangement. Journal of Hydrodynamics, Ser. B, Springer Nature, v. 23, n. 1, p. 114-126, feb 2011.

EçA, L.; VAZ, G.; HOEKSTRA, M. A verification and validation exercise for the flow over a backward facing step. In: ECCOMAS CFD - V European Conference on Computational Fluid Dynamics. Lisbon, Portugal: [s.n.], 2010.

GERRARD, J. H. The mechanics of the formation region of vortices behind bluff bodies. Fluid Mechanics, v. 25, p. 401-413, 1996.

GU, Z.; SUN, T. Classifications of flow pattern on three circular cylinders in equilateral-triangular arrangements. Journal of Wind Engineering and Industrial Aerodynamics, Elsevier BV, v. 89, n. 6, p. 553-568, may 2001.

LAM, K.; GONG, W.; SO, R. Numerical simulation of cross-flow around four cylinders in an in-line square configuration. Journal of Fluids and Structures, Elsevier BV, v. 24, n. 1, p. 34-57, jan 2008.

LIU, C.; ZHENG, X.; SUNG, C. H. Preconditioned multigrid methods for unsteady incompressible flows. Journal of Computational Physics, 1998.

MENEGHINI, J. R. Mecânica da geração e desprendimento de vórtices no escoamento ao redor de cilindros. In: . [S.l.: s.n.], 2002. cap. 6, p. 217-344.

MUNSON, B. R.; YOUNG, D. F.; OKIISHI, T. H. Fundamentos da Mecânica dos Fluidos. [S.l.]: Edgard Blucher, 2004. 
ROSENFELD, M.; KWAK, D.; VINOKUR, M. A fractional step solution method for the unsteady incompressible navier-stokes equations in generalized coordinate systems. Journal of Computational Physics, 1991.

ROSETTI, G. F.; VAZ, G.; FUJARRA, A. L. C. URANS calculations for smooth circular cylinder flow in a wide range of reynolds numbers: Solution verification and validation. Journal of Fluids Engineering, ASME International, v. 134, n. 12, p. 121103, nov 2012.

RUSSELL, D.; WANG, Z. J. A cartesian grid method for modeling multiple moving objects in 2d incompressible viscous flow. Journal of Computational Physics, 2003.

SARVGHAD-MOGHADDAM, H.; NOOREDIN, N.; GHADIRI-DEHKORDI, B. Numerical simulation of flow over two side-by-side circular cylinders. Journal of Hydrodynamics, Ser. B, Springer Nature, v. 23, n. 6, p. 792-805, dec 2011.

SUMNER, D. Two circular cylinders in cross-flow: A review. Journal of Fluids and Structures, Elsevier BV, v. 26, n. 6, p. 849-899, aug 2010.

SUMNER, D.; PRICE, S. J.; PAIDOUSSIS, M. P. Flow-pattern identification for two staggerd circular cylinders in cross-flow. Journal of Fluid Mechanics, v. 411, p. 263-303, 2000 .

VERSTEEG, H. K.; MALALASEKERA, W. An Introduction to Computational Fluid Dynamics. The Finite Volume Method. Second. [S.1.]: Pearson Education Limited, 2007.

WANG, Y. tao; YAN, Z. min; WANG, H. min. Numerical simulation of low-reynolds number flows past two tandem cylinders of different diameters. Water Science and Engineering, 2013.

WEIDNER, S.; WALLINGFORD, M. P. FLUENT Learning Modules. [S.l.], 2017. Disponível em: < https://confluence.cornell.edu/display/SIMULATION/FLUENT+ Learning + Modules $>$.

WILLIAMSON, C. H. K. 2-d and 3-d aspects of the wake of a cylinder, and their relation to wake computations. Vortex Dynamics and Vortex Methods, v. 28, p. 719-751, 1991.

WRIGHT, J. A.; SMITH, R. W. An edge-based method for the incompressible navier-stokes equations on polygonal meshes. Journal of Computational Physics, 2001.

ZDRAVKOVICH, M. M. REVIEW - review of flow interference between two circular cylinders in various arrangements. Journal of Fluids Engineering, ASME International, v. 99 , n. 4, p. $618,1977$.

ZDRAVKOVICH, M. M. The effect of interference between circular cylinders in cross flow. Journal of Fluids and Structures, 1987.

ZHAO, X.; CHENG, D.; ZHANG, D.; HU, Z. Numerical study of low-reynolds-number flow past two tandem square cylinders with varying incident angles of the downstream one using a CIP-based model. Ocean Engineering, Elsevier BV, v. 121, p. 414-421, jul 2016.

ZHENG, S.; ZHANG, W.; LV, X. Numerical simulation of cross-flow around three equal diameter cylinders in an equilateral-triangular configuration at low reynolds numbers. Computers \&f Fluids, Elsevier BV, v. 130, p. 94-108, may 2016. 
ZHOU, Y.; ALAM, M. M. Wake of two interacting circular cylinders: A review. International Journal of Heat and Fluid Flow, Elsevier BV, v. 62, p. 510-537, dec 2016. 
Apêndices 


\section{APÊNDICE A - Séries temporais dos coeficientes de arrasto}

A.1 $\beta=0^{\circ}$

Figura 40 - Série temporal do coeficiente de arrasto para $\beta=0^{\circ}$ e (a) $s=3,5 D$; (b) $s=4 D ;(\mathrm{c}) s=4,5 D$ e (d) $s=5 D$.

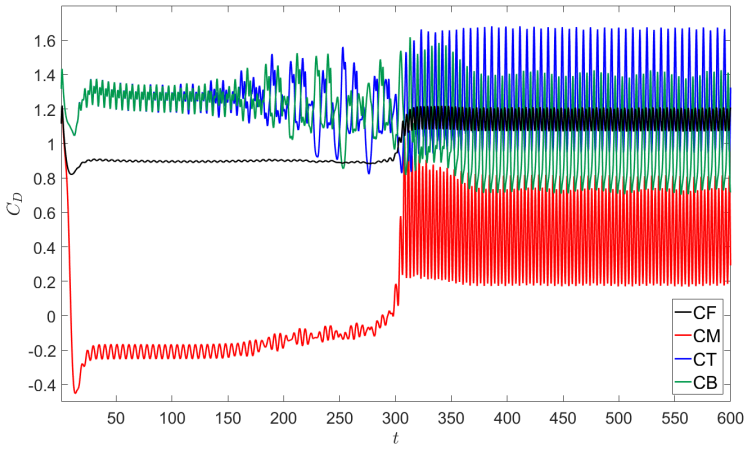

(a)

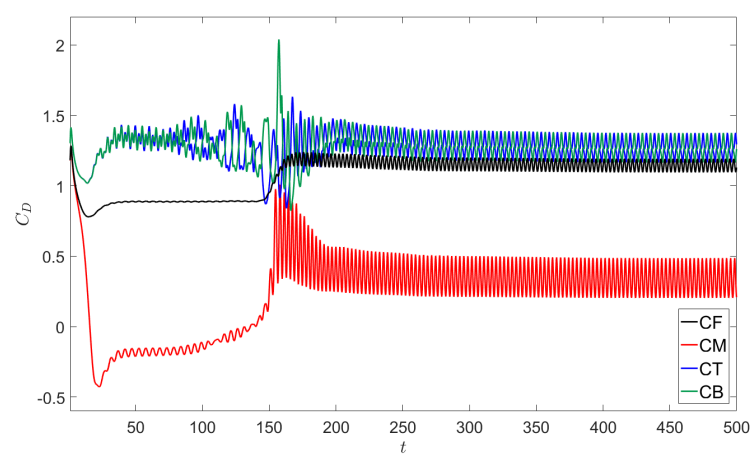

(c)

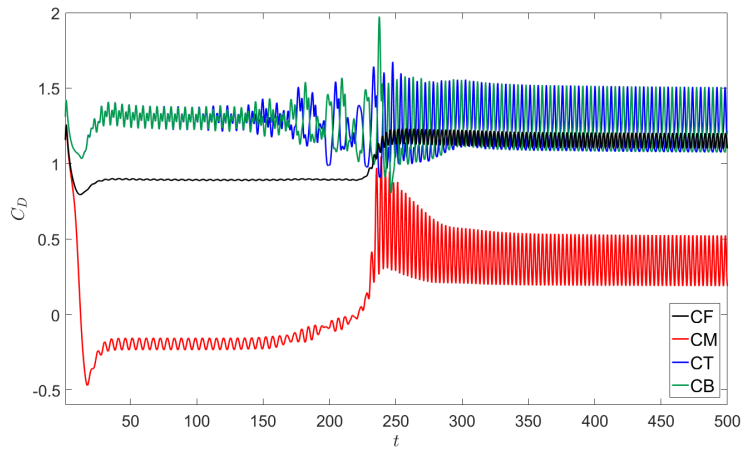

(b)

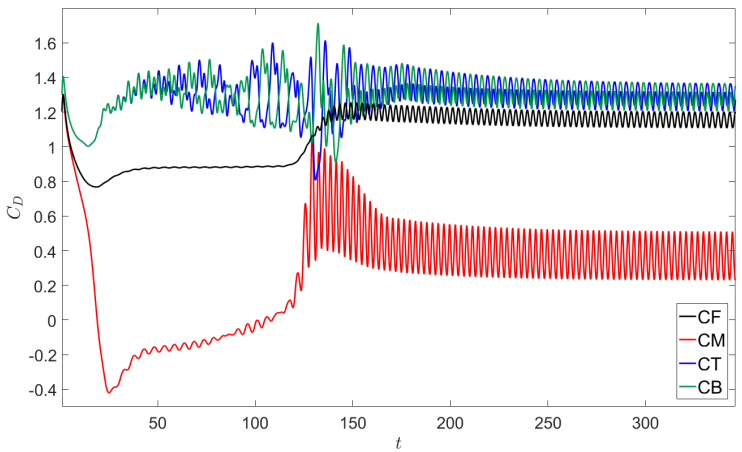

(d)

Fonte: Autora. 


\section{A.2 $\beta=180^{\circ}$}

Figura 41 - Série temporal do coeficiente de arrasto para $\beta=180^{\circ}$ e (a) $s=3 D$; (b) $s=3,5 D ;$ (c) $s=4 D ;$ (d) $s=4,5 D$ e (e) $s=5 D$.

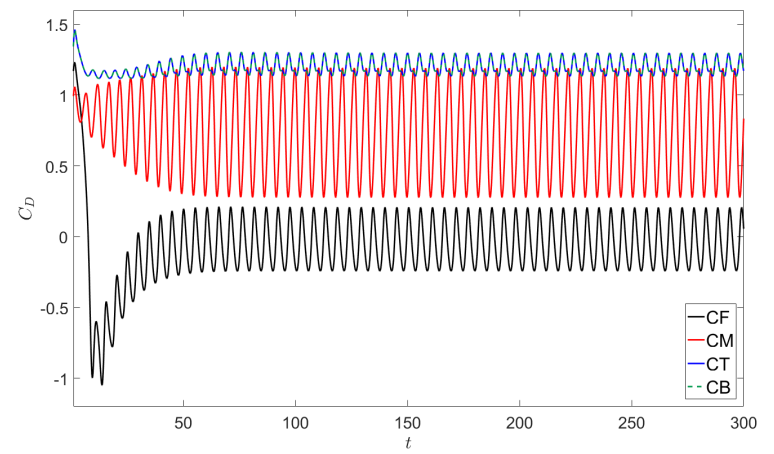

(a)

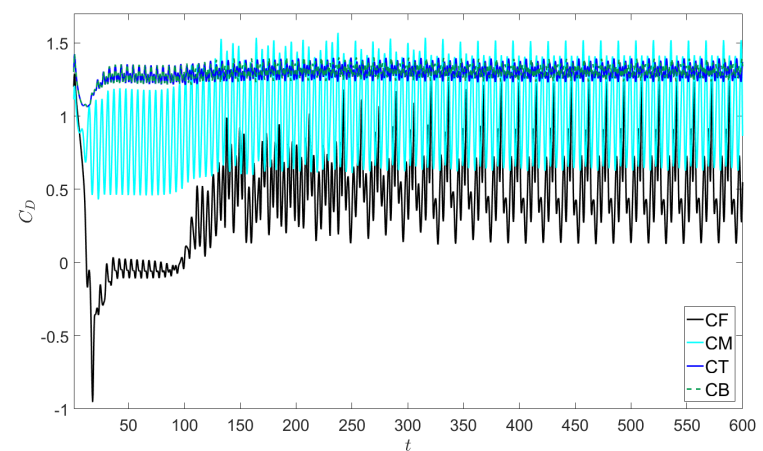

(c)

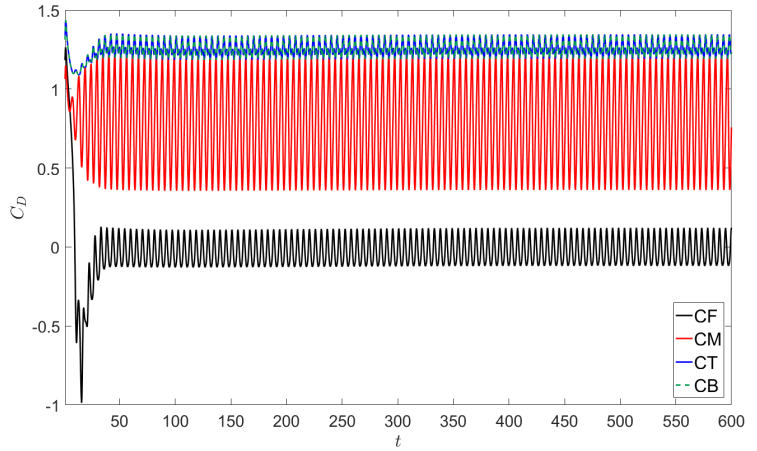

(b)

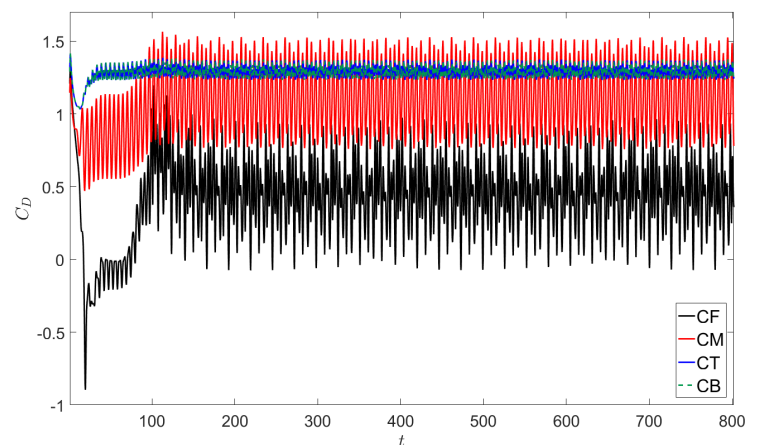

(d)

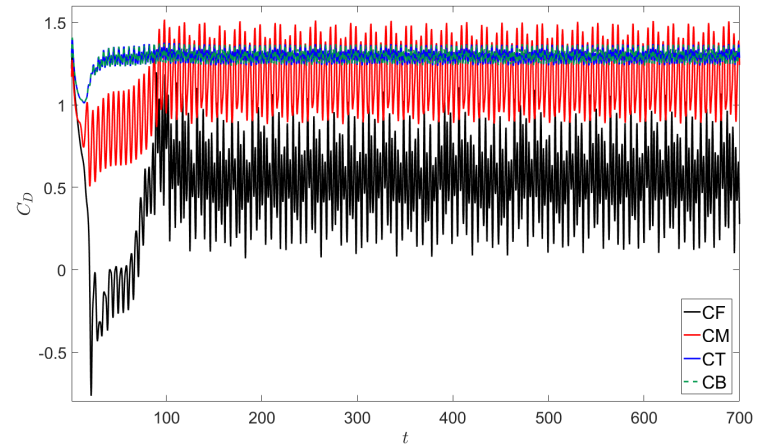

(e)

Fonte: Autora. 


\section{APÊNDICE B - Linhas de corrente}

\section{B.1 $\beta=0^{\circ}$}

Figura 42 - Linhas de corrente para um particular instante do campo de velocidades para $\beta=0^{\circ}$ e (a) $s=3,5 D$; (b) $s=4 D$; (c) $s=4,5 D$ e (d) $s=5 D$.

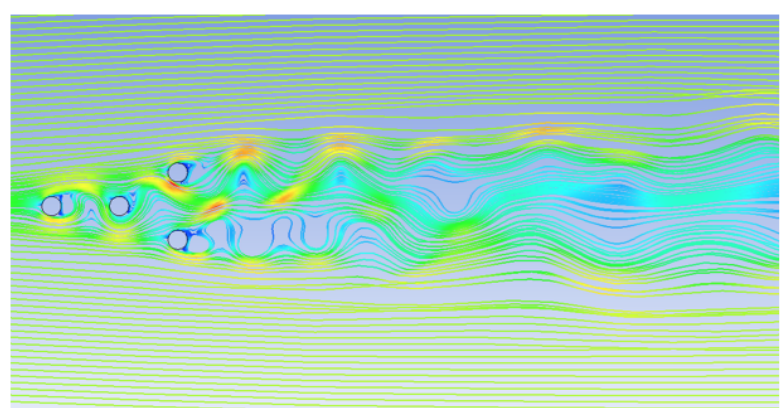

(a)

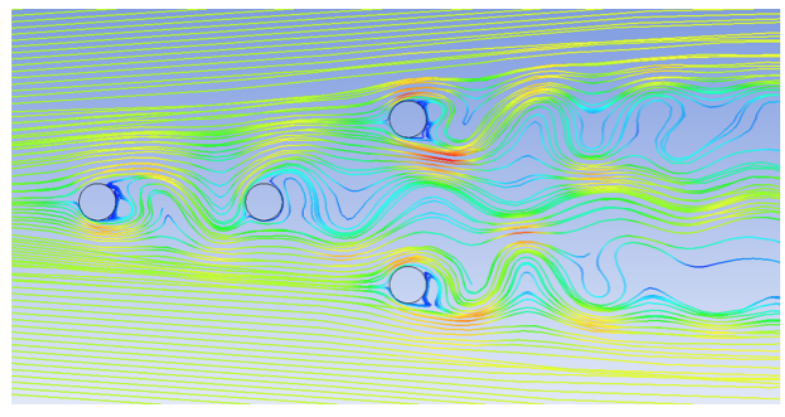

(c)

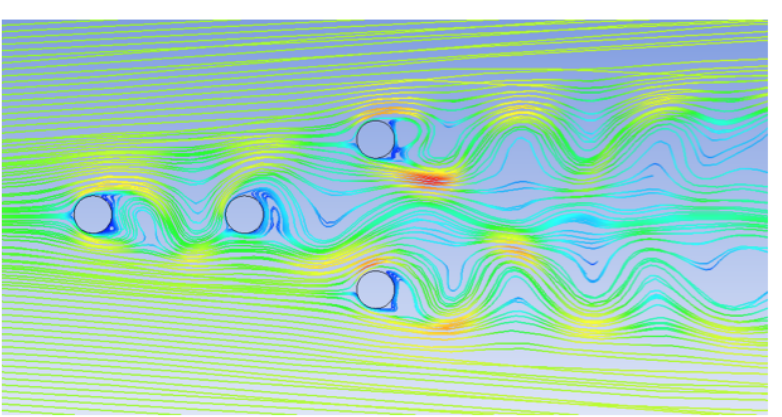

(b)

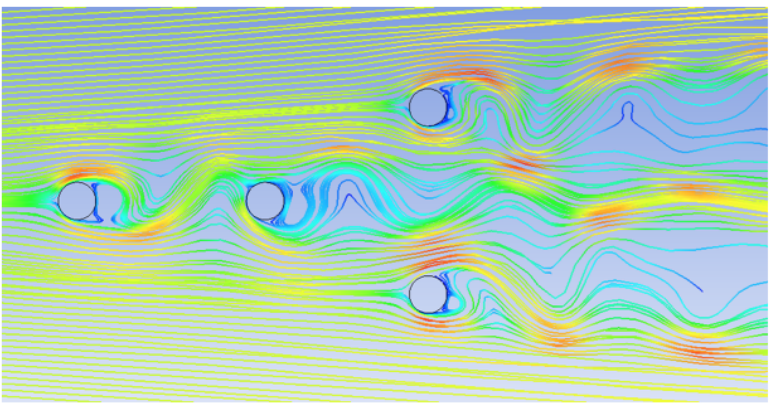

(d)

Fonte: Autora. 


\section{B.2 $\beta=180^{\circ}$}

Figura 43 - Linhas de corrente para um particular instante do campo de velocidades para $\beta=180^{\circ}$ e (a) $s=4 D$; (b) $s=4,5 D$ e (c) $s=5 D$.

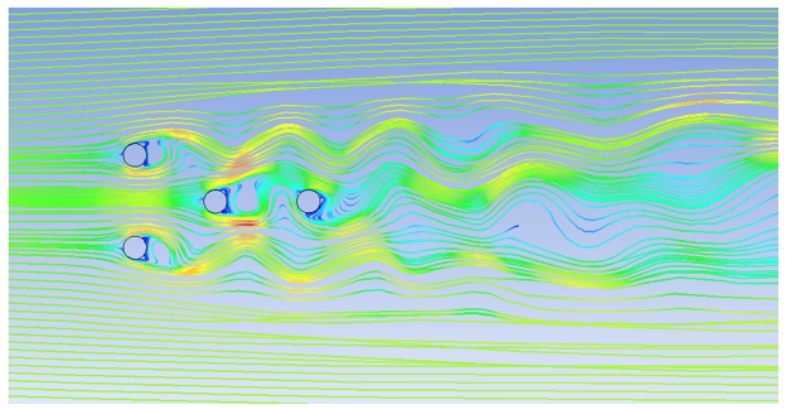

(a)

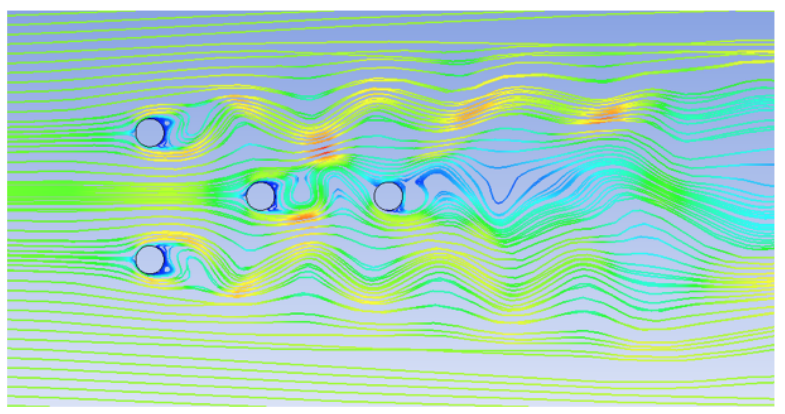

(b)

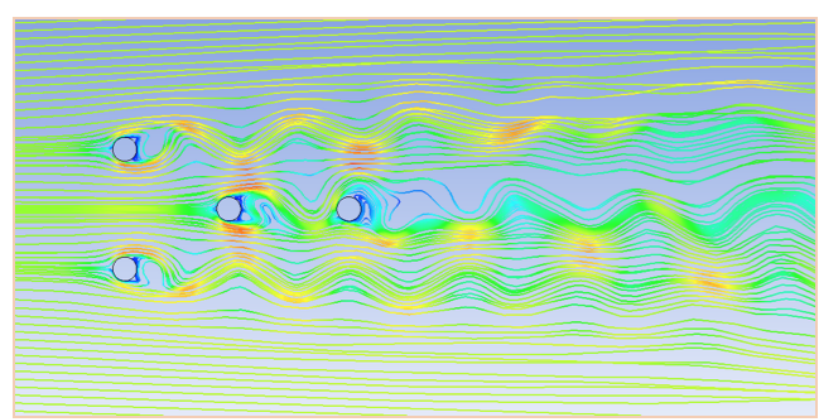

(c)

Fonte: Autora. 